\title{
Oxidized Lipids in Persistent Pain States
}

\author{
Tabea Osthues ${ }^{1}$ and Marco Sisignano ${ }^{2 *}$ \\ ${ }^{1}$ Fraunhofer Institute for Molecular Biology and Applied Ecology IME, Branch for Translational Medicine and Pharmacology \\ TMP, Frankfurt, Germany, ${ }^{2}$ Institute of Clinical Pharmacology, Pharmazentrum Frankfurt/ZAFES, University Hospital, \\ Goethe-University, Frankfurt, Germany
}

OPEN ACCESS

Edited by:

Michael Costigan,

Boston Children's Hospital and Harvard Medical School

United States

Reviewed by:

Li Zhang,

National Institutes of Health (NIH), United States

Bronwyn Maree Kivell, Victoria University of Wellington, New Zealand

*Correspondence:

Marco Sisignano

Marco.Sisignano@med.uni-frankfurt.de

Specialty section:

This article was submitted to

Neuropharmacology,

a section of the journal

Frontiers in Pharmacology

Received: 22 May 2019 Accepted: 05 September 2019

Published: 15 October 2019

Citation:

Osthues T and Sisignano M (2019) Oxidized Lipids in

Persistent Pain States.

Front. Pharmacol. 10:1147. doi: 10.3389/fphar.2019.01147
Chemotherapy, nerve injuries, or diseases like multiple sclerosis can cause pathophysiological processes of persistent and neuropathic pain. Thereby, the activation threshold of ion channels is reduced in peripheral sensory neurons to normally noxious stimuli like heat, cold, acid, or mechanical due to sensitization processes. This leads to enhanced neuronal activity, which can result in mechanical allodynia, cold allodynia, thermal hyperalgesia, spontaneous pain, and may initiate persistent and neuropathic pain. The treatment options for persistent and neuropathic pain patients are limited; for about $50 \%$ of them, current medication is not efficient due to severe side effects or low response to the treatment. Therefore, it is of special interest to find additional treatment strategies. One approach is the control of neuronal sensitization processes. Herein, signaling lipids are crucial mediators and play an important role during the onset and maintenance of pain. As preclinical studies demonstrate, lipids may act as endogenous ligands or may sensitize transient receptor potential (TRP)-channels. Likewise, they can cause enhanced activity of sensory neurons by mechanisms involving G-protein coupled receptors and activation of intracellular protein kinases. In this regard, oxidized metabolites of the essential fatty acid linoleic acid, 9- and 13-hydroxyoctadecadienoic acid (HODE), their dihydroxy-metabolites (DiHOMEs), as well as epoxides of linoleic acid (EpOMEs) and of arachidonic acid (EETs), as well as lysophospholipids, sphingolipids, and specialized pro-resolving mediators (SPMs) have been reported to play distinct roles in pain transmission or inhibition. Here, we discuss the underlying molecular mechanisms of the oxidized linoleic acid metabolites and eicosanoids. Furthermore, we critically evaluate their role as potential targets for the development of novel analgesics and for the treatment of persistent or neuropathic pain.

\footnotetext{
Keywords: pain, transient receptor potential channels, linoleic acid metabolites, eicosanoids, HODE, lipids inflammatory pain, neuropathic pain
}

\section{INTRODUCTION}

Pain is considered to protect the organism of tissue damage and harm (Kuner and Flor, 2016; Peirs and Seal, 2016). Such harm and potentially damaging stimuli can be thermal, chemical, or mechanical stimuli like heat, extreme cold, pressure, and chemicals (Dubin and Patapoutian, 2010). The stimuli are detected by peripheral sensory neurons of the somatosensory system, which arise in the skin, muscles, joints, and fascia (Colloca et al., 2017). Through activation of specific ion channels located in the plasma membrane of sensory neurons, like the transient receptor potential (TRP) and purinergic channels, the stimuli are converted into electrical activity (Kuner, 2010; Talbot et al., 2016). 
The transmission of the signal happens only in an all-or-none action potential manner and leads to pain perception, depending on the frequency and intensity (Dubin and Patapoutian, 2010). Thereby, the action potentials are transmitted via the peripheral axonal branch to the cell bodies of the nociceptors, located in

Abbreviations: 11H-12,13E-LA, 11-hydroxy-12,13-tans-epoxy-(9Z)-octadecenoat; 13-/9-HODE, 13-/9-Hydroxyoctadecadienoic acid; 13H-9,10E-LA, 13-hydroxy-9,10trans-epoxy-(11E)-octadecenoate; 13H-9,10-E-LA, 13-hydroxy-9,10-trans-epoxyoctadecenoate; 19,20-DHDP, 19,20-Dihydroxydocosapentaenoic acid; 9K-12,13E-LA, 9-keto-12,13-trans-epoxy-10E-octadecenoate; AA, Arachidonic acid; $\mathrm{AACOCF}_{3}$, Arachidonyl trifluoromethyl ketone; ATP, Adenosine triphosphate; AUDA, 12-(3-adamantan-1-yl-ureido)-dodecanoic acid; BEL, Bromoenol lactone; BLT, B-leukotriene receptor; CaMKII, calcium/calmodulin-dependent protein kinase II; cAMP, cyclic adenosine monophosphate; $\mathrm{CB}$, Cannabinoid receptor; $\mathrm{CCI}$, Chronicconstriction-injury; CCL, chemokine ligand; CFA, Complete Freund's adjuvant; cGMP, cyclic guanosine monophosphate; CGRP, Calcitonin gene-related peptide; CIPN, Chemotherapy-induced peripheral neuropathy; CMKLR, Chemerin chemokine like receptor; CNS, central nervous system; COX, cyclooxygenase; $\mathrm{CPLA}_{2}, \mathrm{Ca}^{2+}$-activated phospholipase $\mathrm{A}_{2}$; CXCR4, C-X-C chemokine receptor type 4; CYP450, Cytochrome $\mathrm{P}_{450}$; DHA, Docosahexaenoic acid; DHET, Dihydroxyeicosatrienoic acid; DiHOME, Dihydroxyoctadecenoic acid; DRG, Dorsal root ganglia; DsiRNA, 27mer dicersubstrate silencer RNA; EET, Epoxyeicosatrienoic acid; EIA, enzyme immunoassay; ELISA, enzyme-linked immunosorbent assay; EpOME, Epoxyoctadecenoic acid; ER, Endoplasmatic reticulum; ERK, Extracellular-signal regulated kinase; ESI-LC/ MS, electrospray ionization interface liquid chromatography - mass spectrometry; FABP, Fatty acid-binding protein; FACS, fluorescence-activated cell sorting; FFAR, Free fatty acid receptor; G2A, G2 accumulation GPR; GC/EI/MS, gas chromatography electron ionization mass spectrometry; GIRK, G-protein coupled inwardly rectifying potassium channel; GM-CSF, Granulocyte-macrophage colony-stimulating factor; GPCR, G-protein coupled receptor; HETE, Monohydroxyeicosatetraenoic acid; HPETE, Hydroperoxyeicosatetraenoic acid; IB4, Isolectin B4; iCGRP, immunoreactive CGRP; IHC, immunohistochemistry; IKK, Inhibitor of nuclear factor kappa-B kinase;

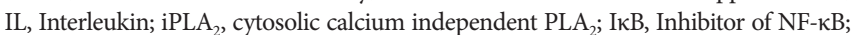
JNK, c-Jun N terminal kinase; LA, Linoleic acid; LC-MS/MS, liquid chromatographytandem mass spectrometry; LOX, Lipoxygenase; LPA, Lysophosphatidic acid; LPAR, Lysophosphatidic acid receptor; LPC, Lysophosphatidylcholine; LPS, Lipopolysaccharide; LTB4, Leukotriene $\mathrm{B}_{4}$; LTP, long-term potentiation; MAPK, Mitogen-activated protein kinases; MCP, Monocyte chemoattractant protein; MELC, multi-epitope-ligand-cartography; MIA, Mono-sodium iodoacetate; MTT, 3(4,5-dimethylthiazol-2-yl)-2,5-diphenyltetrazolium bromide; NDGA, Nordihydroguaiaretic acid; NF- $\mathrm{B}$, Nuclear factor kappa-light-chain-enhancer of activated B-cells; NICI/GC/MS, negative ion chemical ionization gas chromatography mass spectrometry; NK, Neurokinin; NMR, nuclear magnetic resonance; NNT, Number needed to treat; NPD1, Neuroprotection D1; NSAID, Non-steroidal antiinflammatory drug; OGR1, Ovarian cancer G-protein coupled receptor 1; OIPN, Oxaliplatin-induced peripheral neuropathic pain; PBR, Peripheral benzodiazepine receptor; PG, Prostaglandin; $\mathrm{PGE}_{2}$, Prostaglandin $\mathrm{E}_{2} ; \mathrm{PGG}_{2}$, Prostaglandin $\mathrm{G}_{2}$; PGH, Prostaglandin H; PI3K/Akt, Phosphoinositide 3-kinase; PKA, Protein kinase A; PKC, Protein kinase C; PLA 2 , Phospholipase $A_{2}$; PLAG2A, Phospholipase A2, encoded by the PLA2G2A gene; PNS, Peripheral nervous system; PPAR, Peroxisome proliferator-activated receptor; PTGER/EP, Prostaglandin E receptor; qPCR, quantitative real-time polymerase chain reaction; Rho, Ras homolog GTPase; ROCK, Rho-associated, coiled-coil-containing protein kinase 1; RT-PCR, real-time PCR; S1P, Spingosine-1-phosphate; S1PR, Spingosine-1-phosphate receptor; sEH, Soluble epoxide hydrolase; SNL, Spinal nerve ligation; SPM, Specialized pro-resolving mediators; StARD1, Steroidogenic acute regulatory protein 1; STZ, Streptozotocin; tDPPO, trans-diphenylpropene oxide; TLC, thin layer chromatorgraphy; TDAG8, T-cell death associated gene 8; TG, trigeminal ganglion; TGF, Transforming growth factor; TLR4, Toll-like receptor 4; TNF, Tumor necrosis factor; TP, Thromboxane receptor; TPPU, 1-Trifluoromethoxyphenyl-3-(1-propionylpiperidin-4-yl) urea; TRP, Transient receptor potential; TRPA, Transient receptor potential ankyrin ion channel; TRPC, Transient receptor potential canonical ion channel; TRPM, Transient receptor potential melastatin ion channel; TRPV, Transient receptor potential vanilloid ion channel; TSPO, Translocator protein; UPLC-MS/MS, ultra-performance liquid chromatography-tandem mass spectrometry; VEGF, Vascular endothelial growth factor; vlPAG, ventrolateral periaqueductal grey matter; Wnt, Int-1 and related genes. the dorsal root ganglia (DRG), and then via the central axonal branch to the spinal cord (Basbaum et al., 2009). Here, after synaptic processing, the signal is transmitted into the central nervous system through the thalamus to the somatosensory cortex and associated areas (Scholz and Woolf, 2002).

\section{Pathophysiologic Pain States}

Apart from its protective function, pain can become chronic when maladaptive processes such as persisting tissue damage or pathophysiological conditions after healed injury, provoke an unresolved sensitization (Basbaum et al., 2009; Kuner and Flor, 2016; Peirs and Seal, 2016). Pathophysiological conditions are highly diverse ranging from viral infection, inflammation, tumor growth, autoimmune diseases, metabolic disorders, and vascular diseases (Kuner and Flor, 2016) and involve signaling mediators, such as cytokines, chemokines, and lipids. The pain manifests with different qualities including stabbing, pricking, burning, or arching (Peirs and Seal, 2016). In this pathophysiological state, the activation threshold of sensory neurons is reduced, resulting in peripheral sensitization. Moreover, increased responsiveness of the postsynaptic neurons in the spinal cord may occur in pathophysiological states by increased synaptic activity and disinhibition of spinal nociceptive input. These plasticity changes in the spinal cord are defined as central sensitization, leading to increased pain perception (Latremoliere et al., 2015). Typically chronic pain states are characterized by hyperalgesia, which is defined as an increased response to painful thermal and mechanical stimuli as well as allodynia, where nociceptive responses occur to normally innocuous stimuli such as light touch (Ji et al., 2014; Lim and Kim, 2016). A special form of chronic pain is neuropathic pain which is characterized by neuronal damage of the peripheral or central nervous system through nerve injury, amputation, trauma, infections, toxic substances, or metabolic disorders, such as diabetes (Kobayashi et al., 2015; Kuner and Flor, 2016). However, neuropathic pain is not only provoked by nerve injury or tissue damage. It is also associated with an imbalance of activity in inflammatory pathways as response of the somatosensory, immune, autonomic, and vascular/circulatory system to tissue damage, pathogens, or irritants (Ji et al., 2016; Kuner and Flor, 2016). Additionally, neuropathic pain is characterized by mechanical allodynia and hyperalgesia, but can also involve spontaneous pain (Kobayashi et al., 2015). According to epidemiological estimations, 1 in 26 people worldwide suffers from neuropathic pain (van Hecke et al., 2014; Peirs and Seal, 2016).

\section{Current Treatment of Neuropathic Pain}

Neuropathic pain is among the most difficult types of chronic pain to treat, which not only significantly impairs patients' quality of life but also adds to the burden of direct and indirect medical cost for our society (Leung and Cahill, 2010; Colloca et al., 2017). Currently, there is a broad variety of treatment options for patients. They range from tricyclic antidepressants, serotoninnoradrenaline reuptake inhibitors, antiepileptics to botulinum toxin A, capsaicin, and opioids (Finnerup et al., 2015; Colloca et al., 2017). However, it is reported that the efficacy of those therapeutics is low, and the number needed to treat (NNT) for 
first-line treatments is considerably high (Finnerup et al., 2015). For example one in seven to eight patients treated with pregabalin, a calcium channel blocker, showed a significant effect in pain relief (Finnerup et al., 2015). Likewise, various studies demonstrate that less than $50 \%$ of patients experience satisfactory pain relief and suffer from accompanying side effects of neuropathic pain therapy (O'Connor and Dworkin, 2009; Tesfaye et al., 2013).

\section{Lipids as Alternative Treatment Option}

Those numbers indicate a need for novel treatment options of persistent and neuropathic pain. During the past decades research has proceeded in identifying key mechanisms in signaling pathways and other alterations underlying neuropathic and chronic pain. For example, it was found that after peripheral nerve damage an extensive immune response occurs around the cell bodies of injured and uninjured sensory neurons (Calvo et al., 2012). This is accompanied not only by activation of resident immune cells and migration of immune cells, but also with increased concentrations of cytokines in the injured nervous tissue (Kiguchi et al., 2012). In this regard, signaling lipids of the arachidonic acid (AA) and linoleic acid (LA) pathway seem to be particular important mediators that are released by immune cells or neurons and act as paracrine mediators, by activation of G-protein coupled receptors (GPCRs) and/or modulating the activity of ion channels in peripheral sensory neurons (Sisignano et al., 2014). These activations mediate second messenger signaling cascades that lower the threshold of ion channels, including the transient receptor potential cation channel subfamily vanilloid 1 (TRPV1) channel, leading to increased activity of peripheral sensory neurons (Moran et al., 2011; Lim and Kim, 2016; PinhoRibeiro et al., 2017). Here, the TRPV1 channel is of special interest, because it plays not only a well-established role in inflammatory pain, but is also upregulated in different models of peripheral neuropathic pain both at dorsal root ganglion (DRG) peripheral and central synapses (Rivat et al., 2018).

It was shown before, that antagonizing TRPV1 leads to hyperthermia in humans (Gavva et al., 2008), but not in mice (Moran et al., 2011), which implies, that targeting TRPV1 is not a favorable strategy in the treatment of chronic or neuropathic pain.

Moreover, it is not desirable to silence or antagonize TRPV1 completely, because of its protective function in responding to noxious heat stimuli (Moran et al., 2011; Calvo et al., 2012; De Petrocellis et al., 2012). Therefore, an alternative strategy to target this channel may be to reduce its increased activity during chronic pain and to abolish its sensitization. In this regard, lipid mediators, their synthesis, metabolism, and signaling pathways may represent alternative targets to reduce excessive neuronal activity in chronic pain states. Endogenous lipids, including some oxidized lipid metabolites from linoleic acid and arachidonic acid, have previously been shown to cause nociceptor excitation and pain (Patwardhan et al., 2010; De Petrocellis et al., 2012; Gregus et al., 2012). Such biologically active metabolites are 9and 13-hydroxyoctadecadienoic acid (HODE), both of which contribute to the heat responsiveness and sensitization of TRPV1, as earlier studies showed (Patwardhan et al., 2010).

In the last years further metabolites of the linoleic acid were investigated, like their dihydroxy-metabolites (DiHOMEs) and the epoxides of linoleic acid, the epoxy-octadecenoic acids (EpOMEs) regarding their role in nociception (Sisignano et al., 2012; Zimmer et al., 2018).

In this review we first discuss the effects of the different lipid metabolites in states of inflammation and pain. In the second part, we critically discuss their synthesizing and metabolizing enzymes or receptors as potential novel targets for the treatment of chronic and neuropathic pain in patients.

\section{METABOLISM OF OXIDIZED LIPIDS}

The omega- 6 fatty acids linoleic acid (LA) and arachidonic acid (AA) metabolites are of special interest as pain modulators, because abnormalities of lipid metabolism play a central role in various diseases, like type 1 diabetes, epilepsy, and inflammation as well as during pain (Coste TC et al., 2003; Inceoglu et al., 2008; Hung et al., 2015; Hohmann et al., 2017; Zimmer et al., 2018). In the following section, we focus on the effects of LA- and AA-derived lipids and their role in pain pathology.

Linoleic acid is one of the essential $\omega-6$ fatty acids, which leads to formation of the smooth, non-dry outer epidermal barrier upon dietary intake (Hansen et al., 1958; Gill and Valivety, 1997; Nakamura and Nara, 2003; Ramsden et al., 2017). After transport into the cell, delta-6 desaturase metabolize LA to $\gamma$-linoleic acid, being the substrate of elongase enzymes followed by delta- 5 desaturase to form arachidonic acid in the endoplasmatic reticulum (Gill and Valivety, 1997; Nakamura and Nara, 2003; Russo, 2009). AA is ubiquitously present in human tissue, especially within phosphoplipids of the cell membrane. Liberation of AA is hydrolyzed upon stimulation of various cellular signaling pathways, for example in the context of inflammation through activation of the $\mathrm{Ca}^{2+}$-activated phospholipase $\mathrm{A}_{2}\left(\mathrm{cPLA}_{2}\right.$ ) (Davies et al., 1984; Murakami and Kudo, 2002; Spector and Kim, 2015) (Figure 1).

There are three major enzyme classes for further metabolization of AA. First, there are the cyclooxygenases (COX), which catalyze a bis-dioxygenation reaction to form the unstable endoperoxide intermediate prostaglandin $\mathrm{G}_{2}\left(\mathrm{PGG}_{2}\right)$ (Davies et al., 1984; Brenneis et al., 2011). $\mathrm{PGG}_{2}$ is then reduced by a hydroperoxidase to prostaglandin $\mathrm{H}_{2}$ and then either by various isomerases or non-enzymatic reactions into several prostanoids (Davies et al., 1984; Hiesinger et al., 2019). They act as bioactive mediators, for example prostaglandin $\mathrm{E}_{2}$ causes inflammatory pain by binding to its respective receptors in neurons, the EP receptor family, and subsequent activation of protein kinases and sensitization of TRPV1 (Kawabata, 2011).

The second class of metabolizing enzymes of AA are the lipoxygenases (LOX), in particular the 5-, 12- and 15-LOX. They produce hydroperoxyeicosatetraenoic acids (HPETEs) which are reduced by the glutathione peroxidase system to the corresponding monohydroxyeicosatetraenoic acids (HETEs) (Davies et al., 1984; Hiesinger et al., 2019). Thus, 5-HPETE is further metabolized by 5-LOX into leukotriene $\mathrm{A}_{4}$, being the precursor of leukotriene $\mathrm{B}_{4}$ and $\mathrm{C}_{4}$ and lipoxins (Davies et al., 1984; Russo, 2009; Hiesinger et al., 2019). Leukotrienes are well known for their role in asthma and allergy, whereas lipoxins play a role in the resolution of 


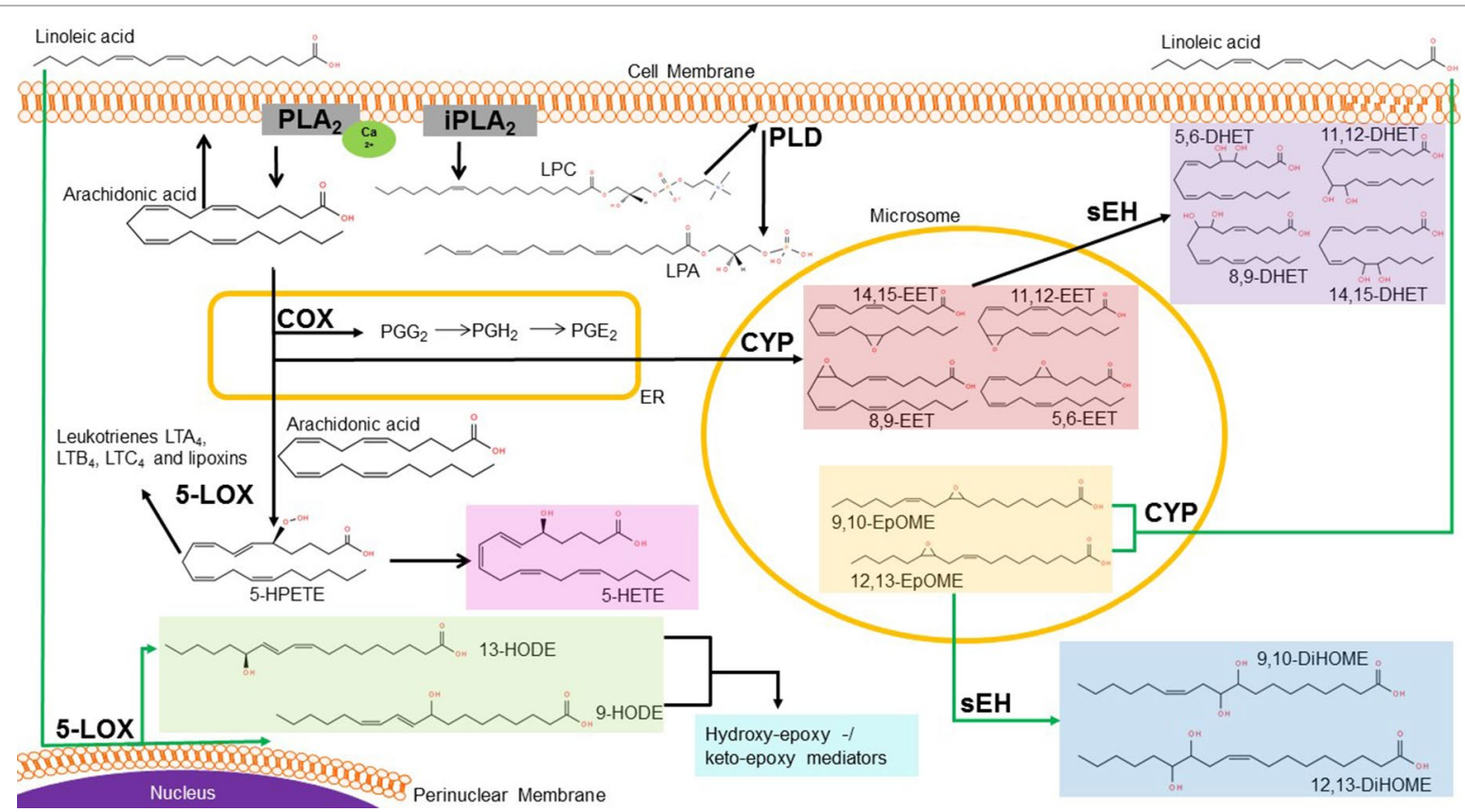

FIGURE 1 | Metabolic pathway of linoleic and arachidonic acid. In the cell, linoleic acid (LA) is rapidly metabolized via different enzymes into various bioactive metabolites. Lipoxygenases (LOX) can generate 13- and 9-HODE at the perinuclear membrane of the nucleus, whereas the cytochrome- $\mathrm{P}_{450^{-}}$enzymes (CYP) metabolize LA into EpOMEs. These are further metabolized to DiHOMEs via soluble epoxide hydrolase (sEH). In the endoplasmatic reticulum (ER), AA is the precursor of the cyclooxygenase (COX) products prostaglandins (e.g. $\mathrm{PGE}_{2}$ ). AA can also be metabolized to the epoxyeicosatrienoic acids (EETs), which are further metabolized by SEH to DHETs in the cytosol. At the plasma membrane, phospholipase A liberates either AA out of the phospholipids or generates lysophophatidylcholine (LPC). LPC is then metabolized through the extracellular phospholipase D (PLD) autotaxin to lysophosphatidic acid (LPA). Abbreviations: LTA, leukotriene A; LTB, leukotriene B; LTC, leukotriene C; LOX, lipoxygenase; 5-HPETE, arachidonic acid 5-hydroperoxide; 5-HETE, 5-Hydroxyeicosatetraenoic acid; 13-/9-HODE, 13-/9-Hydroxyoctadecadienoic acid; EET, epoxyeicosatrienoic acid; PG, prostaglandin; COX, cyclooxygenase; CYP, cytochrome enzymes; DHET, Dihydroxy eicosatrienoic acid; EpOME, Epoxy octadecenoic acid; DiHOME, Dihydroxy-octadecenoic acid; LPC, lysophosphatidylcholine, LPA, lysophosphatidic acid; PLD, phospholipase D; sEH, soluble epoxide hydrolase; ER, endoplasmatic reticulum. Source structural formula: http://lipidmaps.org/.

inflammation and can also be produced by 12 - and 15-LOX (Dennis and Norris, 2015; Hiesinger et al., 2019) (Figure 1).

Additionally, LOX enzymes can oxygenate LA by oxidizing the carbons at position 9 or 13 of its backbone and by this produce 9Sand 13S-hydroperoxides, like 9- or 13- hydroxyoctadecadienoic acid (HODE) (Oliw, 1994; Andreou et al., 2009; Newcomer and Brash, 2015). 9- and 13-HODE are released in skin upon temperature increase leading to heat responsiveness of TRPV1 in vitro and in vivo (Patwardhan et al., 2010). Through hydroxylation of the $\omega$-side chain of LA 18-, 17- and 16-HODE are formed, while allylic hydroxylation yields in 8-, 11- and 14-HODE (Oliw, 1994).

The cytochrome P450 (CYP450) enzymes are the third class of AA-metabolizing enzymes, which are primarily monooxygenases with some substrate selectivity (Hiesinger et al., 2019). There are two forms of CYP enzymes, the hydroxylases and the epoxygenases. Latter ones, namely isoforms of the families CYP2C and CYP2J, convert the AA to epoxyeicosatrienoic acids (EETs) (Spector et al., 2004; Fleming, 2007; Hiesinger et al., 2019). In this reaction, one of the four double bonds of AA is oxidized to an epoxide. Depending on the site of oxygenation, this leads to the production of one of the four regioisomers: 5,6-EET, 8,9EET, 11,12-EET or 14,15-EET (Marowsky et al., 2009; Sisignano et al., 2012; Mule et al., 2017). EETs can be released from cells to act as paracrine signaling mediators (Sisignano et al., 2012). In various studies, EETs were shown to decrease inflammatory pain, but they may also have pronociceptive effects at certain concentrations and time points during onset or maintenance of persistent pain (Inceoglu et al., 2006) (see Figure 1).

Both, LOX enzymes and CYP epoxygenases, can metabolize LA as further substrate, to generate epoxyoctadecenoic acids (EpOMEs) (Zhang et al., 2014). The EpOMEs and the EETs are rapidly converted by the soluble epoxide hydrolase (sEH) to pro-inflammatory dihydroxyoctadecenoic acids (DiHOMEs) and dihydroeicosatrienoic acids (DHETs) (Inceoglu et al., 2006). The latter one are reported to have lower activities than their corresponding EETs (Wagner et al., 2011). In contrast, a more toxic effect was reported for the DiHOMEs than for the EpOMEs (Moghaddam et al., 1997). The contradictory effects of oxidized LA- and AA metabolites in persistent pain require a more detailed analysis to identify the individual role of each lipid mediator in pain pathology. Furthermore, a detailed analysis helps to identify targets within lipid synthesis, metabolism and signaling that may give rise to novel analgesics. In the last decades, accumulating evidence suggests a central role of LA and AA metabolites in the regulation of persistent and neuropathic pain as well as involved pathways. In the following passage we critically discuss the effects of these lipids with focus on epoxy- and dihydroxy-metabolites of 
arachidonic acid (EETs and DHETs) and linoleic acid (EpOMEs and DiHOMEs).

\section{THE ROLES OF OXIDIZED LIPIDS IN INFLAMMATION AND PAIN}

\section{EETs \\ 5,6-EET}

Neuroinflammation is a characteristic feature of neuropathic and persistent pain (Ji et al., 2016). Thus, metabolites of AA with effects on inflammatory and neuropathic pain are of special interest in pain research. One of them, the 5,6-EET regioisomer, has dilatatory effects on cerebral arterioles in vivo indicating a proinflammatory role since increased blood flow to the inflamed site and extravasation of fluid, plasma protein, and leukocytes are features of inflammation (Pober and Sessa, 2014; Dennis and Norris, 2015). Proinflammatory cytokines such as interleukin (IL)-6 and tumor necrosis factor (TNF)- $a$ were found to be elevated in macrophages after 5,6-EET and lipopolysaccharide (LPS) treatment, confirming the proinflammatory effect of 5,6EET (Zhang et al., 2018).

Unfortunately, very little is known about the functions of 5,6EET in neuroinflammation and neuropathic pain, because it is an unstable metabolite of AA and undergoes rapid hydrolysis (Zhang et al., 2014). Interestingly, cupping therapy, which is used against muscle pain and inflammation, resulted in elevated levels of 5,6-EET in skin of treated mice, whereas the concentrations of its corresponding diol 5,6-DHET were not increased (Zhang et al., 2018).

After application of all four EETs in LPS-induced inflammation a pronociceptive effect was observed (Inceoglu et al., 2006). On the other hand, the EETs reversed thermal hyperalgesia, which could be due to the mixture of all four EET regioisomers (Inceoglu et al., 2006). Moreover, it was reported that 5,6-EET is synthesized in dorsal root ganglia (DRG) and spinal cord during nociceptive activity after induction of acute pain. This resulted in activation of the ligand-gated ion channel transient receptor potential ankyrin 1 (TRPA1) and subsequent release of the proinflammatory neuropeptide calcitonin gene-related peptide (CGRP) from peripheral nerves causing mechanical allodynia (Sisignano et al., 2012). These results imply a role for 5,6-EET in the transition between acute and persistent pain (Table 1A). However, a direct binding of 5,6-EET to TRPA1 was not shown.

Apart from TRPA1, 5,6- EET seems to activate another member of the family of TRP channels. It was reported that the temperature sensor TRPV4 acts as a receptor for 5,6-EET and gets activated through binding of 5,6-EET (Watanabe et al., 2003) (Table 1A).

In summary, these observations lead to the conclusion, that 5,6-EET can have pronociceptive and proinflammatory effects. However, EETs were found to bind to the anti-inflammatory nuclear peroxisome proliferator-activated receptor (PPAR) $a$ and $\gamma$ (Hiesinger et al., 2019). Indeed, the binding of EETs to the PPAR $\gamma$ contributes to an anti-inflammatory effect, but only in the low micromolar range (Liu et al., 2005). This low binding effect raises the question whether other, more potent receptors and pathways for EET signaling exist. In endothelial cells it was observed that 5,6-EET is involved in activation of phosphoinositide 3-kinase/ protein kinase $\mathrm{B}$ (PI3K/Akt) signaling and proliferation (Pozzi et al., 2005) (Table 1A).

Although, the binding of 5,6-EET to a corresponding receptor remains elusive. It is known that AA metabolites of cyclooxygenase act through G protein coupled receptors (GPCR), like E and $\mathrm{D}$ prostanoid receptors. The endocannabinoids, which have similarities with AA-metabolites as lipid signal messenger, affect nociception through GPCRs like the cannabinoid receptor $\mathrm{CB}_{1}$ and $\mathrm{CB}_{2}$ indicating that EETs might act through GPCRs as well (Wagner et al., 2011). At low micromolar concentrations EETs displaced the high affinity ligands of peripheral benzodiazepine receptor (PBR), $\mathrm{CB}_{2}$ receptor, neurokinin $\mathrm{NK}_{2}$ receptor, and dopamine $\mathrm{D}_{3}$ receptor (Inceoglu et al., 2007). Moreover, Snider and colleagues could show that 5,6-EET ethanolamide binds with high affinity to human $\mathrm{CB}_{2}$ receptor (Snider et al., 2009) (Table 1A). However, a specific 5,6-EET receptor is not known yet.

\section{8,9-EET}

EETs enter cells and interact directly with intracellular effectors like fatty acid-binding proteins (FABP) and PPAR $\gamma$ (Widstrom et al., 2001; Widstrom et al., 2003; Fleming, 2007). Thus, EETs increase PPAR $\gamma$ transcription activity, a key molecular event involved in inhibiting NF-kB contributing to the anti-inflammatory effect of the EETs (Liu et al., 2005; Norwood S. et al., 2010). Blocking of PPAR $\gamma$ reduced EET/sEH inhibitor-mediated anti-inflammatory effects (Norwood S. et al., 2010). However, 8,9-EET inhibited NF$\mathrm{kB}$ activation to a lesser extent than 11,12-EET in endothelial cells (Node et al., 1999) (Table 1A).

In sEH knock-out mice, 8,9-DHET levels were reduced leading simultaneously to an increased 8,9-EET level. Thereby, 8,9-EET increases intracellular calcium concentrations in cultured DRG neurons (Brenneis et al., 2011). The calcium increase induced the activation of mitogen-activated protein kinase (MAPK) p38 and extracellular-signal regulated kinase (ERK) most potently with 8,9-EET, resulting in increased nociceptive activity (Obata and Noguchi, 2004; Pozzi et al., 2005). In this context, it was shown that 8,9-EET can sensitize TRPA1 expressing primary afferent neurons and may contribute to a reduced mechanical pain threshold (Brenneis et al., 2011) (Table 1A). However, one only can speculate about a direct interaction of 8,9-EET with TRPA1.

Additionally, it was shown that EETs activate translocator protein (TSPO) and increase steroidogenic acute regulatory protein 1 (StARD1) expression in the spinal cord resulting in an upregulation of circulating progesterone, an analgesic molecule and precursor for neurosteroid production (Inceoglu et al., 2008). How this activation of TSPO is mediated is currently unknown. One possible way could be through the activation of a GPCR. Stimulation of the free fatty acid receptor-1 (FFAR1, also GPR40) with 8,9-EET leads to an increase in intracellular calcium concentration in FFAR1 and GPR120 expressing cells. However, in comparison to the other regioisomers, 5,6- and 8,9-EET were less potent for FFAR1 stimulation. In contrast, the receptor for long chain $\omega-3$ fatty acids GPR120, was stimulated equally by $8,9-, 11,12$ - and 14,15-EET (Park et al., 2018) (Table 1A). 
TABLE 1A | Metabolites of arachidonic acid (AA) in inflammation and pain.

\begin{tabular}{|c|c|c|c|c|c|c|}
\hline Animals/tissue/cell type & Effect & Signaling & Experiment & Experimental details & Target & Refs. \\
\hline \multicolumn{7}{|c|}{ 5,6-EET } \\
\hline $\begin{array}{l}\text { Cerebral arterioles of tsA-201 cells, } \\
\text { Cav } 3.1 \mathrm{KO} \text { and } \mathrm{Ca}_{\mathrm{v}} 3.2 \mathrm{KO} \text { mice, } \\
\text { tsA-201 cells }\end{array}$ & Dilation & $\begin{array}{l}\text { Inhibition of T-type calcium } \\
\text { channels }\end{array}$ & In vivo, in vitro & $\begin{array}{l}\text { Transfection, electrophysiological recordings, } \\
\text { microperfusion of mesenteric resistance arteries }\end{array}$ & \multirow[t]{2}{*}{$\mathrm{Ca}_{v} 3.1, \mathrm{Ca}_{v} 3.2, \mathrm{Ca}_{v} 3.3$} & $\begin{array}{l}\text { (Dennis et al., 2011; } \\
\text { Cazade et al., 2014) }\end{array}$ \\
\hline $\begin{array}{l}\text { Nude and C57BI/6 mice, } \\
\text { RAW264.7 cells, bone marrow } \\
\text { derived macrophages }\end{array}$ & Proinflammatory & $\begin{array}{l}\text { Proinflammatory cytokine } \\
\text { production }\end{array}$ & $\begin{array}{l}\text { In vitro, in vivo } \\
\text { cupping } \\
\text { therapy }\end{array}$ & $\begin{array}{l}\text { Ultra-performance liquid chromatography - tandem } \\
\text { mass spectrometry (UPLC-MS/MS), cupping } \\
\text { treatment, enzyme-linked immunosorbent assay } \\
\text { (ELISA), fluorescence-activated cell sorting (FACS) } \\
\text { analysis }\end{array}$ & & (Zhang et al., 2018) \\
\hline $\begin{array}{l}\text { bovine aortic endothelial cells, } \\
\text { HUVECs, 3T3-L1 }\end{array}$ & & $\begin{array}{l}\text { Activation of PPAR } \gamma- \\
\text { regulated transcription }\end{array}$ & In vitro & $\begin{array}{l}\text { Transfection, PPAR } \gamma \text {-competition binding assay } \\
\text { with [3H]rosiglitazone, plate flow for laminar } \\
\text { shear stress experiments, quantitative real-time } \\
\text { polymerase chain reaction (qPCR), sEH activity } \\
\text { assay, reverse-phase high performance liquid } \\
\text { chromatography (HPLC), lipid quantification } \\
\text { by Quattro Ultima tandem quadrupole mass } \\
\text { spectrometer, immunoblotting analysis }\end{array}$ & \multirow[t]{2}{*}{ PPAR $\gamma$} & $\begin{array}{l}\text { (Liu et al., 2005; } \\
\text { Hiesinger et al., 2019) }\end{array}$ \\
\hline $\begin{array}{l}\text { pulmonary murine microvascular } \\
\text { endothelial cells }\end{array}$ & no & $\begin{array}{l}\text { PI3K/Akt pathway } \\
\text { activation, proliferation, } \\
\text { migration }\end{array}$ & In vitro & $\begin{array}{l}\text { stimulation with EETs/DHETs and quantification with } \\
\left.\mathrm{NICl/GC/MS,} \mathrm{proliferation} \mathrm{assay} \mathrm{with} \mathrm{[}{ }^{3} \mathrm{H}\right] \text { thymidine, } \\
\text { transwell migration assay, matrigel-based capillary } \\
\text { formation assay, Western Blot, QPCR, in vivo } \\
\text { angiogenesis in subcutaneous sponge model, } \\
\text { immunofluorescence of tumors from human non- } \\
\text { small cell lung cancer cells }\end{array}$ & & (Pozzi et al., 2005) \\
\hline $\begin{array}{l}\text { CHO-K1 cells, BV-2 microglial } \\
\text { cells, BALB/c mice brain tissue }\end{array}$ & & Activation of $\mathrm{CB}_{2}$ receptor & In vitro & $\begin{array}{l}\text { transfection, preparation of membranes and } \\
\text { binding assays with CB1/CB2 agonists, } \\
\text { competition binding assays, CAMP inhibition } \\
\text { assays, whole-cell metabolism assay, immunoblot, } \\
\text { ESI-LC/MS }\end{array}$ & Human $\mathrm{CB}_{2}$ & (Snider et al., 2009) \\
\hline $\begin{array}{l}\text { C57BI/6 mice, TRPA1-deficient } \\
\text { mice (B6129PF2/J), DRG cultures }\end{array}$ & Mechanical allodynia & & In vivo & $\begin{array}{l}\text { licking time, dynamic plantar and hargreaves } \\
\text { behavioral studies, injection of 5,6-EET in hindpaw, } \\
\text { Ca-imaging, LC-MS/MS, patch-clamp recordings }\end{array}$ & TRPA1 & (Sisignano et al., 2012) \\
\hline HEK-293 cells, & pronociceptive & & In vitro, & Ca-imaging, patch-clamp & TRPV4 & (Watanabe et al., 2003) \\
\hline \multicolumn{7}{|c|}{ 8,9-EET } \\
\hline $\begin{array}{l}\text { human endothelial cell, human } \\
\text { coronary artery tissue, vascular } \\
\text { smooth muscle cells, bovine aortic } \\
\text { endothelial cells }\end{array}$ & Antiinflammatory & $\mathbb{I K \kappa}$ and NF-кB inhibition & In vitro & $\begin{array}{l}\text { qPCR, immunohistochemistry (IHC), reversed- } \\
\text { phase HPLC, cell-surface enzyme immunoassay, } \\
\text { Western Blot, TNFo stimulation }\end{array}$ & PPAR $\gamma$ & (Node et al., 1999) \\
\hline $\begin{array}{l}\text { DRG neurons, } \\
\text { pulmonary murine microvascular } \\
\text { endothelial cells }\end{array}$ & & p38 MAPK, ERK pathway & $\begin{array}{l}\text { In vitro, in vivo } \\
\text { angiogenesis }\end{array}$ & $\begin{array}{l}\text { stimulation with EETs/DHETs and quantification with } \\
\left.\mathrm{NICl} / \mathrm{GC} / \mathrm{MS} \text {, proliferation assay with [ }{ }^{3} \mathrm{H}\right] \text { thymidine, } \\
\text { transwell migration assay, matrigel-based capillary } \\
\text { formation assay, Western Blot, } \mathrm{PPCR} \text {, in vivo } \\
\text { angiogenesis in subcutaneous sponge model, } \\
\text { immunofluorescence of tumors from human non- } \\
\text { small cell lung cancer cells }\end{array}$ & & $\begin{array}{l}\text { (Obata and Noguchi, } \\
\text { 2004; Pozzi et al., 2005) }\end{array}$ \\
\hline
\end{tabular}




\section{Animals/tissue/cell type}

C57BL/6 WT and sEH KO mice,

DRG cultures

HUVECs, HCaECs, HaoSMCs,

BCAECs, HEK-293, INS-1 832/13

small bovine coronary arteries, coronary arterial endothelial cells,

vascular smooth muscle cells

TRVP4 KO mice, second branch

order mesenteric resistance arteries

Sprague-Dawley rats, mononuclear

cells

wound tissue of naked SKH-1 mice Proinflammatory

bovine aortic endothelial cells,

HUVECs, human coronary artery

tissue, vascular smooth muscle

cells, Sprague-Dawley rats,

RPAECS

HUVECs, HCaECs, HaoSMCs,

BCAECs, HEK-293, INS-1 832/13

Hippocampus of C57BI/6 mice

Antinocicpetive

Nude and C57BI/6 mice,

RAW264.7 cells, bone marrow

derived macrophages

porcine thoracic aortic smooth

muscle cells (SMC) from SJL mice,

brain microvessel, human lung

tissue, bronchial ring, Spraque-

Dawley rats, $\mathrm{BK}_{\mathrm{Ca}} \mathrm{KO}$ mice, EP3

$\mathrm{KO}$ mice, guinea pigs, TRPV4 KO

mice, conduit smooth muscle rings

and nonvascular smooth muscle

strips

Proinflammatory

Antiinflmmatory
Experimen

Experimental details

In vivo

injection of lipids or zy

Plantar behavioral studies, Westendpaw, Dynamic

multi-epitope-ligand-cartography Blot analysis,

CGRP-enzyme immunoassay (EIA), LC-MS/MS

transfection of GPCRs, $\left[\mathrm{Ca}^{2+}\right]$ assay with

fluorescence, radioligand binding assay, GPCR,

immunoblotting, Western Blot, isometric tension

measurement, whole-cell patch-clamp

dilation, hyperpolarization Stimulation of endogenous in vitro ADP-ribosylation through

$\mathrm{G}_{\mathrm{S}}$, activation of TRPV4-

like currents

attenuation of $\mathrm{PGE}_{2}$

In vitro

LPS-stimulation of monocytes, $\mathrm{PGE}_{2}$ assay in supernatant of monocytes, Western Blot of COX-2 protein, COX-2 activity assay with $\left[{ }^{14} \mathrm{C}\right] \mathrm{AA}$

ischemia of the mouse ear, wound creating by circular punch, treatment of wound with different $E E T s$, direct visualization of epithelialization, $\mathrm{IHC}$ qPCR, IHC, reversed-phase HPLC, cell-surface enzyme immunoassay, TNF $\alpha$ stimulation experiments

Immunofluorescence, Cell viability via $\mathrm{MTT}$, extraction of cytosolic and nuclear fractions, Western Blot, ELISA

Calcium influx, ERK phosphorylation, COX-2 expression, gab junction, disassembly, cAMP

increase

Reduced excitatory transmission

NF-kB inhibition, decrease TNF $\alpha$ expression,

decrease IL-6,

Inhibition of PGH

synthase, reduction

of $P G E_{2}$, vasodilation,

inhibition of NF-kB

induced transcription

transfection of GPRs, $\left[\mathrm{Ca}^{2+}\right]$ assay with

immunoblotting, Western Blot, whole-cel

patch-clamp

In vitro

$\mathrm{HC}$ of brain tissue, electrophysiology

\section{4,15-EET}

in vitro, in UPLC-MS/MS, cupping treatment, ELISA, FACS vivo cupping analysis

therapy

In vitro mRNA analysis by sequential hybridization, Western Blot, DNA synthesis analysis by using [ $\left.{ }^{3} \mathrm{H}\right]$ thymidine, treatment of bronchial rings with TNF $\alpha$, EET and

Target

Refs.

TRPA1

(Brenneis et al., 2011)

GPR40, GPR120

(Park et al., 2018)

fluorescence, radioligand binding assay, GPCR,

radiolabelled EETs and AA treatment of cells, revers-phase $\mathrm{HPLC}, \mathrm{PGE}_{2}$ radioimmunoassay, AUDA, isometric tension measurements, qPCR, tissue relaxation and contraction experiments, platelet aggregation, competition binding assay, selectivity profile of EET and DHET and human TP receptor and GPRs, ion channels and transporters
(Li et al., 1999; Earley et al., 2009)

(Sommer et al., 2019)

(Node et al., 1999;

Liu et al., 2005) (Jiang et al., 2014; Somme et al., 2019)

(Thompson and

Hammock, 2007; Morisseau et al., 2010; Park et al., 2018)

(Mule et al., 2017)

(Zhang et al., 2018) Morin et al., 2008; Behm et al., 2009)
(Kozak et al., 2003)

(Fang et al., 1998; 
mouse mesenteric arteries, HEK-

Xenopus laevis ooytes

Hippocampus of $\mathrm{C} 57 \mathrm{BI} / 6$ mice

Antinociceptive

Hippocampus of C57B//6 mice

Brain of Sprague-Dawley rats

Antinociceptive

Reduced excitatory transmission

PKA, ERK and CaMKII

activation

Activation of $\beta$-endorphin

and met-enkephalin

Axon growth through

endogenous 14,15-EET

In vitro

cortical and sensory neuron culture

Antinociceptive

Inhibition axon growth

of Sprague-Dawley rats, primary

Proinflammatory

In vitro

In vivo
In vitro

transfection, cAMP detection assay, oocyte expression system by injection of cRNA, cell

surface expression of GPR detection, ERK

phosphorylation detection by Western blot

luminescence method, PathHunter $\beta$-arrestin

enzyme fragment complementation assay

$\mathrm{IHC}$ of brain tissue, electrophysiology

electrophysiological recordings of hippocampus,

Western Blot analysis

Ventrolateral periaqueductal grey matter

(vIPAG) microinjection, tail-flick response

measurement after radiant heat application,

treatment with different drugs, AA or EETs,

membrane binding assay of 14,15-EET with $\mu$

and $\delta$-opioid receptors

Immunocytochemistry, MTT assay of cell viability,

morphometric analyses by staining with Protein

Gene Product 9.5 or tau-specific antibody,

C-quantification of EETs

14,15-DHET

ransactivation assay, liquid chromatography mass spectrometry (LCMS), gel shift assay,

QPCR, immunocytochemistry, MTT assay of cel

viability, morphometric analyses by staining with

Protein Gene Product 9.5 or tau-specific antibody,

LC-quantification of EET

EP4, EP2, CXCR4 (Liu et al., 2017)

CMKLR1

GIRK1/4

(Mule et al., 2017)

(Wu et al., 2017)

(Terashvili et al., 2008)

(Abdu et al., 2011)

PPAR $\alpha$ and $\gamma$

(Ng et al., 2007; Abdu et al., 2011)

CaMKII, Ca2+/Calmodulin-dependent protein kinase II: CAMP, cytosolic adenosine monophosphate; Ca,3, T-type calcium channel 3; CCL, chemokine ligand; COX, cyclooxygenase; CRNA, Complementary RNA; DHET, Dihydroxyeicosatrienoic acid; DRG, dorsal root ganglion; EET, epoxyeicosatrienoic acid; ELISA, enzyme-linked immunosorbent assay; EP, prostaglandin E receptor; ER, endoplasmatic reticulum; ERK, extracellular-signal regulated kinase; ESI-LC/MS, electrospray ionization interface for liquid chromatography - mass spectrometry; FACS, fluorescence-activated cell sorting; GIRK, G-protein coupled inwardly rectifying potassium channel; GPR, GPCR, G protein-coupled receptor; HPLC, high performance liquid chromatography; IHC, immunohistochemistry; IKk, inhibitor of nuclear factor kappa-B kinase; IL, interleukin; KO, knock-out; LC-MS, liquid chromatography-mass spectrometry; LOX, lipoxygenase; LPS, lipopolysaccharide; MAPK, mitogen-activated protein kinases; MELC, multi-epitope-ligand-cartography; MTT, 3(4,5-dimethylthizzol-2-yl)-2,5-diphenyltetrazolium bromide; NF-kB, nuclear factor 'kappa-light-chain-enhancer'; NICI/GC/MS, negative ion chemical ionization gas chromatography - mass spectrometry; NO, Nitric oxide; PG, prostaglandin; PI3K Akt, phosphoinositide 3-kinase/protein kinase B; PKA, protein kinase A; PPAR, peroxisome proliferator-activated receptor; qPCR, quantitative real-time polymerase chain reaction; Refs: references; TGF, transforming growth factor; TNF, tumor necrosis factor; TP, thromboxane receptor; TPPU, N-[1-(1-Oxopropy)-4-piperidinyl]-N"-24-(trifluoromethoxy)phenyl/urea; TRPA, transient receptor potential ion channel ankyrin subtype: TRPM, transient receptor potential ion channel melastatin subtype; TRPV, transient receptor potential ion channel vanilloid subtype: UPLC-MS/MS, Ultra-performance liquid chromatography-tandem mass spectrometry; VEGF, vascular endothelial growth factor. 
Furthermore 11,12-EETs activates $\mathrm{K}^{+} \mathrm{Ca}$ channels in coronary smooth muscle cells via a $\mathrm{G}_{\mathrm{as}}$-mediated mechanism ( $\mathrm{Li}$ and Campbell, 1997). Since the structure of 11,12-EET is very similar to that of 8,9-EET, 8,9-EET might act in a same signaling manner and may be able to activate the unidentified EET-receptor in a Ga-mediated mechanism.

\section{1,12-EET}

The role of 11,12 -EET in activation of different $\mathrm{K}^{+}$channels, especially in the cardiovascular milieu has been extensively studied (Krotz et al., 2004; Lu et al., 2006). The occurring activation via the $G_{a s}$ receptor leads to hyperpolarization and arterial dilation through TRPV4 activation (Li et al., 1999; Earley et al., 2009). However, 11,12-EET does not have any effect on neuronal TRPV4 channels (Brenneis et al., 2011). Earlier studies indicate that levels of 11,12-EET are not altered in any tissue or nociceptive model and peripheral injection of 11,12-EET did not cause any nocifensive behavior in mice (Brenneis et al., 2011; Sisignano et al., 2012) (Table 1A).

Moreover, the role of 11,12-EET in the context of inflammation has been studied thoroughly. The 11,12-EET was found capable of inhibiting NF-kB after LPS-induction or TNFa treatment at nanomolar concentrations (Node et al., 1999; Liu et al., 2005). LPS-stimulated cells treated with 11,12-EET showed decreased prostaglandin $\mathrm{E}_{2}\left(\mathrm{PGE}_{2}\right)$ secretion by inhibition of COX-2 activity (Kozak et al., 2003). This contributes further to the antiinflammatory effect of 11,12-EET as well as the inhibition of p38 phosphorylation, the degradation of $\mathrm{I} \kappa \mathrm{B} \alpha$ and the suppression of LOX-1 receptor expression (Node et al., 1999; Jiang et al., 2014). In wounds after ischemia, 11,12-EET increased both vascular endothelial growth factor (VEGF) and transforming growth factor (TGF)- $\beta$ expression leading to improved wound healing (Sommer et al., 2019). In inflammatory pain, exogenous delivery of different epoxides or the stabilization of EETs via inhibition of soluble epoxide hydrolase $(\mathrm{sEH})$ in the paw resulted in reduced mechanical pain hypersensitivity in vivo (Inceoglu et al., 2007; Morisseau et al., 2010) (Table 1A). However, in this study, all four EET regioisomers were administered, and it remains unclear, which of the EETs is the most active compound in this context.

In contrast, activation of free fatty acid receptor-1 (FFAR1, also GPR40) through 11,12-EET leads to increased COX-2 expression, NF- $\kappa \mathrm{B}$ activation and ERK phosphorylation resulting in gap junction disassembly (Popp et al., 2002; Michaelis et al., 2005; Park et al., 2018). The activation of FFAR1 was mediated by a $G_{q}$ signaling pathway to increase the intracellular calcium concentration and cyclic adenosine monophosphate (cAMP) (Hauge et al., 2015; Park et al., 2018). Decreased levels of cAMP were observed with the diol 11,12-DHET suggesting the involvement of a $G_{a i}$ signaling pathway (Abukhashim et al., 2011). However, there is a lot more evidence for 11,12-EET acting through a $\mathrm{G}_{\mathrm{S}}$ signaling mechanism (Node et al., 2001; Ding et al., 2014; Hauge et al., 2015). Interestingly, EET effects were not altered by FFAR1 antagonism indicating the existence of an 11,12-EET receptor that compensates for the reduced FFAR1 activation. However, Park et al. suggested a direct interaction of 11,12-EET with FFAR1, which might be the receptor for tans-EETs as it is for trans-fatty acids (Park et al., 2018). In this study the corresponding diols, which are thought to be inactive products of EETs, showed less stimulatory activity on FFAR1 than the parent EETs (Spector et al., 2004; Park et al., 2018).

Nevertheless, binding to GPCRs remains controversial. Recently 11,12-EET and-DHET were reported to bind to the GPR132 (G2A). Interestingly, 11,12-DHET was the more potent activator of G2A, even if it is still a low affinity receptor with physiological relevance in hematopoiesis (Lahvic et al., 2018). In this regard, 11,12-DHET seems to be a critical modulator of progenitor cell proliferation and mobilization by activation of the canonical int-1 and related genes (Wnt) signaling cascade (Fromel et al., 2012) (Table 1A).

In the neuronal system, 11,12-EET opens $G$ protein-coupled inward rectifier potassium (GIRK) channels in CA1 pyramidal cells in mouse hippocampus via $\mathrm{G}_{\mathrm{i} / \mathrm{o}}$ proteins (Mule et al., 2017). This leads to reduced excitatory transmission in hippocampus acting on pre- and postsynaptic targets (Mule et al., 2017). However, in cultured DRG neurons, 11,12-EET had no effect on the intracellular calcium concentration, since it may inhibit L-type $\mathrm{Ca}^{2+}$-channels independent of intracellular cAMP levels or protein phosphorylation (Chen et al., 1999). The intracellular cAMP concentration plays an important role during the increase of transient receptor potential ion channel canonical subtype (TPRC)6 channel translocation to the plasma membrane; an effect mediated by 11,12-EET (Fleming et al., 2007; Loot and Fleming, 2011; Ding et al., 2014) (Table 1A).

A common approach to increase EET levels is to use either an activator of CYP epoxygenases, like omeprazole, or a sEH inhibitor like, for example, 1-Trifluoromethoxyphenyl3-(1-propionylpiperidin-4-yl) urea (TPPU). This leads to a simultaneous decrease of DHET and DiHOME levels in plasma and to enhanced anti-hyperalgesia in an acute inflammatory pain model (Inceoglu et al., 2006; Goswami et al., 2015). However, this effect might not only be due to 11,12-EET and may rather be caused by the mixture of EETs, because 11,12-EET alone has been shown to have no effect on nociceptive behavior in acute pain models (Sisignano et al., 2012).

In summary, 11,12-EET plays important roles in the cardiovascular system and during inflammation. But, its individual role in peripheral neurons and nociceptive behavior seems to be negligible.

\section{4,15 -EET}

The effects of 14,15-EET are widely studied in the cardiovascular milieu. In this context it reduced proteasomal and caspase- 3 activity having anti-apoptotic effects and by that promoting the survival of cardiac cells (Chen et al., 2001; Samokhvalov et al., 2013).

In an inflammatory context 14,15-EET can cause activation of PPAR $\gamma$ leading to a decreased NF- $\kappa \mathrm{B}$ response and $\mathrm{TNF} \alpha$ expression in cardiomyocytes (Liu et al., 2005; Samokhvalov et al., 2014). Even after cupping therapy, IL-6 and TNFa were decreased (Zhang et al., 2018). Surprisingly, the diol 14,15DHET is together with 11,12-EET the most potent activator of PPAR $\gamma$ and PPARa (Ng et al., 2007) (Table 1A).

In later time points of acute zymosan-induced inflammation 14,15-EET levels were decreased (Brenneis et al., 2011). They 
were increased when sEH was deleted, but did not alter the zymosan-induced inflammatory hyperalgesia by inhibiting the prostaglandin synthesis (Brenneis et al., 2011; Zhang et al., 2014). The inhibition was also observed in smooth muscle cells, where 14,15-EET acts as competitive inhibitor of prostaglandin $\mathrm{H}(\mathrm{PGH})$ synthase and thus reduce $\mathrm{PGE}_{2}$ reduction (Fang et al., 1998). Anti-inflammatory effects were also observed in human bronchi with 14,15-EET after TNFa stimulation (Mule et al., 2017). These effects might occur due to 14,15-EET antagonizing the thromboxane receptor (Morin et al., 2008; Behm et al., 2009). In contrast, the anti-inflammatory effect was missing in bovine aortic endothelial cells after treatment with 14,15-EET and TNFa (Node et al., 1999). In conclusion, the anti-inflammatory effects of 14,15-EET depend on the organism and the inflammation context and seem to be weaker, as with 11,12-EET.

The actions of 14,15-EET are connected to Gas signaling increasing the expression of tissue-type plasminogen activator followed by an increase of intracellular cAMP (Node et al., 2001). The elevated levels of cAMP then act in a negative feedback loop and decrease binding of 14,15-EET (Wong et al., 2000).

The effects of 14,15-EET may be mediated by a receptor. So far, there are various receptors known which might act as 14,15EET receptor. In a screen of GPCRs, Liu and colleagues identified as putative 14,15-EET receptors the prostaglandin receptor subtypes $\mathrm{EP}_{4}$ and $\mathrm{EP}_{2}$. The $\mathrm{EP}_{2}$ receptor is postulated to mediate the vasodilatory effect of 14,15-EET and not as 11,12-EET does, through the activation of $\mathrm{BK}_{\mathrm{Ca}}$ channels or TRPV4 (Wong et al., 1997; Yang et al., 2008; Behm et al., 2009; Earley et al., 2009; Spector and Kim, 2015). However, very little dilatatory effects were seen in vivo in cerebral arterioles with 14,15-EET (Ellis et al., 1990).

Another GPCR, the free-fatty acid receptor FFAR1 (also known as GPR40), was found to be activated by 14,15-EET in a similar potency as with 11,12-EET. Whereas 11,12-DHET and 14,15-DHET were less active in stimulating FFAR1 (Park et al., 2018).

The GPCR G2A was activated by 14,15 -EET as well, but only the zebrafish GPR132 and not the human variant (Lahvic et al., 2018).

Additionally, C-X-C chemokine receptor type 4 (CXCR4) and Chemerin chemokine-like receptor 1 (CMKLR1) receptors were activated by 14,15 -EET. However, none of these receptors meet the criteria of a high-affinity receptor for 14,15-EET (Liu et al., 2017). Thus, it is still unclear whether 14,15-EET is a natural ligand of one of the named receptors or whether there is a highaffinity receptor, which is still unknown.

Regarding nociception, 14,15-EET had no effect on nociceptive behavior in mice after injection into the paw (Brenneis et al., 2011), but it was capable of reducing thermally induced pain in a dose-dependent manner (Terashvili et al., 2008). The antinociceptive effect of 14,15-EET was also observed after injection into the rat ventrolaterale periaqueductal gray due to the activation of $ß$-endorphin and met-enkephalin (Terashvili et al., 2008). Similar results were obtained with morphine indicating an endogenous opioid dependent analgesia (Terashvili et al., 2008). Additionally, neurons are able to produce endogenous 14,15 -EET leading to stimulated axon growth in primary cortical and sensory neuron cultures (Abdu et al., 2011). In contrast, its corresponding diol, 14,15-DHET seems to inhibit axonal growth (Abdu et al., 2011) (Table 1A).

In summary, all four regioisomers have different but overlapping effects. The 5,6-, 8,9- and 14,15-EET can act through PPAR $\gamma$ (Liu et al., 2005; Pober and Sessa, 2014). However, the underlying pathways seem to be different. The 5,6-EET can activate the PI3A/Akt pathway and has vasodilatatory effects on cerebral arterioles, whereas the 14,15-EET has almost no dilatatory effect in this setting (Pozzi et al., 2005; Pober and Sessa, 2014). Regarding neuropathic pain and nociceptive behavior, there is only little known about their role. The 5,6- and 8,9-EET induce acute pain behavior through activation and/or sensitization of TRPA1 in peripheral sensory neurons (Brenneis et al., 2011; Sisignano et al., 2012). In contrast, 11,12- and 14,15EET showed no direct effects on nociceptive behavior (Brenneis et al., 2011; Sisignano et al., 2012). Only 14,15-EET seems to have anti-nociceptive effects and seems to play a role in the excitatory transmission in the peripheral and central nervous system (Terashvili et al., 2008). Thus, all EETs seem to act via individual mechanisms and pathways, which should be kept in mind when using sEH inhibitors as potential therapeutic agent, since it affects all the regioisomers and thus can have different effects at the same time in the whole organism.

There is large evidence that EETs can activate a $\mathrm{G}_{\alpha \mathrm{s}}$-coupled GPCR (Li et al., 1999). However, a specific EET-receptor remains unknown.

\section{EpOMEs and DiHOMEs}

Next to the AA metabolites, LA products have effects on nociception and pain as well. 9,10- and 12,13- epoxyoctadecenoic acid (EpOME) are some of those metabolites, synthesized by epoxidation of LA (Oliw, 1994). They are also called leukotoxins, because EpOMEs are produced after treatment with LA and calcium by inflammatory leukocytes such as macrophages and neutrophils (Hayakawa et al., 1986; Thompson and Hammock, 2007). Neutrophil influx with increased production of EpOME levels occur for example in acute respiratory distress syndrome (Ozawa et al., 1988). When neutrophils are treated with EpOMEs a slight respiratory burst occurs, which was strongly inhibited by the corresponding diols 9,10- and 12,13-DiHOME, generated by soluble epoxide hydrolase (Inceoglu et al., 2006; Thompson and Hammock, 2007; Morisseau et al., 2010). Interestingly, DiHOMEs showed more toxic effects than the EpOMEs in acute respiratory distress syndrome (Zheng et al., 2001). Similar results were observed in endothelial cells, where DiHOMEs disrupted endothelial barrier function and induced more IL-6 expression than the EpOMEs (Moghaddam et al., 1997; Greene et al., 2000a; Slim et al., 2001). A detoxification pathway by glucuronidation of the diols was postulated by Greene and colleagues (Greene et al., 2000a). On the other hand, the diols were incorporated into phospholipids and therefore the toxicity of free diols was lost (Table 1B).

This toxicity of DiHOMEs caused a reduced cell viability, attenuation of insulin signal, overall collapse in mitochondrial function and endoplasmatic reticulum stress as well as cell death in murine hearts (Bettaieb et al., 2013; Samokhvalov et al., 2018). Furthermore, DiHOMEs seem to promote proinflammatory 


\begin{tabular}{lll}
\hline Animals/tissue/cell type Effect & Signaling
\end{tabular}

porcine pulmonary artery

Proinflammatory

endothelial cells, SF-21 cells,

alveolar type II cells, Sprague-

Dawley rats, Swiss-Webster

mice

Ephx2-gene deficient mice,

$\mathrm{HL}-1$ cardiac cells, neonatal

rat cardiomyocytes

Neutrophils, Sprague-Dawley rats, blood, HL-60 cells

Lung tissue of Swiss Webster mice

Ephx2-gene deficient mice $\mathrm{HL}-1$ cardiac cells, neonatal rat cardiomyocytes, HepG2 cells

Plasma, female participants age 20-65 y, C57BL/6N WT and TRPV1 KO mice, DRG cultures

Proinflammatory MCP-1 syndrome

\section{IL-6 expression,}

disruption endothelial

barrier function

Release of TNF $\alpha$ and

In vitro

Respiratory burst

In vivo, in vitro

\section{Hargreaves radiant heat and von Frey filament}

behavioral studies, EETs or sEH inhibitors applied via cream, reverse-phase HPLC, LC-MS/MS, WST-1-

reducing activity measurement by lucigenin-dependent

chemiluminescence, $\beta$-glucuronidase release assay, immunoblot analysis, Western Blot

Respiratory distress

In vivo histopathology via inflation with fixation via a tracheal cannula, immersion deflated or immersion after maintenance of inflation by ligation of the trachea, synthesis of leukotoxin and gas liquid chromatography, sEH preparation of liver cytosol, immunocytochemistry

Reduced cell viability, attenuation of insulin signal, collapse in mitochondrial function, ER stress, cell death

Thermal hypersensitivity Decreased amount, TRPV1 sensitization
In vitro, in vivo mitochondrial function via citrate synthase. $\mathrm{NADH}$ :ubiquinone oxidoreductase and succinate dehydrogenase activity measurement, mitochondrial respiration by glutamate and ADP-stimulated respiration, immunoblotting, aconitase activity, 20 S proteasome and malondialdehyde assays, LC-MS/MS, echocardiography, ELISA of TNF $\alpha$ and MCP-1, treatment of cells with different EpOMEs, DiHOMEs, ATP-level measurement via luciferase-based method, High fat diet of mice, treatment with sEH-inhibitor, Western Blot, qPCR

Clinical, in vivo Blood sample lipid extraction and analysis with UPLC, zymosan/CFA/lipid injection in hind paw, oral administration of TPPU, thermal behavioral studies, LC-MS/MS, Ca-imaging, CGRP ELISA,
Target

Refs.

(Moghaddam et al., 1997; Greene et al., 2000a; Slim et al., 2001)

(Slim et al., 2001; Samokhvalov et al., 2018)

(Inceoglu et al., 2006; Thompson and Hammock, 2007; Morisseau et al. 2010)

(Zheng et al., 2001)

(Bettaieb et al., 2013; Samokhvalov et al., 2018)

(Hellstrom et al., 2016: Zimmer et al., 2018) 


Ca-transient induction in In vivo, in vitro

zymosan/CFA/lipid injection in hind paw, ora

(Zimmer et al., 2018)

administration of TPPU, Hargreaves radiant heat

behavioral studies, LC-MS/MS, Ca-imaging, CGRP

\section{EUISA}

\section{EpOME}

Sprague-Dawley rats, $\mathrm{CHO}$ - Proinflammatory, cells, C57B//6 mice, TRPV1 KO Pronociceptive

mice, primary DRG cultures

TRPV1 sensitization,

calcium influx,

PKA-activation

In vitro, in vivo

Deral burn injury, paclitaxel-induced neuropathic pain, paw-withdrawal latency measurement with radiant heat and dynamic plantar, drug injection, HPLC-ESI-MS/ MS, transfection, calcium imaging on sensory neurons, electrophysiology, blood pressure measurements, GPCR, LC-MS/MS, ${ }^{35}$ S]GTP $\gamma S$ binding assays, peripheral burn injury

Mongrel dogs heart arteries canine splenic artery, porcine sMCs

Proinflammatory

Relaxation of coronary arteries, calcium

influx, cGMP level

increase, stimulation of biosynthesis of COX-

derived vasodilators

RAW264.5 (ATCC) cells, peritoneal macrophages HEK293, rat DRG cells

THP-1, HeLa, CV-1 cells, human peripheral blood, Cos7 cells, human peripheral monocytes, patients with type 2 diabetes
HEK293, rat DRG cells C57B//6 WT and TRPV1 KO mice, Sprague-Dawley rats; $\mathrm{CHO}$ cells; TG cultures G2A KO mice, DRG cultures,

\section{Cold sensitivity}

Mechanical allodynia, thermal hyperalgesia
Antagonizing TRPM8mediated calcium influx

TRPV1-sensitization

Macrophage gene expression during atherogenesis, increase of FABP4 expression

\section{3-HODE}

In vitro

prease assay, biosynthesis of prostacyclin via radioimmuoassay, HPLC analysis of 13-HPODE and 13-HODE, Ca-imaging,

cGMP levels by radioimmunoassay

western blot analysis, northern blot analysis, transient transfection

TRPV1/TRPV2/TRPA1/TRPM8 transfection, Ca-imaging

In vitro

In vitro, in vivo -TRPV1/TRPV2/TRPA1/TRPM8 transfection,

Ca-imaging, HPLC and MS analysis, electrophysiology, immunoreactive CGRP (iCGRP) release, Oxaliplatintreatment, 9-HODE injection in hind paw, mechanical and thermal behavioral studies, LC-MS/MS, Ca-imaging, CGRP ELISA, electrophysiology, qPCR, lipophilic

substance isolation from superfusate of spinal cord

tissue, electrophysiology, 9-HODE ELISA, CFA treatment, $\lambda$-Carrageenan injection into paw and 15-LOX inhibitor and anti-13- and -9-HODE injection, hyperalgesia measurements, LC-MS/MS

\section{9-HODE}

In vitro, clinical northern analysis, native and oxidized LDL association and uptake via labelled LDL or oxLDL measurements with flow cytometry, transfection, ligand binding assays, protein expression and purification, crystallisation, structure determination, ligand assignment, mass spectrometry, circular dichroism of thermal denaturation measurements, transfection and reporter gene assay, incubation of cells with LA, 9- or 13-HODE and/or with PPAR $\gamma$ antagonist, multiplex flowcytomix system for cytokine measurement, flow cytometry of activated monocytes, immunocytochemistry, qPCR, GPR132 gene silencing with siRNA
TRPA1, TRPV1 ～(Green et al., 2016; Sisignano et al., 2016; Zimmer et al., 2018)

L-type channels, TP (De Meyer et al., 1992; Stol et al., 1994)

PPAR

(Ricote et al., 2000)

(De Petrocellis et al., 2012)

(Patwardhan et al., 2009; Patwardhan et al., 2010; De Petrocellis et al., 2012; Alsalem et al., 2013; Hohmann et al., 2017)

(Nagy et al., 1998; Ricote et al., 2000; Itoh et al. 2008; Vangaveti et al., 2018) 
Experiment

CHO-K1 cells, HEK-293 cells

Proinflammatory

IL-6, IL-8 and GM-CSF

release, PKC-dependen

In vitro

RPV1 sensitization

Elevated plasma levels

Clinical

20-65 y

HEK293, rat DRG cells,

C57BI/6 WT and TRPV1 KO

mice, Sprague-Dawley rats:

$\mathrm{CHO}$ cells; TG cultures G2A

KO mice, DRG cultures,

Sprague-Dawley rats, hind

paw, sciatic nerve, DRG,

trigeminal ganglia (TG), dorsal

Proinflammatory

horn tissue, human skin

biopsies

C57BI/6 mice, brain tissue

Chronic inflammation

(Amygdala, PGA), Sprague-

Dawley rats, hind paw, sciatic

pronociceptive

nerve, DRG, TG, dorsal horn

tissue, human skin biopsies

Sprague-Dawley rats, hind

paw, sciatic nerve, DRG, TG,

Proinflammatory

dorsal horn tissue, human

skin biopsies
Reduced amounts

In vivo

Sensitization of

afferent DRG neurons,

headaches

itch

Sensitization of afferent DRG neurons, therma hypersensitivity

\section{Clinical}

vitro, in vivo

(n)

TRPV1/TRPV2/TRPA1/TRPM8 transfection, Ca-imaging,

HPLC and MS analysis, electrophysiology, CGRP

release, Oxaliplatin-treatment, 9-HODE injection

in hind paw, mechanical and thermal behaviora

studies, LC-MS/MS, Ca-imaging, CGRP ELISA,

electrophysiology, QPCR, lipophilic substance isolation

from superfusate of spinal cord tissue, electrophysiology,

9-HODE ELISA, CFA treatment, $\lambda$-Carrageenan injection

into paw and 15-LOX inhibitor and anti-13- and

-9-HODE injection, LC-MS/MS

\section{H-9,10E-LA}

fatty acid analysis, gas chromatography, RNAseq

LC-MS/MS, CGRP release assays, intradermal injection

of lipids in mice, scratching and thermal behaviora

studies,

CFA treatment of ankles, solid phase extraction following

LC-MS/MS

\section{H-12,13E-LA}

Clinical, in vitro, CFA treatment of ankles, solid phase extraction following

LC-MS/MS, fatty acid analysis, gas chromatography,

RNAseq, LC-MS/MS, CGRP release assays, intraderma

injection of lipids in mice, scratching and thermal

behavioral studies

9K-12,13E-LA

Clinical, in vitro, fatty acid analysis, gas chromatography, RNAseq

in vivo LC-MS/MS, CGRP release assays, intradermal injection

of lipids in mice, scratching behavior, thermal behaviora studies,
(Obinata et al., 2005;

Kabarowski, 2009)

(Hellstrom et al., 2016)

(Patwardhan et al., 2009;

Patwardhan et al., 2010;

De Petrocellis et al., 2012

Alsalem et al., 2013;

Hohmann et al., 2017)

(Ramsden et al., 2017)

(Jensen et al., 2018)

(Ramsden et al., 2017; Jensen et al., 2018)

(Ramsden et al., 2017)

13-/9-HODE, 13-/9-hydroxyoctadecadienoic acid; 13H-9, 10E-LA, 13-hydroxy-9, 10-trans-epoxy-octadecenoate; 11H-12, 13E-LA, 11-hydroxy-12,13-trans-epoxy-(9Z)-octadecenoate; 9K-12, 13E-LA, 9-keto-12, 13-trans-epoxy-10Eoctadecenoate; CAMP, cytosolic adenosine monophosphate; CFA, complete Freund's adjuvant; CGMP, cyclic guanosine monophosphate; CGRP, calcitonin gene-related peptide DiHOME, dihydroxyoctadecenoic acid; EpOME, epoxyoctadecenoic acid; G2A, G2 accumulation GPCR; GPR, GPCR, G protein-coupled receptor; GC/El/MS, gas chromatography electron ionisation mass spectrometry; GM-CSF, granulocyte-macrophage colony-stimulating factor; IL, interleukin; KO, knock-out; LC-MS/MS, liquid chromatography tandem mass spectrometry LDL, low-density lipoprotein; MCP, monocyte chemoattractant protein; NADH, nicotinamide adenine dinucleotide; NMR, nuclear magnetic resonance; NO, nitric oxide; PKC, protein kinase C; PLA, phospholipase A; PPAR, peroxisome proliferator-activated receptor; Refs, references; tDPPO, trans-dipheny/propene oxide; sEH, soluble epoxide hydrolase; TG, trigeminal ganglia; TLC, thin layer chromatography; TPPU, N-[1-(1-Oxopropyl)-4-piperidinyl]-N'-[4-(trifluoromethoxy)phenyl]urea; WT, wild-type. 
cascades such as NF- $\kappa \mathrm{B}$ because of a massive release of TNFa and Monocyte chemoattractant protein 1 (MCP-1) from HL-1 cells (Slim et al., 2001; Samokhvalov et al., 2018).

Thus, in acute and persistent inflammatory pain mouse models application of 12,13-DiHOME leads to increased thermal hypersensitivity due to its sensitizing effects on TRPV1, whereas 9,10-DiHOME showed no effect (Inceoglu et al., 2006; Eskander et al., 2015; Zimmer et al., 2018). Interestingly, in chronic inflammatory pain reduced concentrations of EpOMEs and 9,10-DiHOME were observed in the amygdala and the periaqueductal gray (Jensen et al., 2018).

In patients with chronic neck pain, plasma levels of 9,10- and 12,13-DiHOME were increased, although a direct correlation between the elevated metabolites and pain levels is missing (Hellstrom et al., 2016).

Several more pain models were investigated concerning the effects of EpOMEs and DiHOMEs on the different pain states. In a model of peripheral burn injury both mediators were increased in spinal cord and caused activation of TRPV1 and TRPA1 in heterologous expression systems, suggesting TRPV1and TRPA1-mediated effects on mechanical and thermal hypersensitivity (Green et al., 2016). However, in DRG cultures 12,13-DiHOME showed no effect on TRPA1 sensitization, indicating TRPA1 sensitization through 9,10-DiHOME (Zimmer et al., 2018) (Table 1B).

Regarding chemotherapy-induced neuropathic pain, levels of 9,10-DiHOME and 12,13-DiHOME were unaltered, whereas 9,10-EpOME was increased in DRG neurons (Sisignano et al., 2016; Hohmann et al., 2017). It was synthesized by neurons and glial cells and contributed to calcium influx in DRG neurons due to a protein kinase A (PKA)-mediated sensitizing effect on TRPV1 (Sisignano et al., 2016). As a result, thermal and mechanical hypersensitivity was elevated in paclitaxel-induced neuropathic pain via 9,10-EpOME (Sisignano et al., 2016).

Thus, it seems that DiHOMEs and EpOMEs have different effects on the various kinds of neuropathic pain. How those effects are mediated by the metabolites is not examined yet. It is still unclear, whether there is a receptor for EpOMEs or DiHOMEs. For the G2A receptor a low affinity binding of EpOMEs has been reported (Lahvic et al., 2018). Regarding the described high toxicity of DiHOMEs Greene and colleagues proposed that it does not seem to be a receptor-mediated mechanism (Greene et al., 2000b).

\section{HODEs}

The hydroperoxides HODEs are stable oxidation products of LA. Their concentrations are elevated under oxidative stress such as ischemic brain injury or cardiac arrest (Liu et al., 1998; Yoshida and Niki, 2006; Hennebelle et al., 2017). How the HODEs are synthesized is not fully understood. An earlier study suggested that 15-LOX oxidized LA to 13-HPODE, that is reduced through glutathione-peroxidase to 13-HODE (Reinaud et al., 1989). Inhibition experiments indicate that especially $13-\mathrm{HODE}$ is produced by LOX enzymes, whereas, 8-,9-, 11- and 14-HODE are produced in microsomes either through $\mathrm{PGH}$ synthase, lipoxygenase or non-enzymatically (Oliw, 1994; Engels et al., 1986; Green, 1989; De Meyer et al., 1992; Jisaka et al., 1997).
The 13-HODE increases calcium influx and intracellular cGMP levels inducing relaxation of canine splenic and coronary artery segments (De Meyer et al., 1992; Stoll et al., 1994). This effect might be mediated through an L-type channel that is regulated by a cGMP-dependent kinase (Stoll et al., 1994). On the other hand, at high concentrations 13-HODE contract the segments by activation of thromboxane receptor (De Meyer et al., 1992). Together with 9-HODE, it also binds in a micromolar range to $\operatorname{PPAR} \gamma$, depending on the activation state of macrophages, and causes increased activity of fatty acid binding protein 4 (Nagy et al., 1998; Ricote et al., 2000; Itoh et al., 2008; Vangaveti et al., 2018) (Table 1B). A receptor with higher binding affinity for 13-HODE has not yet been identified.

However, 9(S)- and 13-HODE seem to antagonize intracellular calcium influx, mediated by the cold-thermosensor of sensory nerves in deeper tissue TRPM8 and seem to activate TRPA1 in a heterologous expression system. However, 13-HODE was more potent in TRPA1 activation than 9-HODE (De Petrocellis et al., 2012). In this system, 9-HODE was also able to activate TRPV1-mediated intracellular calcium elevation at a nanomolar range, whereas 13-HODE was not such effective (Patwardhan et al., 2009; Patwardhan et al., 2010; De Petrocellis et al., 2012; Alsalem et al., 2013). In trigeminal neurons, capsaicin-sensitive neurons responded to $9-\mathrm{HODE}$ by an increase of intracellular calcium level (Patwardhan et al., 2009; Patwardhan et al., 2010). Injection of 9-HODE and 13-HODE into the paw caused strong spontaneous nociceptive behavior and thermal hypersensitivity in rats (Patwardhan et al., 2010). Interestingly, when 9-HODE was injected intrathecally a longer mechanical allodynia was seen than with capsaicin (Patwardhan et al., 2009). Antinociception and reversion of mechanical allodynia was obtained when LA oxidation or HODEs were blocked (Patwardhan et al., 2009; Patwardhan et al., 2010). However, intrathecal injection of 9- and 13-HODE blocking antibodies had no effect on thermal allodynia (Green et al., 2016). In the periphery, the concentrations of 9- and 13-HODE as well as their metabolites 9- and 13-oxoHODE were elevated after severe burn injury, in irradiated or in heated skin and mediated inflammatory heat hyperalgesia (Patwardhan et al., 2010; Alsalem et al., 2013; Green et al., 2013; Sisignano et al., 2013). The occurring thermal hypersensitivity was reduced by injection of 9- and 13-HODE blocking antibodies into the paw, suggesting a local effect of the LA metabolites. This local effect of 9- and 13-HODE blocking antibodies was also seen in thermal injury and in chronic inflammatory hyperalgesia in the paw, as well as after inhibition of CYP enzymes, indicating CYP enzymes to produce TRPV1 active metabolites of LA (Ruparel et al., 2012a; Green et al., 2013). Likewise, an attenuation of inflammatory hyperalgesia was observed after inhibition of 15-LOX in paw tissue, but no altered calcium response was produced by exogenous 9- and 13-HODE in DRGs. The authors concluded both lipids to be responsible for the TRPV1-mediated calcium influx (Alsalem et al., 2013).

In chemotherapy-induced neuropathic pain 9-HODE levels were elevated in sciatic nerve and DRG neurons indicating a release by neuronal tissue (Hohmann et al., 2017). Both, 9and 13-HODE also can be generated from non-neuronal tissue (Patwardhan et al., 2010) (Table 1B). However, the concrete binding action to a receptor of 13 -HODE remains elusive. 
In contrast, 9-HODE binds to the GPCR G2A, a receptor that is expressed by immune cells, especially by macrophages and T cells (Obinata et al., 2005; Kabarowski, 2009), but also by TRPV1-positive primary sensory neurons (Kwan et al., 2007). In contrast, 13-HODE only showed moderate activity on G2A (Yin et al., 2009; Hohmann et al., 2017).

The 9-HODE evokes intracellular calcium mobilization, activation of c-Jun $\mathrm{N}$ terminal kinase (JNK), and inhibition of cAMP accumulation (Obinata et al., 2005). In human keratinocytes and $\mathrm{HaCaT}$ cells oxidative stress resulted in G2A expression and 9-HODE generation. The 9(S)-HODE then caused enhanced IL-6, -8 and release of granulocyte-macrophage colony-stimulating factor (GM-CSF), as well as inhibited proliferation due to cell cycle arrest in the G0/1-phase (Hattori et al., 2008; Obinata and Izumi, 2009). These effects were not observed with 13-HODE (Hattori et al., 2008).

G2A activation by $9-\mathrm{HODE}$ is concentration-dependent and in oxaliplatin-induced peripheral neuropathic pain (OIPN) it can lead to TRPV1 sensitization (Hohmann et al., 2017). Injection of 9-HODE during OIPN causes increased mechanical hypersensitivity in vivo that seems to be mediated by a protein kinase C (PKC)-dependent mechanism, whereas direct injection into the paw of naïve wild-type mice had no effect on nociceptive behavior (Hohmann et al., 2017) (Table 1B).

In conclusion, 9-HODE plays an important role during inflammatory and neuropathic pain, possibly by binding to the G2A receptor and sensitizing TRPV1. On the other hand, the effects of 13-HODE seem to be more restricted to the skin and the cardiovascular milieu. However, all studies were performed in vitro or in mice so far. Less is known about the effects of 9and 13-HODE in chronic or persistent pain patients. One study observed elevated 9- and 13-HODE plasma levels in patients with chronic neck pain (Hellstrom et al., 2016). Herein, 9- and 13-HODE levels showed a positive correlation to the daily pain rate (Hellstrom et al., 2016). Nevertheless, further investigations are needed to evaluate the role of 9- and 13-HODE in chronic and persistent pain in humans.

\section{Additional Metabolites of LA and AA}

Recently further LA metabolites were found to play a role in pain and itch. In inflamed psoriatic human skin, the concentrations of the previously unknown endogenous lipids 11-hydroxy12,13-tans-epoxy-(9Z)-octadecenoate (11H-12,13E-LA) and the already known 13-hydroxy-9,10-trans-epoxy-(11E)octadecenoate (13H-9,10E-LA) were increased. These lipids were also capable of sensitizing primary afferent DRG neurons and induction of thermal hypersensitivity (Ramsden et al., 2017). Interestingly, in the amygdala, the concentrations of $13 \mathrm{H}-9,10 \mathrm{E}-\mathrm{LA}$ were reduced in chronic inflammatory pain (Jensen et al., 2018). This metabolite is suggested to be synthesized by conversion of HODEs through CYP450, whereas the synthesis pathway of $11 \mathrm{H}-12,13 \mathrm{E}-\mathrm{LA}$ and other metabolites is still unclear (Ramsden et al., 2017). They may be released by phospholipases or may be metabolized by peroxidation followed by hydroperoxide isomerization of LA (Ramsden et al., 2017). The concentrations of $11 \mathrm{H}-12,13 \mathrm{E}-\mathrm{LA}$ are positively correlated with the occurrence of daily headaches in patients. Thus, lowering dietary intake of
LA caused a reduction of $11 \mathrm{H}-12,13 \mathrm{E}-\mathrm{LA}$ concentrations in plasma (Ramsden et al., 2017).

Not only in plasma was a correlation of the LA metabolites and pain observed. In psoriatic lesions the LA metabolite 9-keto-12,13-trans-epoxy-10E-octadecenoate (9K-12,13E-LA) was found to be increased and induced itch relating behavior (Ramsden et al., 2017).

Likewise, other lipids seem to influence chronic and persistent pain. The enzyme phospholipase $\mathrm{A}_{2}\left(\mathrm{PLA}_{2}\right)$, responsible for liberating $\mathrm{AA}$ of the phospholipid membrane, hydrolyzes the ester bond of glycerophospholipids to release polyunsaturated fatty acids and lysophopholipids like lysophosphatidylcholine (LPC) (Murakami and Kudo, 2002; Andersson et al., 2007]. LPC increases the temperature activation threshold of TRPM8 and thus increase cold sensitivity (Andersson et al., 2007; Gentry et al., 2010; Dennis and Norris, 2015). Decrease of LPC by inhibition of cytosolic calcium independent $\mathrm{PLA}_{2}\left(\mathrm{iPLA}_{2}\right)$ causes a reduction of calcium influx. When iPLA ${ }_{2}$ synthesizes LPC, the LPC further leads to prolonged TRPM8 channel opening, suggesting LPC as potent TRPM8 activator (Vanden Abeele et al., 2006) (Table 1C).

Upon intense stimulation of spinal cord neurons LPC is generated followed by a conversion through the extracellular lysophospholipase D autotaxin to lysophosphatidic acid (LPA) (Ueda, 2011). The roles of LPA in neuropathic pain are reviewed elsewhere in more detail (Ueda, 2011). In general, LPA leads to activation of peripheral nociceptor endings by increasing pain transmission, $\mathrm{PKC} \gamma$ signaling and leading to the release of histamine (Ueda, 2011). Furthermore, LPA activates the $\mathrm{LPA}_{1}$ receptor and by this RhoA-rho-associated, coiled-coil-containing protein kinase 1 (ROCK)-JNK signaling resulting in a negative regulation of myelin protein gene expression, which may cause demyelination (Ueda, 2011). Studies indicate that LPA induces calcium signaling in microglia, as well as proliferation, adenosine triphosphate (ATP) release and ERK signaling during the early stage of neuropathic pain development (Blaho and Hla, 2011; Ueda, 2011).

The expression of the LPA1 receptor is altered through signaling of sphingosine-1-phosphate (S1P), which is altered in chemotherapy-induced peripheral neuropathy (CIPN) and associated pain (Blaho and Hla, 2011; Stockstill et al., 2018). S1P signaling induces TNF $\alpha$ and IL- $1 \beta$ release, decrease of antiinflammatory cytokines and activation of p38 signaling (Blaho and Hla, 2011; Stockstill et al., 2018). Apart from that, ex vivo S1P mediated LPC activation (Blaho and Hla, 2011).

Nerve-injury induced neuropathic pain and ongoing pain can be reduced by application of neuroprotectin D1 (NPD1) (Xu et al., 2013b). It can be synthesized from LA, which is converted through desaturases into eicosapentaenoic, into docosahexaenoic acid and then to NPD1 (Coste TC et al., 2003; Xu et al., 2013b; Dennis and Norris, 2015; Bang et al., 2018). NPD1 induces the inhibition of inflammation and inflammatory pain, by reducing IL-1 $\beta$, C-C motif chemokine ligand 2 (CCL2) expression and phosphorylation of p38 and ERK (Xu et al., 2013b; Bang et al., 2018). This effect was a $G_{i}$-mediated mechanism by the GPCR GPR37, which is mainly expressed on macrophages (Bang et al., 2018). Thereby NPD1 increases phagocytosis of macrophages, as well as expression of IL-10 and TGF- $\beta$ in acute inflammation (Bang et al., 2018) (Table 1C). Whether the infiltration of 
TABLE 1C | Other recently described lipids in inflammation and pain.

Animals/tissue/cell type Effect Signaling

Experiment Experimental details

Target

Refs.

C57BL/6 mice, GPR37-KO Antiinflammatory, mice and Cx3cr1-GFP mice, antinociceptive spinal cord, brain and skin

tissue, DRGs, peripheral

macrophages, CD1 mice

Sprague-Dawley rats, Slprl Proinflammatory

$\mathrm{KO}$ and $\mathrm{KD}$ mice, human

multiple myeloma cells

CHO cells expressing mouse Pronociceptive

TRPM8, DRG cultures,

Wistar rats, WT and

TRPA1-KO mice, HEK-293

cells

Neurons

Pronociceptive at early stage neuropathic pain
Reduction of IL-1 $\beta$, CCL2 expression, phosphorylation of p38 and ERK, Increase of phagocytosis, expression of $\| \mathrm{L}-10$ and TGF- $\beta$

PA receptor expression, TNF $\alpha$ In vivo and $\mathrm{IL}-1 \beta$ release, decrease anti-inflammatory cytokines, p38 signaling, LPC activation

Cold sensitivity

NPD1 (precursor: DHA)

In vivo, in vitro zymosan inflammatory pain model, intraplanar drug injection, in situ hybridization, LacZ staining, IHC, ELISA for IL-1 $\beta$, TGF- $\beta$ and IL-10, qPCR, Western Blot analysis, transfection, dot blot assay

for lipid-binding protein, Ca-imaging, flow cytometry, phagocytosis assay by epifluorescence microscopy, licking or flinching time measurement, mechanical hypersensitivity via von Frey test, Randall-Selitto, behavioral studies, rotarod test, $\mathrm{CCl}$ model, with local peri-surgical pre-treatment of NPD1/PD1, autotomy/axotomy and chamber preference measurements with clonidine, long-term potentiation (LTP) measurements, mechanical allodynia studies, sEPSCs measurements

\section{S1P}

intrathecal catheters or osmotic minipump for administration of compounds like fingolimod, D24 or D25, bortezomib injection intra peritoneal, S1pr1 silencing with 27mer dicer-substrate silencer RNA (DsiRNA), mechanical allodynia and hyperalgesia tests via von Frey and the Randall and Sellitto paw pressure test, mass spectrometry, Western Blot analysis, S1PR1 knockdown PCR, immunofluorescence, cytokine assay via multiplex cytokine kit,

in vitro whole-cell recordings, tumor cell-killing assay via MTT assay

\section{LPC (precursor: phospholipids)}

In vivo, in vitro Ca-imaging, electrophysiology, intracellular calcium assay, subcutaneous injection in paw of icilin, menthol, LPC, BEL, saline, $\alpha, \beta$-methylene ATP, Allyl isothiocyanate (AITC), cinnamaldehyde, cold plate and acetone evaporation measurement, heat sensitivity by hot-plate measurements, mechanical sensitivity transfection, iPLA2 activity assay, electrophysiology, fluorescence measurements of cytosolic calcium concentrations

\section{LPA (precursor: lysophospholipids)}

See references (reviews)
GPR37

(Xu et al., 2013b; Bang et al., 2018)

(Blaho and Hla, 2011; Stockstill et al., 2018)
Increasing histamine release, demyelination, $\mathrm{PKC}$ and

RhoA-ROCK-JNK signaling,

Pro-liferation, calcium signaling,

ATP release, ERK signaling,

early stage neuropathic pain

Ca, calcium; CCL, chemokine ligand; CXCR1, C-X-C chemokine receptor type 1; DRGs, dorsal root ganglia; ELISA, enzyme-linked immunosorbent assay; ERK, extracellular-signal regulated kinase; IHC, immunohistochemistry; IL, interleukin; iPLA2, calcium-independent phospholipase 2; KD, knockdown; LPA, Iysophosphatidic acid; LPC, Iysophosphatidylcholine; LTP, Iong-term potentiation; MTT, 3(4,5-dimethylthiazol-2-yl)-2,5-diphenyltetrazolium bromide; sEPSCS, spontaneous excitatory post synaptic currents; TGF, transforming growth factor; NPD1, neuroprotectin D1; S1P, sphingosine-1 phosphate; S1PR1, S1P receptor 1; DHA, docosahexaenoic acid; TNF, tumor necrosis factor; LPAR, Iysophosphatidic acid receptor; TRPM8, transient receptor potential melastatin ion channel 8; ROCK, Rho-associated, coiled-coil-containing protein kinase; PKC, protein kinase C; GPR, G-protein coupled receptor. 
inflammatory macrophages into DRG neurons is prevented through NPD1-GPR37 binding or by action of NPD1 itself is still unclear. However, treatment with NPD1 is effective in reducing neuropathic pain in vivo. It also shows no anti-nociceptive tolerance as opioids does and is capable of preventing diabetesinduced mechanical hypersensitivity (Xu et al., 2015). Thus, it seems to be a promising agent against neuropathic pain, which should be studied in more detail.

\section{PHARMACOLOGICAL IMPLICATIONS OF LIPID SIGNALING IN CHRONIC AND/OR NEUROPATHIC PAIN}

The above-mentioned involvement of signaling lipids in different aspects of peripheral or central sensitization and their essential role in the pathophysiology of chronic and neuropathic pain raises the question, whether targeting synthesis, metabolism, or downstream signaling of these lipids may be a novel pharmacological strategy for the treatment of persistent pain states in patients. In this section, we therefore analyze and critically discuss the role of crucial proteins involved in lipid bioactivation and oxygenation, such as phospholipases and lipid oxygenases, lipid metabolism, such as soluble epoxide hydrolase, and lipid receptors, such as G2A and FFAR as targets for the treatment of chronic or neuropathic pain states.

The strongest evidence for the crucial involvement of lipid signaling in pain pathophysiology are prostaglandins, synthesized by cyclooxygenases COX-1 and COX-2. Both are targeted by non-steroidal anti-inflammatory drugs (NSAIDs), such as ibuprofen and diclofenac, which are widely used for the treatment of inflammatory pain (Day and Garry, 2013).

The significance of prostaglandins in inflammatory pain suggests an equally important role for other lipids in the pathophysiological processes of different pain states and that their regulating enzymes may represent targets for the development of novel analgesics, as shown by recent studies.

\section{Phospholipases}

The crucial enzymes for bioactivation of signaling lipids and for releasing them from complex membrane forming lipids are phospholipases. In this group of enzymes, cPLA2, iPLA2, and the extracellular phospholipase D2 autotaxin seem to be particularly important for the release of fatty acids and lysophospholipids (Astudillo et al., 2018; Law et al., 2019).

Both, cPLA2 and iPLA2, are highly expressed in peripheral sensory neurons and central nervous neurons. cPLA2 cleaves fatty acids, such as linoleic acid and arachidonic acid by hydrolyzing the $\mathrm{sn}_{2}$ ester bond in phospholipids leading to bioactivation and liberation of these fatty acids (Farooqui et al., 2006; Sun et al., 2014). The activation of cPLA2 in peripheral sensory neurons is caused by increases in intracellular calcium concentrations through ion channels or release of intracellular calcium stores and by subsequent activation of $\mathrm{Ca}^{2+} /$ calmodulin-dependent protein kinase II (CaMKII). These synergistic mechanisms lead to enhanced activity of cPLA2 which has been connected with increased neuronal activity and nerve-injury-induced neuropathic pain in preclinical studies (Tsuda et al., 2007; Hasegawa et al., 2009).

In contrast, iPLA2 activation does not depend on intracellular calcium changes. Other than CPLA2, iPLA2 cleaves the head group of complex phospholipids, resulting in release of lysophospholipids (Ramanadham et al., 2015). During nerveinjury-induced neuropathic pain, spinal cPLA2 and iPLA2activity are increased. Thus, intrathecal injection of both the dual PLA2 inhibitor Arachidonyl trifluoromethyl ketone $\left(\mathrm{AACOCF}_{3}\right)$ and the selective iPLA2 inhibitor bromoenol lactone (BEL) caused a reduction of lipid release in the spinal cord and neuropathic pain in vivo (Ma et al., 2010). Moreover, administration of the dual PLA2-inhibitor $\mathrm{AACOCF}_{3}$ reduced thermal hyperalgesia and formalin-induced flinching in vivo (Lucas et al., 2005) (Table 2, Figure 2) suggesting an involvement of PLAs in the pathophysiological processes leading to inflammatory and/or neuropathic pain.

In contrast to the intracellular acting PLAs, autotaxin is an extracellular phospholipase D that processes released lysophospholipids, such as lysophosphaditylcholine, by removing the choline head group. This results in the bioactivation of free lysophosphatidic acids (Albers and Ovaa, 2012). In plasma and synovial fluid of patients suffering from knee osteoarthritis and associated pain, autotaxin is markedly increased and seems to correlate with severity of osteoarthritis in patients (Mabey et al., 2015). Recently, potent and orally available inhibitors of autotaxin have been developed (Jones et al., 2016). Administration of one test compound caused a decrease of joint pain in the monosodium iodoacetate (MIA) model of osteoarthritis as well as a reduction of bone fracture pain in the osteotomy model in rodents (Thirunavukkarasu et al., 2017) (Figure 2, Table 2). Moreover, in the pathophysiological process of nerve-injuryinduced neuropathic pain, LPAs seem to contribute to Schwann cell degradation and demyelination (Inoue et al., 2008). However, the role of autotaxin inhibitors in this context has not yet been investigated.

These observations imply a role for phospholipases in pain pathophysiology. However, the central role of these enzymes in the bioactivation of signaling lipids in many different contexts hamper specific targeting of these enzymes in chronic and/or neuropathic pain states respectively. For example, cPLA2 seems to play a role in a variety of diseases which involve transient or chronic inflammation, such as brain injury, pulmonary fibrosis and Alzheimer's disease (Dennis et al., 2011). However, the role of CPLA2 in these pathophysiological contexts seems to be contrasting, as it's metabolites may have beneficial effects for example in cardiac fibrosis, but may also promote disease progression and severity, as for example in allergic reactions (Aloulou et al., 2012). Similar contrasting effects are known for iPLA2 in many different disease states (Ramanadham et al., 2015).

These contrasting roles and the essential requirement of phospholipases in many physiological and pathophysiological conditions, speak against systemic targeting of phospholipases during pain treatment, as many unwanted effects are likely to occur. In this regard, it may be more useful to apply phospholipase inhibitors more locally and transiently to inhibit phospholipases only in specific cellular subpopulations and only 
TABLE 2 | The role of proteins involved in lipid release, synthesis and metabolism, as well as lipid GPCRs in various pathophysiological mechanism of persistent and neuropathic pain

receptor

Effect

Pathophysiological relevance

Effect of inhibitor or knock-out

Pain state investigated (model)

Refs.

CPLA2

Releases fatty acids (LA,

Increased in the PNS and CNS during

Intrathecal injection of $\mathrm{AACOCF}_{3}$ caused

Inflammatory pain (carrageenan, formalin),

(Lucas et al., 2005; Ma

AA) from membranes

inflammatory and neuropathic pain

in vivo

iPLA2 Releases fatty acids (LPC) Increased in the CNS during from membranes neuropathic pain

Autotaxin (PLD) Converts LPCs to LPAs Increased in the plasma and synovial extracellularly fluid of OA patients

CYP2J2 Oxidizes fatty acids (LA, AA) Increased in the PNS during inflammatory and paclitaxel-induced neuropathic pain

Spinal eLOX3 increased during

inflammatory pain

Microglial 15-LOX-1 increased during LPS-induced inflammatory pain

sEH Hydrolyzes epoxylipids

Concentrations of anti-inflammatory

(EpOMEs, EETs)

epoxylipids are systemically increased

by sEH inhibition

G2A (GPR132) Activated by 9-HODE and Increased 9-HODE concentrations other lipids oxaliplatin-induced neuropathic pain

FFAR1 (GPR40) Activated by medium- and Increased expression in DRG neurons long-chain fatty acids during inflammatory and neuropathic pain

LPAR $1 / 3 \quad$ Activated by

LPAR1 activation causes increased Iysophosphatidic acids of neuronal activity, and Schwan cell various chain lengths dependent demyelination

Intrathecal injection of $\mathrm{AACOCF}_{3}$ and BEL caused reduction of neuropathic pain in vivo

Test compound reduced joint pain and fracture pain in vivo. Autotaxin-knock-out mice have

reduced nerve injury- induced neuropathic pain

Ketoconazole reduced CFA-induced inflammaton pain and Telmisartan reduced paclitaxel-induced mechanical hypersensitivity in vivo

Intraplantar injection of NDGA caused reduction of heat hyperalgesia; systemic treatmen

with NDGA caused reduction of mechanical hypersensitivity

Systemic treatment of $\mathrm{sEH}$ causes a reduction

of inflammatory pain and diabetes-induced

neuropathic pain

neuropathic pain (nerve injury)

et al., 2010)

neuropathic pain (nerve injury)

(Ma et al., 2010)

MIA model for osteoarthritis and osteotomy (Inoue et al., 2008; model; neuropathic pain

CFA model for inflammatory pain, paclitaxel (Ruparel et al., 2012a; model for chemotherapy-induced neuropathic Sisignano et al., 2016) pain

Dissolved compounds isolated from heated skin superfusates were injected intraplantar (model for inflammatory pain); carrageenaninduced inflammatory pain

LPS, carrageenan, zymosan and CFA-induced inflammatory pain, Streptozotocin (STZ)induced neuropathic pain

(Buczynski et al., 2010; Patwardhan et al., 2010; Gregus et al., 2013; Gregus et al., 2018)

(Inceoglu et al., 2006; Schmelzer et al., 2006; Inceoglu et al., 2008; inceoglu et al., 2012; Zimmer et al., 2018)

G2A-deficient mice have less oxaliplatininduced neuropathic pain and less zymosaninduced thermal hyperalgesia

Selective agonists MEDICA16 or GW9508 cause a reduction of inflammatory and nerveinjury-induced neuropathic pain

LPAR1-deficient mice have reduced inflammatory and neuropathic pain, both LPAR1- and LPAR3-deficient mice have reduced paclitaxel-induced neuropathic pain

Oxaliplatin-induced neuropathic pain, (Hohmann et al., 2017;

zymosan-induced peripheral inflammation and Kern et al., 2018) inflammatory pain

CFA- and carrageenan model for inflammatory ～(Nakamoto et al., 2012; pain, formalin model for acute/inflammatory Karki et al., 2015) pain, SNL model for neuropathic pain

Partial sciatic nerve injury model for

neuropathic pain (LPAR1);

(Inoue et al., 2004; carrageenan-model for orofacial inflammatory Srikanth et al., 2018) pain (LPAR1)

Paclitaxel model for chemotherapy-induced neuropathic pain LPAR1/3);

Mice deficient of astrocytes expressing S1P1R have reduce bortezomib-induced neuropathic pain; pharmacological blockade of the S1P1R causes reduction of bortezomib-induced and

CCl-induced neuropathic pain

Mice treated with a BLT2 agonist show reduced Zymosan model for inflammatory pain Bortezomib-induced neuropathic pain

$\mathrm{CCl}$ models of nerve injury induced

(Stockstill et al., 2018; spinal astrocytes after bortezomibtreatment and after nerve injury neuropathic pain

mechanical and thermal hypersensitivity during

BLT1 activation causes TRPV 1 $\left(\mathrm{LTB}_{4}\right)$

sensitization, BLT2 activation reduces TRPV1 sensitization in sensory neurons

GRP37

Activated by Neuroprotectin Causes increases of $\left[\mathrm{Ca}^{2+}\right]$ in D1 (NPD1)

macrophages and promotes phago

GPR37-knock-out mice have reduced

Zymosan model for inflammatory pain

(Zinn et al., 2017)

inflammatory pain (heat hyperalgesia and

mechanical allodynia)

AA, arachidonic acid; BEL, bromoenol lactone; BLT, B-Leukotriene receptor; CCI, chronic constriction injury; CFA, complete Freund's adjuvant; CNS, central nervous system; CYP, cytochrome- $P_{450}$ epoxygenase; DRG, dorsal root ganglion; EET, epoxyeicosatrienoic acid; EDOME, epoxyoctadecadienoic acid; FFAR, free fatty acid receptor; G2A, G2-accumulating GPCR; HODE, hydroxyotadecadienoic acid; LA, linoleic acid; LPAR, Iysophosphatidic acid receptor; LPC, lysophosphatidylcholine; LPS, lipopolysaccharide; LOX, lipoxygenease; LTB Refs, references; SEH, soluble epoxide hydrolase; SNL, spinal nerve ligation; S1P, sphingosine-1-phosphate; S1PR1, sphingosine-1-phosphate receptor 1; STZ, Streptozotocin; TRPV1, transient receptor potential vanilloid 1 channel. 


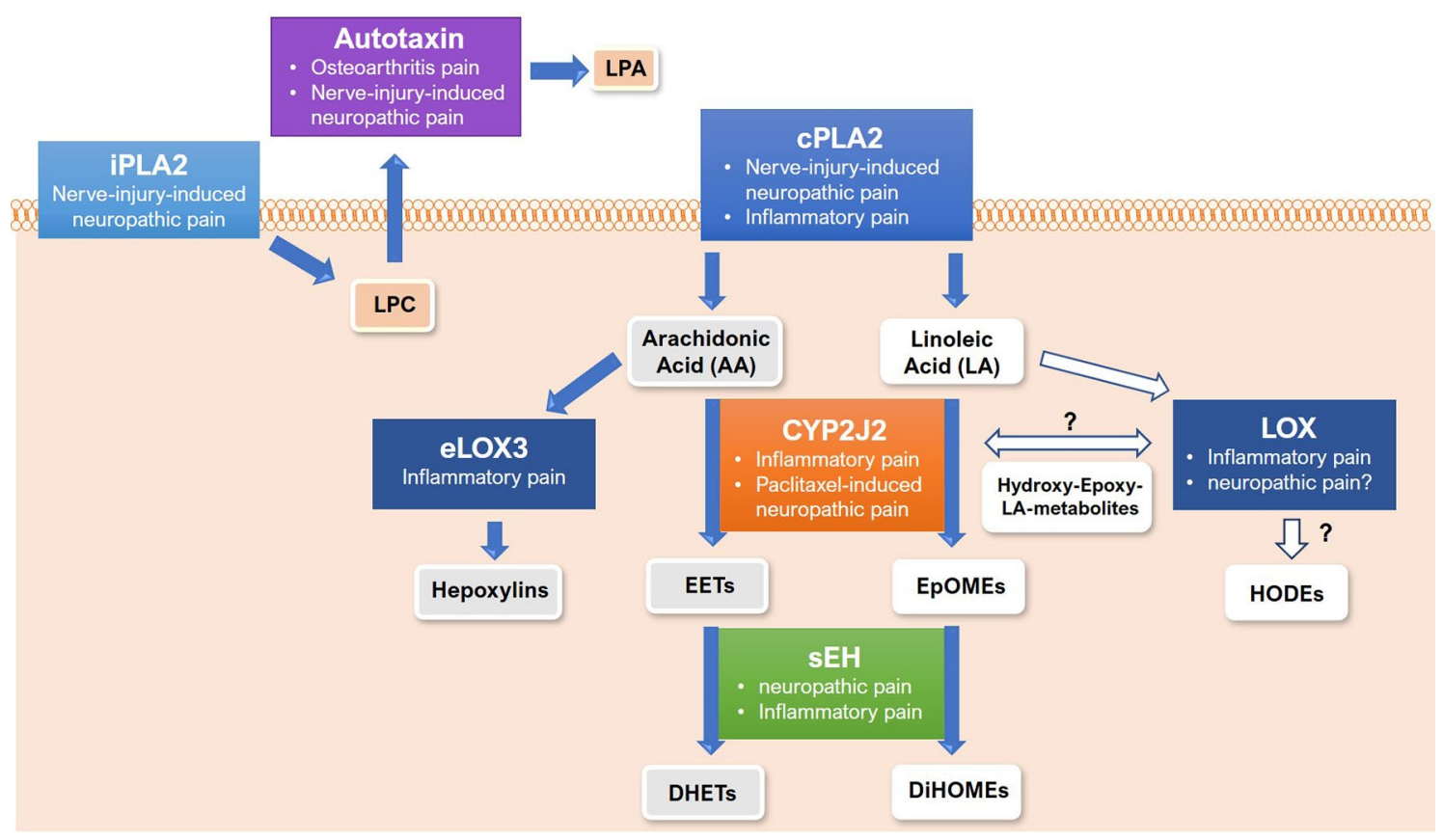

FIGURE 2 | Proteins of lipid release, synthesis and metabolism in the pathology of persistent and/or neuropathic pain states. Shown are the proteins involved in release of lysophospholipids (in beige background), synthesis and metabolism of linoleic acid metabolites (in white background) or arachidonic acid metabolites (in grey background) and the respective pain state that each protein is connected with. White arrows indicate unknown synthesis or metabolism pathway. PLA, phospholipase; LA, linoleic acid; AA, arachidonic acid; LPC, lysophosphatidylcholine; CYP, cytochrome-P ${ }_{450-}$ epoxygenase; LOX, lipoxygnease; sEH, soluble epoxide hydrolase; EET, epoxyeicosatrienoic acid; EpOME, epoxyoctadecadienoic acid; HODE, hydroxyotadecadienoic acid; DHET, dihydroxy-eicosatrienoic acid; DiHOME, dihydroxy-octadecenoic acid.

at the time of their aberrant activity. However, until now, there is no pharmacological inhibitor of phospholipases available for clinical use. In general, more research is required to understand the specific contribution of phospholipases to persistent pain states, as well as their temporal activity in pain pathophysiology that may allow targeting these enzymes for the treatment of chronic or neuropathic pain in patients.

\section{Lipid Oxygenases - CYP and LOX}

The liberation of fatty acids from membrane lipids by cPLA2 makes them available as substrates for lipid oxygenases. There are three main classes of lipid oxygenases: 1 . the abovementioned cyclooxygenases (COX), 2. lipoxygenases (LOX) and 3. cytochrom- $\mathrm{P}_{450}$-epoxygenases (CYP). Because the role of COX and its prostanoid metabolites in persistent pain states have been reviewed previously (Eisenach et al., 2010; Chen et al., 2013), we focus on recent observations involving LOX and CYP enzymes in inflammatory or neuropathic pain states.

Lipoxygenases catalyse their reaction with iron and CYPepoxygenases contain a full cytochrome as cofactor. Lipoxygenases usually attach a hydroperoxide group onto one of the substrates' double bonds that is subsequently reduced to a hydroxide group. CYP-epoxygenases attach epoxide groups or terminal hydroxide groups to their substrate fatty acids. These enzymes can oxidize a variety of different substrates, but the most abundant are the $\omega-6$ fatty acids linoleic acid (giving rise to oxidized linoleic acid metabolites) and arachidonic acid (giving rise to oxidized eicosanoids, Figure 2) (Haeggstrom and Funk, 2011; Xu et al., 2013a; Spector and Kim, 2015).

Several lines of evidence suggest a crucial role for CYPepoxygenases of the subfamily $2 \mathrm{~J}$ in the pathogenesis of persistent or neuropathic pain.

The expression of the genes encoding for the CYP-epoxygenase isoforms $2 \mathrm{~J}$ and $3 \mathrm{~A}$ was elevated in dental pulp samples of patients with inflammatory dental pain as well as in trigeminal neurons of rats during complete Freund's adjuvant (CFA)-induced inflammatory pain (Ruparel et al., 2012b; Ruparel et al., 2013). In this context, treatment of rodents with the unspecific CYPepoxygenase inhibitor ketoconazole caused a reduction of pain hypersensitivity during CFA-induced inflammation (Ruparel et al., 2012a).

CYP-epoxygenases are essential proteins for the biotransformation of xenobiotic substances. Therefore, exogenous and potentially toxic substances may trigger increased activity of CYP-epoxygenases (Murray, 2016). Indeed, it was shown that paclitaxel, a cytostatic that is widely used for the treatment of breast cancer and that causes neuropathic pain in patients, can enter peripheral sensory neurons easily (Park et al., 2013). In a preclinical study it was observed that paclitaxel causes increased expression of the gene encoding for the CYP-epoxygenase isoform 2J6 (CYP2J6, in human: CYP2J2) in murine sensory neurons. Administration of the CYP2J2 inhibitor Telmisartan was sufficient to reduce neuronal synthesis of CYP2J2 derived oxidized lipids and to reduce mechanical hypersensitivity of 
mice during paclitaxel-induced neuropathic pain in a dosedependent and preventive manner (Sisignano et al., 2016) (Figure 2, Table 2).

Apart from CYP-epoxygenases, available free linoleic and arachidonic acid can also be converted by lipoxygenases (LOX).

As stated above, the hydroxylated linoleic acid metabolites 9- and 13-HODE show pronociceptive effects in preclinical inflammatory and neuropathic pain models. Unlike other lipids discussed in the first chapter, the synthesizing enzyme for HODEs, particularly for 9-HODE, remains unclear. Likewise, for novel linoleic acid-derived hydroxy-epoxy or keto epoxy-mediators that have been described to contribute to pain and itch (Ramsden et al., 2017), the synthesis pathway and the involvement of specific lipoxygenases and/or CYP-epoxygenases is unclear. However, the presence of non-terminal hydroxide groups in these lipids implies a role for LOX enzymes in their synthesis.

In the state of inflammatory pain, the expression of the gene encoding for eLOX3 was found increased in the spinal cord. Additionally, microglial expression of the gene encoding for 15-LOX-1 was elevated after LPS-induced induction of spinal toll-like receptor 4 (TLR4) in rodents, pointing towards induction of specific spinal lipoxygenase isoforms during inflammatory pain (Gregus et al., 2013; Gregus et al., 2018). Indeed, systemic treatment with the unspecific LOX inhibitor nordihydroguaiaretic acid (NDGA) caused a reduction of spinal LOX-derived lipids and led to a decrease of mechanical hypersensitivity in rats during carrageenan-induced inflammatory pain (Buczynski et al., 2010). In another study, dissolved compounds isolated from heated skin superfusates were injected intraplantar to induce a peripheral inflammation and inflammatory pain. In this model, peripheral intraplantar injection of the LOX inhibitor NDGA in the inflamed paw of rodents caused a reduction of inflammatory heat hyperalgesia in vivo (Patwardhan et al., 2010) (Figure 2, Table 2).

In summary, these results are promising and indicate a crucial role for CYP2J2 in paclitaxel-induced neuropathic pain and for both CYP2J2 and specific lipoxygenase isoforms in inflammatory pain. Telmisartan can be easily repurposed as CYP2J2 inhibitor due to long clinical experience with this drug and its good tolerability in patients (Battershill and Scott, 2006), whereas the unselective antifungal CYP-inhibitor ketoconazole is not suitable for systemic use due to high cross-reactivity, and it may cause hepatotoxicity upon systemic administration (Gupta and Lyons, 2015).

For the above-mentioned lipoxygenases eLOX3 and 15-LOX-1 specific and clinically available inhibitors are lacking. The unspecific inhibitor NDGA that was used in rodent models is not suitable for clinical use in patients and may cause unwanted side effects. Moreover, it may inhibit isoforms of lipoxygenases that are required for normal lipid homeostasis under physiological conditions. Therefore, more research is required on identification and clinical development of safe and specific inhibitors of lipoxygenase isoforms that are dysregulated in persistent pain states. These substances may be used as novel analgesics for the treatment of persistent and neuropathic pain in patients.

\section{Soluble Epoxide Hydrolase}

Soluble epoxide hydrolase (sEH) is the enzyme that converts epoxylipids, such as EpOMEs and EETs to diol lipids by hydrolysis of the epoxide group (Yu et al., 2000). This enzyme has a unique dual functioning role, as it contains both a hydrolase domain, that is responsible for lipid hydrolysis, and a lipid phosphatase domain which may be involved in the metabolism of lysophosphatidic acids (LPAs) (Newman et al., 2003; Morisseau et al., 2012). However, the role of the phosphatase group, especially in pathophysiological states, is unknown, and the available inhibitors of sEH mainly target the hydrolase domain (Shen and Hammock, 2012).

Inhibiting sEH leads to an increase in cellular and systemic epoxylipid concentration and a decrease in the concentrations of diol-metabolites. Because epoxy-metabolites of arachidonic acid (EETs) have previously been identified as potent vasodilators, and $\mathrm{sEH}$-inhibition leads to their systemic accumulation, $\mathrm{sEH}$ inhibitors were considered as promising novel pharmacological therapies for the treatment of cardiovascular diseases (Imig and Hammock, 2009). However, later studies demonstrated the involvement of epoxylipids, diol-metabolites, and sEH as their regulatory enzyme in the pathogenesis of persistent and neuropathic pain.

It was shown that the inhibition of $\mathrm{sEH}$ can reduce the levels of the proinflammatory and proalgesic mediator prostaglandin $\mathrm{E}_{2}$. sEH may also reduce the activity of spinal COX-2 during inflammatory pain, which points towards a cross-regulation of CYP and COX pathways. Moreover, treatment of rodents with $\mathrm{sEH}$ inhibitors caused a reduction of inflammatory pain hypersensitivity in vivo (Inceoglu et al., 2006; Schmelzer et al., 2006; Inceoglu et al., 2008) (Table 2, Figure 2).

Interestingly, the analgesic efficacy of $\mathrm{sEH}$ inhibitors seems to be not only restricted to inflammatory pain. In a rat model of streptozotozin (STZ)-induced diabetic neuropathy, the administration of three different $\mathrm{sEH}$-inhibitors caused a reduction of mechanical hypersensitivity in vivo. This effect was similarly strong as the analgesic effect of the calcium channel blocker gabapentin (Inceoglu et al., 2012).

The antihyperalgesic effects of $\mathrm{sEH}$ inhibitors in preclinical studies are impressive and suggest $\mathrm{sEH}$ as promising target for the development of novel analgesics but there are still many open questions and limitations of these compounds for a clinical use in patients. The mechanistic basis of their actions has long been attributed to systemic increase of epoxylipid concentrations and their anti-inflammatory actions (Thomson et al., 2012).

Moreover, the diol metabolites of sEH were previously considered to be biologically less active than their parent epoxilipids (Spector and Norris, 2007). However, this image is challenged by recent studies and there is evidence for the involvement of diollipids in several pathophysiological mechanisms. In one study, the linoleic acid-derived diol metabolite of sEH, 12,13-DiHOME was identified as TRPV1-sensitizing mediator that is produced in neuronal tissue during zymosan- or CFA-induced inflammatory pain. Treatment of mice with the sEH inhibitor TPPU causes a reduction of 12,13-DiHOMEs synthesis in neuronal tissue and reduces both CFA- and zymosan-induced thermal hyperalgesia in vivo (Zimmer et al., 2018) (Figure 2, Table 2). Similarly, the sEH metabolite 19,20-DHDP has recently been identified as crucial mediator of diabetic retinopathy and treatment of mice with an $\mathrm{sEH}$ inhibitor caused a reduction of 19,20-Dihydroxydocosapentaenoic 
acid (19,20-DHDP) concentrations in the retina and a reduction of diabetic retinopathy in vivo (Hu et al., 2017).

These recent observations challenge the idea, that diolmetabolites are less active than their parent epoxylipids. Moreover, these results indicate that the effects of sEH-inhibitors may be caused not just by increasing epoxylipid concentrations, but by a simultaneous decrease of diol-lipid concentrations.

However, it is still unknown which physiological and pathophysiological role the phosphatase domain of sEH has. It has been proposed that the phosphatase domain may be relevant for the metabolization of lysophosphatidic acids (LPAs) (Morisseau et al., 2012). This indicates that sEH may be a crucial regulator at the interface of both lysophospholipid and fatty acid metabolism, yet more research is required to identify the role of this enzyme and in particular, the regulatory functions of the phosphatase domain in physiological and pathophysiological processes.

Additionally, it remains to be investigated which potential side effects sEH inhibitors may cause. For example, the sEH inhibitor 12-(3-adamantan-1-yl-ureido)-dodecanoic acid (AUDA), that was used in early in vivo studies, was found to directly activate the peroxisome proliferator-activated receptor (PPAR)- $\alpha$ (Fang et al., 2005). This receptor may in part be responsible for some of its anti-inflammatory effects independent of lipid-mediated effects. However, newer soluble epoxide hydrolase inhibitors seem to be more specific (Lee et al., 2014). Indeed, selected sEH-inhibitors have already proceeded to clinical testing in inflammatory contexts (clinicaltrials.gov), but conclusive results concerning their effects in patients have not yet been published.

\section{Lipid GPCRs}

G-protein coupled receptors (GPCRs) are still the most important target proteins in pharmacology and by now the high-resolution structures of more than 50 individual GPCRs have been solved (Alexander et al., 2017). Among these GPCRs are also specific receptors for signaling lipids which contribute to the transmission of cell-cell-signals in physiological and pathophysiological conditions. The pain relevant GPCRs comprise of prostanoid receptors, cannabinoid receptors, leukotriene receptors, as well as LPA receptor 1 and 3, S1P receptor 1, G2A, FFAR1 (GPR40) and GPR37 (Audet and Stevens, 2019). While the various functions of prostanoid and cannabinoid receptors have previously been reviewed (Manzanares et al., 2006; Narumiya, 2007), we focus on recently described lipid GPCRs that may be involved in pathogenesis of persistent and neuropathic pain and may represent targets for the development of novel analgesics (Figure 3).

\section{Fatty Acid GPCRs - G2A and FFAR1}

The PTX-sensitive G2A receptor (GPR132) was initially described to be accumulating in the $G_{2} / M$ phase of the cell cycle and generally seems to be induced by DNA damage and related cellular stress. Due to the accumulation of the receptor in the $G_{2}$ phase it was named G2A(ccumulating) receptor (Weng et al., 1998). By means of sequence analysis and comparison to different classes of GPCRs, G2A was categorized within the group of proton-sensing GPCRs and seems to be activated by mild pH reduction (Murakami et al., 2004). However, G2A lacks crucial histidine residues, that all other proton-sensing GPCRs
[GPR4, T-cell death associated gene 8 (TDAG8) and Ovarian cancer G-protein coupled receptor 1 (OGR1)] contain and is therefore only weakly activated by $\mathrm{pH}$ reduction (Radu et al., 2005). In contrast, heterologous expressed G2A can be activated by various oxidized eicosanoids and linoleic acid metabolites. The strongest activator seems to be the oxidized linoleic acid metabolite 9-HODE (Obinata et al., 2005).

G2A is expressed in immune cells, such as macrophages, neutrophils, and T-cells, but also in a subset of TRPV1- and isolectin B4 (IB4)-positive primary sensory neurons in the dorsal root ganglia (Kwan et al., 2007; Justus et al., 2013). In these neurons, G2A seems to be activated by excessive 9-HODE and seems to contribute to TRPV1 sensitization via $\mathrm{G}_{\mathrm{q}}$-coupling and activation of PKC during oxaliplatin-induced neuropathic pain. This causes increased activity of sensory neurons, increased release of the proinflammatory neuropeptide CGRP and contributes to oxaliplatin-induced mechanical hypersensitivity in vivo. Indeed, the oxaliplatin-induced mechanical hypersensitivity is significantly reduced in G2A-deficient mice (Hohmann et al., 2017). In macrophages, G2A seems to be responsible for mechanisms involved in migration. Indeed, G2A-deficient mice that were peripherally injected with zymosan, showed reduced numbers of infiltrating macrophages and a decreased intensity of zymosan-induced thermal hyperalgesia compared with wildtype mice (Kern et al., 2018).

These observations point towards a central role of G2A in sensitization processes of peripheral sensory neurons either by direct activation of neuronal PKC and sensitization of TRPV1 or indirectly, by influencing immune cell migration in local inflammations (Figure 3, Table 2).

However, there are currently no selective inhibitors of G2A available which hamper characterization of the role of this receptor in pain pathogenesis and other pathophysiological states. A G2A inhibitor may be used as leads for clinical development. Moreover, the role of G2A under physiological conditions is not well understood and recent studies point towards involvement of this receptor in hematopoiesis (Lahvic et al., 2018).

In summary, although G2A may be a promising target for the development of novel analgesics, research on this receptor is currently at a very early stage and many open questions remain to be answered.

The free-fatty acid receptor 1 FFAR1 (GRP40) is activated by medium- and long-chain fatty acids, plays an important role in glucose homeostasis and insulin secretion and is a long known and well-studied target for the treatment of type 2 diabetes (Wagner et al., 2013).

However, FFAR1 also seems to be expressed in peripheral sensory neurons in the dorsal root ganglia, as well as in spinal cord neurons. Indeed, intrathecal injection of the selective FFAR1 agonists MEDICA16 or GW9508 caused a reduction of mechanical hypersensitivity in CFA-induced inflammatory pain and spinal nerve ligation (SNL)-induced neuropathic pain, as well as a reduction of thermal hyperalgesia in carrageenaninduced inflammatory pain in vivo (Karki et al., 2015). This confirms previous results, that intrathecal injection of GW9508 reduced formalin-induced pain behavior in mice possibly via increase of hypothalamic $\beta$-endorphin (Nakamoto et al., 2012). 

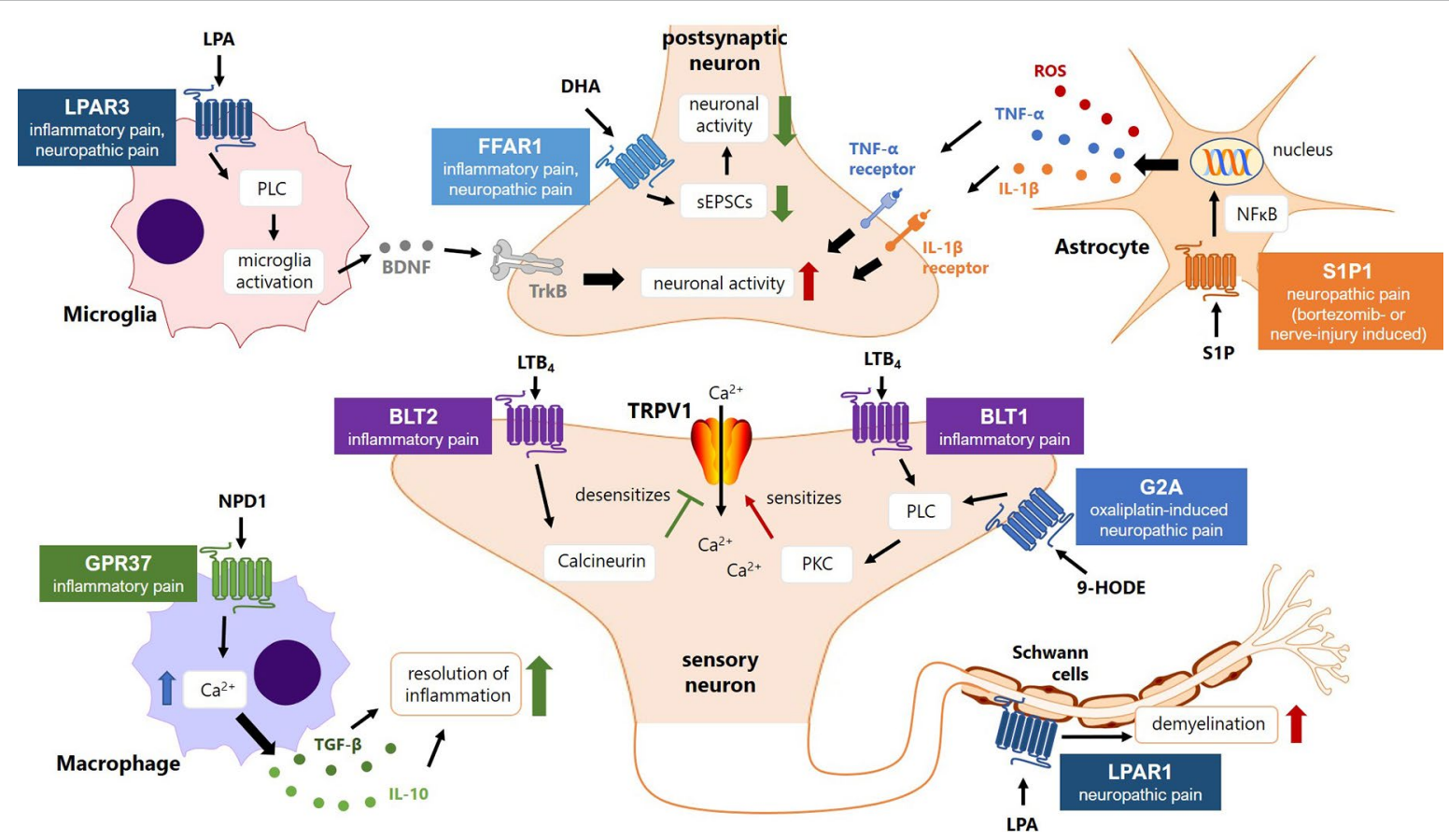

FIGURE 3 | Lipid GPCRs in the pathology of persistent and/or neuropathic pain states. Shown are the six lipid GPCRs that are discussed in the manuscript with an exemplary lipid ligand and their respective intracellular signaling pathways, their cellular distributions and signaling functions in persistent pain states at the interface of the peripheral and central nervous system. LPA, lysophosphatidic acid; LPAR, Iysophosphatidic acid receptor; PLC, phospholipase C; BDNF, brain-derived neurotrophic factor; DHA, docosahexaenoic acid; FFAR, free fatty acid receptor; GPR, G-protein coupled receptor; sEPSCs, spontaneous excitatory postsynaptic currents; TNF- $\alpha$, tumor necrose factor-alpha; IL-1 $\beta$, interleukin-1-beta; S1P, sphingosine-1-phosphate; S1P1R, sphingosine-1-phosphate receptor; NFkB, nuclear factor kappa-lightchain-enhancer of activated B-cells; HODE, hydroxyotadecadienoic acid; G2A, G2-accumulating GPCR; LTB4, leukotriene B 4 ; BLT, B-leukotriene receptor; PKC, protein kinase C; TRPV1, transient receptor potential vanilloid 1 channel; NPD1, neuroprotectin D1; TGF, transforming growth factor-beta; IL-10, Interleukin-10.

Apart from a potential involvement of the endogenous opioid system, the mechanistic basis of the analgesic effects of FFAR1-agonists in various pain models is still unclear. It should be investigated whether these effects are indeed mediated by FFAR1 or caused by unspecific off-target effects by the FFAR1 agonists. In this regard, more research is required to identify the mechanistic involvement of FFAR1 in sensitization and increased activity of peripheral sensory neurons during inflammatory and neuropathic pain. The fact that FFAR1 agonists are already tested in clinical trials (clinicaltrials.gov) and may be available for diabetes patients in the near future, may facilitate repurposing of these compounds for the treatment of chronic or neuropathic pain (Figure 3, Table 2).

\section{Lysophospholipid Receptors - LPR1 and 3 and S1P1R} By now, six lysophosphatidic acid receptors have been identified (LPAR1-6) with various roles in different tissues and pathophysiological contexts (Yung et al., 2014). The role of lysophosphatidic acid and its receptor LPAR1 in neuropathic pain has first been described in 2004 by Inoue et al. (Inoue et al., 2004). The authors showed that intrathecal injection of LPA directly causes mechanical hypersensitivity in rodents and that mice deficient of LPAR1 showed reduced mechanical hypersensitivity in the partial sciatic nerve injury model of neuropathic pain (Inoue et al., 2004). While LPAR1 is the main LPA receptor expressed in DRG neurons and its activation causes increased neuronal activity, it is also expressed in Schwann cells and seems to be involved in demyelination processes that occur at the onset of neuropathic pain (Ueda et al., 2013). Likewise, it has been observed that both, mice that are deficient of the LPAR1 receptor, as well as pharmacological inhibition of LPAR1 cause a reduction of mechanical hypersensitivity in a carrageenan-induced orofacial model of inflammatory pain (Srikanth et al., 2018). It was also described that LPAR1- or LPAR3-deficient mice show reduced paclitaxel-induced mechanical hypersensitivity (Uchida et al., 2014). Moreover, it was shown that the lipid LPA18:1, which is a ligand for the LPA receptors, also causes direct activation of TRPV1 in sensory neurons by interacting with a C-terminal region of the ion channel (Nieto-Posadas et al., 2011).

These observations in various pain models point towards a central role of the LPA receptor system in modulating neuronal activity, Schwann cell dependent demyelination and inflammatory mechanisms in persistent pain states. However, it remains pharmacologically challenging to selectively target LPAR1 or both LPAR1 and LPAR3 with one compound, without affecting the activity of the remaining four LPA receptors, all of which seem to have central physiological roles in various contexts (Yung et al., 2014). Global inhibition of all LPA receptors may therefore be connected with serious side effects and cannot be recommended. This selectivity problem currently restrains targeting the LPA receptor system in the context of inflammatory or neuropathic pain and requires more research and more 
selective targeting approaches to exploit the LPA receptor axis for the development of novel analgesics (Figure 3, Table 2).

The lipid sphingosine-1-phosphate (S1P) is one of the most important signaling lipids and regulates many physiological and pathophysiological processes in mammalian cells and tissues via its five G-protein coupled receptors (S1PR1-5) (Maceyka et al., 2012). A study identified a role for this lipid and specifically for the S1P1 receptor in chemotherapy-induced neuropathic pain caused by the proteasome inhibitor bortezomib. The authors of this study found that bortezomib-treatment increased spinal concentrations of S1P and other related lipids from its metabolic pathway. Moreover, bortezomib causes increased activity of spinal astrocytes via S1P1 receptor signaling. Treatment of mice with fingolimod or NIBR14, both of which are selective inhibitors of the S1P1 receptor, caused a reduction of bortezomib-induced mechanical hypersensitivity in vivo (Stockstill et al., 2018). Likewise, inhibition of the S1P1 receptor was found beneficial in chronic-constriction-injury (CCI)-induced neuropathic pain in vivo as published in a recent study. The authors show that nerve injury increases spinal S1P concentrations causing activation of S1P1 receptors in spinal astrocytes, leading to enhanced synaptic activity of sensory neurons. Inhibition of the astrocytic S1P receptor increases release of IL-10 which reduces the inflammatory response and leads to a decrease in synaptic activity of sensory neurons (Chen et al., 2019).

As discussed above, for the LPA receptors, there is currently no selective antagonist clinically available. In contrast, for the S1P1 receptor, fingolimod, a selective S1P1 receptor antagonist, is an already approved drug for the treatment of multiple sclerosis (Pelletier and Hafler, 2012). This could lead to repurposing of fingolimod for the treatment of bortezomib-induced- and nerveinjury induced neuropathic pain in patients (Figure 3, Table 2).

\section{Leukotriene Receptors BLT1 and 2 and the Neuroprotectin Receptor GPR37}

The signaling lipid leukotriene $\mathrm{B}_{4}$ that is involved in inflammatory processes and can bind two G-protein coupled receptors, called B-leukotriene receptors (BLT1 and BLT2) (Yokomizo, 2015). A recent study investigated the expression of GPCRs in peripheral sensory neurons of the dorsal root ganglia (DRG) and found that the two BLT receptors are among the 10 GPCRs with the strongest basal expression in DRGs (Zinn et al., 2017). Further investigation revealed that $\mathrm{LTB}_{4}$ shows a biphasic activity pattern in sensory neurons and binds BLT1 with high affinity and BLT2 with lower affinity. Moreover, the activation of the BLT1 receptor causes sensitization of the TRPV1 channel in these neurons. However, activation of the BLT2 receptor reduces sensitization of TRPV1 via activation of calcineurin. Treatment of mice with a BLT2 agonist causes a reduction of mechanical and thermal hypersensitivity in zymosan-induced inflammatory pain in vivo (Zinn et al., 2017). These results identify a self-regulating system of TRPV1 sensitization and neuronal activity by the two BLT receptors and indicate that inhibition of BLT1, activation of BLT2 or both mechanisms synergistically could be exploited for the development of novel analgesics in the context of increased TRPV1 sensitization during inflammatory pain.

The omega-3 lipid Neuroprotectin D1 (NPD1) that is synthesized from the precursor docosahexaenoic acid (DHA) has previously been shown to reduce neurogenic inflammation and mechanical hypersensitivity in nerve-injury models of neuropathic pain by reducing spinal activation of microglia and subsequent release of the proinflammatory mediators TNF- $\alpha$ and CCL-2 (Xu et al., 2013b). However, it remained unclear which receptor is mediating these effects of NPD1. Recently, GPR37 was identified as putative NPD1 receptor, and the lipid causes increases in intracellular calcium in GPR37-transfected cells. Moreover, the NPD1-GPR37-calcium-increase axis seems to regulate phagocytosis of zymosan particles as well as cytokine release by macrophages and seems to promote resolution of inflammation This indicates that GPR37 in immune cells mediates the anti-inflammatory effects of NPD1 in the context of inflammatory and neuropathic pain (Bang et al., 2018) (Figure 3, Table 2). These results imply a central role for GRP37 in the resolution of inflammatory pain.

\section{CONCLUDING REMARKS}

In conclusion, the above-mentioned studies demonstrate a crucial role for lipids and the corresponding regulatory proteins in processes that lead to persistent and/or neuropathic pain. As pain states are diverse in their respective pathophysiological mechanisms, it became clear in recent years that the contribution of specific lipid mediators to each pain state is also diverse. For example, the linoleic acid metabolite 12,13-DiHOME but not its sister lipid 9,10-DHOME seems to be critically involved in the development of thermal hyperalgesia in CFA- or zymosan-induced inflammatory pain (Zimmer et al., 2018). However, in paclitaxelinduced neuropathic pain, the parent epoxylipids seem to be present in higher concentrations in nervous tissues and seem to be more active than their diol-metabolites (Sisignano et al., 2016). Also, the cellular origin of these lipids may differ in each pain state. Some lipids may be synthesized and released from immune cells as part of the inflammatory response and others may be synthesized and released from neurons upon oxidative or toxic stress.

In recent years, it became clear that the composition and activity of gut microbes influences signaling and communication between gut and brain. Accumulating evidence suggests that alterations in gut-brain signaling may cause pathophysiological changes in the central nervous system that can contribute to the development of diseases such as depression, anxiety, or persistent pain (Mayer et al., 2014).

The contribution of the gut microbiome to persistent pain was described by characterizing germ-free mice in inflammatory pain models. The germ-free mice showed reduced mechanical hypersensitivity in carrageenan-, LPS- or formalin-induced inflammatory pain. Moreover, in germ-free mice reduced concentrations of TNF- $\alpha$, IL-1b and CXCL1 were observed in carrageenan-induced inflammatory pain (Amaral et al., 2008). Likewise, administration of Lactobacillus strains caused induction of cannabinoid (CB2) and opioid receptors in the intestinal epithelial cells in combination with a reduction of visceral pain in a rat model for irritable bowel syndrome (Rousseaux et al., 2007). Indeed, in the gut brain axis, endocannabinoids and their receptors $\mathrm{CB} 1$ and $\mathrm{CB} 2$ seem to play a crucial role for bidirectional signaling 
and crosstalk (Sharkey and Wiley, 2016; Russo et al., 2018). In patients with inflammatory bowel syndrome the concentrations of the endocannabinoid anandamide are significantly reduced in inflamed mucosa (Di Sabatino et al., 2011).

These results show, that the gut microbiome can modulate the activity of sensory neurons by influencing the expression of pain relevant cytokines, chemokines, or G-protein coupled receptors. However, further research is required to clarify the role of other lipids and lipid-related pathways in this context.

Likewise, the contribution of lipid-related proteins to specific pain pathologies seems to differ according to the etiology of the respective pain state and to the cell type in which these proteins are active. For example, activation of the BLT2 receptor in sensory neurons was found to cause TRPV1 desensitization and to ameliorate inflammatory pain (Zinn et al., 2017). In contrast, the S1P1 receptor is mostly expressed in astrocytes not in sensory neurons and seems to contribute to neuropathic pain caused by the cytostatic bortezomib (Stockstill et al., 2018) (see Figure 2, Table 2).

To identify novel targets for the development of analgesics, it is therefore necessary to determine the contribution of each lipid and its associated signaling pathways to each pain state. In this regard, the use of modern technologies, such as tandem mass spectrometry, is extremely helpful and should be adapted as standard analytical method by future studies.

Despite the complex physiological and pathophysiological properties of signaling lipids in persistent and neuropathic pain states, several potentially druggable targets have been identified in recent years. While some proteins, such as GPR37, have just recently been identified as lipid related. Other proteins, such as $\mathrm{sEH}$, are known to be involved in lipid metabolism for many years and inhibitors of sEH have already been tested in clinical trials (Lazaar et al., 2016) and may be available in the near future.

Moreover, lipid-related proteins have been identified in the pathogenesis of neuropathic pain, that can be targeted

\section{REFERENCES}

Abdu, E., Bruun, D. A., Yang, D., Yang, J., Inceoglu, B., Hammock, B. D., et al. (2011). Epoxyeicosatrienoic acids enhance axonal growth in primary sensory and cortical neuronal cell cultures. J. Neurochem. 117, 632-642. doi: 10.1111/j.1471-4159.2010.07139.x

Abukhashim, M., Wiebe, G. J., and Seubert, J. M. (2011). Regulation of forskolininduced cAMP production by cytochrome P450 epoxygenase metabolites of arachidonic acid in HEK293 cells. Cell Biol. Toxicol. 27, 321-332. doi: 10.1007/ s10565-011-9190-x

Albers, H. M., and Ovaa, H. (2012). Chemical evolution of autotaxin inhibitors. Chem. Rev. 112, 2593-2603. doi: 10.1021/cr2003213

Alexander, S. P., Christopoulos, A., Davenport, A. P., Kelly, E., Marrion, N. V., Peters, J. A., et al. (2017). THE CONCISE GUIDE TO PHARMACOLOGY 2017/18: G protein-coupled receptors. Br. J. Pharmacol. 174 Suppl 1, S17-S129. doi: 10.1111/bph.13878

Aloulou, A., Ali, Y. B., Bezzine, S., Gargouri, Y., and Gelb, M. H. (2012). Phospholipases: an overview. Methods Mol. Biol. 861, 63-85. doi: 10.1007/978-1-61779-600-5_4

Alsalem, M., Wong, A., Millns, P., Arya, P. H., Chan, M. S., Bennett, A., et al. (2013). The contribution of the endogenous TRPV1 ligands 9-HODE and 13 -HODE to nociceptive processing and their role in peripheral inflammatory pain mechanisms. Br. J. Pharmacol. 168 (8), 1961-1974. doi: 10.1111/bph.12092 with already approved drugs, such as CYP2J2 (by telmisartan) (Sisignano et al., 2016) or S1P1 (by fingolimod) (Stockstill et al., 2018). These drugs may easily be repurposed and tested for the treatment of neuropathic pain in patients.

Collectively these results show that targeting lipids and their related proteins is a promising approach in the development of novel analgesics that has already proceeded into clinical testing. However, several questions concerning the abovementioned lipids and their specific roles in pain pathology remain unanswered. For example, it needs to be investigated if all the above-mentioned lipid mediators are ligands for specific GPCRs. The high number of orphan GPCRs with unknown function or ligand implies, that some of them may be lipid receptors (Tang et al., 2012). Therefore, more research is required to identify specific lipid GPCRs and their respective ligands in pain pathogenesis and to develop pharmacological strategies for targeting lipid mediators or the related proteins with monoclonal antibodies or small molecules for the development of novel analgesics.

\section{AUTHOR CONTRIBUTIONS}

TO and MS searched the published work, discussed the content, wrote, edited and revised the article, designed all figures and assembled the information for the table. Both authors read and approved to the final draft of the Review.

\section{ACKNOWLEDGMENTS}

This work was supported by grants SFB1039, TPA09 and Z01 of the DFG (German Research Association) as well as from the State of Hessen to the LOEWE Research Centre for Translational Medicine and Pharmacology and the Fraunhofer Foundation Project: Neuropathic Pain.

Amaral, F. A., Sachs, D., Costa, V. V., Fagundes, C. T., Cisalpino, D., Cunha, T. M. et al. (2008). Commensal microbiota is fundamental for the development of inflammatory pain. P. Natl. Acad. Sci. U. S. A. 105, 2193-2197. doi: 10.1073/ pnas.0711891105

Andersson, D. A., Nash, M., and Bevan, S. (2007). Modulation of the coldactivated channel TRPM8 by lysophospholipids and polyunsaturated fatty acids. J. Neurosci. Off. J. Soc. Neurosci. 27, 3347-3355. doi: 10.1523/ JNEUROSCI.4846-06.2007

Andreou, A., Brodhun, F., and Feussner, I. (2009). Biosynthesis of oxylipins in non-mammals. Prog. Lipid Res. 48, 148-170. doi: 10.1016/j. plipres.2009.02.002

Astudillo, A. M., Balboa, M. A., and Balsinde, J. (2018). Selectivity of phospholipid hydrolysis by phospholipase A2 enzymes in activated cells leading to polyunsaturated fatty acid mobilization. Biochim. Biophys. Acta Mol. Cell Biol. Lipids. 1864 (6), 772-783. doi: 10.1016/j.bbalip.2018.07.002

Audet, M., and Stevens, R. C. (2019). Emerging structural biology of lipid G protein-coupled receptors. Protein Sci. 28, 292-304. doi: 10.1002/pro.3509

Bang, S., Xie, Y. K., Zhang, Z. J., Wang, Z., Xu, Z. Z., and Ji, R. R. (2018). GPR37 regulates macrophage phagocytosis and resolution of inflammatory pain. J. Clin. Invest. 128, 3568-3582. doi: 10.1172/JCI99888

Basbaum, A. I., Bautista, D. M., Scherrer, G., and Julius, D. (2009). Cellular and molecular mechanisms of pain. Cell 139, 267-284. doi: 10.1016/j. cell.2009.09.028 
Battershill, A. J., and Scott, L. J. (2006). Telmisartan - A review of its use in the management of hypertension. Drugs 66, 51-83. doi: 10.2165/00003495-200666010-00004

Behm, D. J., Ogbonna, A., Wu, C., Burns-Kurtis, C. L., and Douglas, S. A. (2009). Epoxyeicosatrienoic acids function as selective, endogenous antagonists of native thromboxane receptors: identification of a novel mechanism of vasodilation. J. Pharmacol. Exp. Ther. 328, 231-239. doi: 10.1124/jpet.108.145102

Bettaieb, A., Nagata, N., AbouBechara, D., Chahed, S., Morisseau, C., Hammock, B. D., et al. (2013). Soluble epoxide hydrolase deficiency or inhibition attenuates diet-induced endoplasmic reticulum stress in liver and adipose tissue. J. Biol. Chem. 288, 14189-14199. doi: 10.1074/jbc.M113.458414

Blaho, V. A., and Hla, T. (2011). Regulation of mammalian physiology, development, and disease by the sphingosine 1-phosphate and lysophosphatidic acid receptors. Chem. Rev. 111, 6299-6320. doi: 10.1021/cr200273u

Brenneis, C., Sisignano, M., Coste, O., Altenrath, K., Fischer, M. J., Angioni, C., et al. (2011). Soluble epoxide hydrolase limits mechanical hyperalgesia during inflammation. Mol. Pain 7, 78. doi: 10.1186/1744-8069-7-78

Buczynski, M. W., Svensson, C. I., Dumlao, D. S., Fitzsimmons, B. L., Shim, J. H., Scherbart, T. J., et al. (2010). Inflammatory hyperalgesia induces essential bioactive lipid production in the spinal cord. J. Neurochem. 114, 981-993. doi: 10.1111/j.1471-4159.2010.06815.x

Calvo, M., Dawes, J. M., and Bennett, D. L. (2012). The role of the immune system in the generation of neuropathic pain. Lancet Neurol. 11, 629-642. doi: 10.1016/ S1474-4422(12)70134-5

Cazade, M., Bidaud, I., Hansen, P. B., Lory, P., and Chemin, J. (2014). 5,6-EET potently inhibits T-type calcium channels: implication in the regulation of the vascular tone. Pflugers Arch. 466, 1759-1768. doi: 10.1007/s00424-013-1411-0

Chen, J., Capdevila, J. H., Zeldin, D. C., and Rosenberg, R. L. (1999). Inhibition of cardiac L-type calcium channels by epoxyeicosatrienoic acids. Mol. Pharmacol. 55, 288-295. doi: 10.1124/mol.55.2.288

Chen, J. K., Capdevila, J., and Harris, R. C. (2001). Cytochrome p450 epoxygenase metabolism of arachidonic acid inhibits apoptosis. Mol. Cell Biol. 21, 63226331. doi: 10.1128/MCB.21.18.6322-6331.2001

Chen, L., Yang, G., and Grosser, T. (2013). Prostanoids and inflammatory pain. Prostaglandins Other Lipid Mediat. 104-105, 58-66. doi: 10.1016/j. prostaglandins.2012.08.006

Chen, Z., Doyle, T. M., Luongo, L., Largent-Milnes, T. M., Giancotti, L. A., Kolar, G., et al. (2019). Sphingosine-1-phosphate receptor 1 activation in astrocytes contributes to neuropathic pain. Proc. Natl. Acad. Sci. U. S. A. 116 (21), 10557-10562. doi: 10.1073/pnas.1820466116

Colloca, L., Ludman, T., Bouhassira, D., Baron, R., Dickenson, A. H., Yarnitsky, D., et al. (2017). Neuropathic pain. Nat. Rev. Dis. Primers 3, 17002-17002. doi: $10.1038 /$ nrdp. 2017.2

Coste TC, G. A., Vague, P., Pieroni, G., and Raccah, D. (2003). Neuroprotective effect of docosahexaenoic acid-enriched phospholipids in experimental diabetic neuropathy. Diabetes 10, 2578-2585. doi: 10.2337/diabetes.52.10.2578

Davies, P., Bailey, P. J., Goldenberg, M. M., and Ford-Hutchinson, A. W. (1984). The role of arachidonic acid oxygenation products in pain and inflammation. Annu. Rev. Immunol. 2, 335-357. doi: 10.1146/annurev.iy.02.040184.002003

Day, R. O. G., and Garry, G. (2013). Non-steroidal anti-inflammatory drugs (NSAIDs). BMJ 7, 3195-3201. doi: 10.1007/978-3-0348-0620-6_52-2

De Meyer, G. R., Bult, H., Verbeuren, T. J., and Herman, A. G. (1992). The role of endothelial cells in the relaxations induced by 13-hydroxy- and 13-hydroperoxylinoleic acid in canine arteries. Br. J. Pharmacol. 107, 597-603. doi: 10.1111/j.1476-5381.1992.tb12789.x

De Petrocellis, L., Schiano Moriello, A., Imperatore, R., Cristino, L., Starowicz, K., and Di Marzo, V. (2012). A re-evaluation of 9-HODE activity at TRPV1 channels in comparison with anandamide: enantioselectivity and effects at other TRP channels and in sensory neurons. Br. J. Pharmacol. 167, 1643-1651. doi: $10.1111 / j .1476-5381.2012 .02122 . x$

Dennis, E. A., and Norris, P. C. (2015). Eicosanoid storm in infection and inflammation. Nat. Rev. Immunol. 15, 511-523. doi: 10.1038/nri3859

Dennis, E. A., Cao, J., Hsu, Y. H., Magrioti, V., and Kokotos, G. (2011). Phospholipase A2 enzymes: physical structure, biological function, disease implication, chemical inhibition, and therapeutic intervention. Chem. Rev. 111, 6130-6185. doi: 10.1021/cr200085w

Di Sabatino, A., Battista, N., Biancheri, P., Rapino, C., Rovedatti, L., Astarita, G., et al. (2011). The endogenous cannabinoid system in the gut of patients with inflammatory bowel disease. Mucosal Immunol. 4, 574-583. doi: 10.1038/ mi.2011.18

Ding, Y., Fromel, T., Popp, R., Falck, J. R., Schunck, W. H., and Fleming, I. (2014). The biological actions of 11,12-epoxyeicosatrienoic acid in endothelial cells are specific to the R/S-enantiomer and require the G(s) protein. J. Pharmacol. Exp. Ther. 350, 14-21. doi: 10.1124/jpet.114.214254

Dubin, A. E., and Patapoutian, A. (2010). Nociceptors: the sensors of the pain pathway. J. Clin. Investig. 120, 3760-3772. doi: 10.1172/JCI42843

Earley, S., Pauyo, T., Drapp, R., Tavares, M. J., Liedtke, W., and Brayden, J. E. (2009). TRPV4-dependent dilation of peripheral resistance arteries influences arterial pressure. Am. J. Physiol. Heart Circ. Physiol. 297, H1096-H1102. doi: 10.1152/ajpheart.00241.2009

Eisenach, J. C., Curry, R., Rauck, R., Pan, P., and Yaksh, T. L. (2010). Role of spinal cyclooxygenase in human postoperative and chronic pain. Anesthesiology 112, 1225-1233. doi: 10.1097/ALN.0b013e3181d94dc0

Ellis, E. F., Police, R. J., Yancey, L., McKinney, J. S., and Amruthesh, S. C. (1990). Dilation of cerebral arterioles by cytochrome P-450 metabolites of arachidonic acid. Am. J. Physiol. 259, H1171-H1177. doi: 10.1152/ ajpheart.1990.259.4.H1171

Engels, F., Willems, H., and Nijkamp, F. P. (1986). Cyclooxygenase-catalyzed formation of 9-hydroxylinoleic acid by guinea pig alveolar macrophages under non-stimulated conditions. FEBS Letters 209, 249-253. doi: 10.1016/0014-5793(86)81121-8

Eskander, M. A., Ruparel, S., Green, D. P., Chen, P. B., Por, E. D., Jeske, N. A., et al. (2015). Persistent Nociception Triggered by Nerve Growth Factor (NGF) Is Mediated by TRPV1 and Oxidative Mechanisms. J. Neurosci. 35, 8593-8603. doi: 10.1523/JNEUROSCI.3993-14.2015

Fang, X., Moore, S. A., Stoll, L. L., Rich, G., Kaduce, T. L., Weintraub, N. L., et al. (1998). 14,15-Epoxyeicosatrienoic acid inhibits prostaglandin E2 production in vascular smooth muscle cells. Am. J. Physiol. 275, H2113-H2121. doi: 10.1152/ajpheart.1998.275.6.H2113

Fang, X., Hu, S. M., Watanabe, T., Weintraub, N. L., Snyder, G. D., Yao, J. R., et al. (2005). Activation of peroxisome proliferator-activated receptor alpha by substituted urea-derived soluble epoxide hydrolase inhibitors. J. Pharmacol. Exp. Ther. 314, 260-270. doi: 10.1124/jpet.105.085605

Farooqui, A. A., Ong, W. Y., and Horrocks, L. A. (2006). Inhibitors of brain phospholipase A(2) activity: Their neuropharmacological effects and therapeutic importance for the treatment of neurologic disorders. Pharmacol. Rev. 58, 591-620. doi: 10.1124/pr.58.3.7

Finnerup, N. B., Attal, N., Haroutounian, S., McNicol, E., Baron, R., Dworkin, R. H., et al. (2015). Pharmacotherapy for neuropathic pain in adults: a systematic review and meta-analysis. Lancet Neurol. 14, 162-173. doi: 10.1016/ S1474-4422(14)70251-0

Fleming, I. (2007). Epoxyeicosatrienoic acids, cell signaling and angiogenesis. Prostaglandins Other Lipid Mediat. 82, 60-67. doi: 10.1016/j. prostaglandins.2006.05.003

Fleming, I., Rueben, A., Popp, R., Fisslthaler, B., Schrodt, S., Sander, A., et al. (2007). Epoxyeicosatrienoic acids regulate Trp channel dependent Ca2+ signaling and hyperpolarization in endothelial cells. Arterioscler. Thromb. Vasc. Biol. 27, 2612-2618. doi: 10.1161/ATVBAHA.107.152074

Fromel, T., Jungblut, B., Hu, J., Trouvain, C., Barbosa-Sicard, E., Popp, R., et al. (2012). Soluble epoxide hydrolase regulates hematopoietic progenitor cell function via generation of fatty acid diols. Proc. Natl. Acad. Sci. U. S. A. 109, 9995-10000. doi: 10.1073/pnas.1206493109

Gavva, N. R., Treanor, J. J., Garami, A., Fang, L., Surapaneni, S., Akrami, A., et al. (2008). Pharmacological blockade of the vanilloid receptor TRPV1 elicits marked hyperthermia in humans. Pain 136, 202-210. doi: 10.1016/j. pain.2008.01.024

Gentry, C., Stoakley, N., Andersson, D. A., and Bevan, S. (2010). The roles of iPLA2, TRPM8 and TRPA1 in chemically induced cold hypersensitivity. Mol. Pain 6, 4. doi: 10.1186/1744-8069-6-4

Gill, I., and Valivety, R. (1997). Polyunsaturated fatty acids, Part 1: Occurrence, biological activities and applications. Trends Biotechnol. 15, 401-409. doi: 10.1016/S0167-7799(97)01076-7

Goswami, S. K., Inceoglu, B., Yang, J., Wan, D., Kodani, S. D., da Silva, C. A., et al. (2015). Omeprazole increases the efficacy of a soluble epoxide hydrolase inhibitor in a PGE(2) induced pain model. Toxicol. Appl. Pharmacol. 289, 419427. doi: 10.1016/j.taap.2015.10.018 
Green, F. A. (1989). Generation and metabolism of lipoxygenase products in normal and membrane-damaged cultured human keratinocytes. J. Investig. Dermatol. 93, 486-491. doi: 10.1111/1523-1747.ep12284046

Green, D. P., Ruparel, S., Roman, L., Henry, M. A., and Hargreaves, K. M. (2013). Role of endogenous TRPV1 agonists in a postburn pain model of partialthickness injury. Pain 154, 2512-2520. doi: 10.1016/j.pain.2013.07.040

Green, D., Ruparel, S., Gao, X., Ruparel, N., Patil, M., Akopian, A., et al. (2016). Central activation of TRPV1 and TRPA1 by novel endogenous agonists contributes to mechanical allodynia and thermal hyperalgesia after burn injury. Mol. Pain 12. doi: 10.1177/1744806916661725

Greene, J. F., Newman, J. W., Williamson, K. C., and Hammock, B. D. (2000a). Toxicity of epoxy fatty acids and related compounds to cells expressing human soluble epoxide hydrolase. Chem. Res. Toxicol. 13, 217-226. doi: 10.1021/ tx990162c

Greene, J. F., Williamson, K. C., Newman, J. W., Morisseau, C., and Hammock, B. D. (2000b). Metabolism of monoepoxides of methyl linoleate: bioactivation and detoxification. Arch. Biochem. Biophys. 376, 420-432. doi: 10.1006/abbi.2000.1753

Gregus, A. M., Doolen, S., Dumlao, D. S., Buczynski, M. W., Takasusuki, T., Fitzsimmons, B. L., et al. (2012). Spinal 12-lipoxygenase-derived hepoxilin A3 contributes to inflammatory hyperalgesia via activation of TRPV1 and TRPA1 receptors. Proc. Natl. Acad. Sci. U. S. A. 109, 6721-6726. doi: 10.1073/ pnas. 1110460109

Gregus, A. M., Dumlao, D. S., Wei, S. C., Norris, P. C., Catella, L. C., Meyerstein, F. G., et al. (2013). Systematic analysis of rat 12/15-lipoxygenase enzymes reveals critical role for spinal eLOX3 hepoxilin synthase activity in inflammatory hyperalgesia. FASEB J. 27, 1939-1949. doi: 10.1096/fj.12-217414

Gregus, A. M., Buczynski, M. W., Dumlao, D. S., Norris, P. C., Rai, G., Simeonov, A., et al. (2018). Inhibition of spinal 15-LOX-1 attenuates TLR4-dependent, nonsteroidal anti-inflammatory drug-unresponsive hyperalgesia in male rats. Pain 159, 2620-2629. doi: 10.1097/j.pain.0000000000001373

Gupta, A. K., and Lyons, D. C. (2015). The rise and fall of oral Ketoconazole. J. Cutan. Med. Surg. 19, 352-357. doi: 10.1177/1203475415574970

Haeggstrom, J. Z., and Funk, C. D. (2011). Lipoxygenase and leukotriene pathways: biochemistry, biology, and roles in disease. Chem. Rev. 111, 5866-5898. doi: $10.1021 / \mathrm{cr} 200246 \mathrm{~d}$

Hansen, A. E., Haggard, M. E., Boelsche, A. N., Adam, D. J., and Wiese, H. F. (1958). Essential fatty acids in infant nutrition. III. Clinical manifestations of linoleic acid deficiency. J. Nutr. 66, 565-576. doi: 10.1093/jn/66.4.565

Hasegawa, S., Kohro, Y., Tsuda, M., and Inoue, K. (2009). Activation of cytosolic phospholipase A2 in dorsal root ganglion neurons by $\mathrm{Ca} 2+/$ calmodulindependent protein kinase II after peripheral nerve injury. Mol. Pain 5, 22. doi: 10.1186/1744-8069-5-22

Hattori, T., Obinata, H., Ogawa, A., Kishi, M., Tatei, K., Ishikawa, O., et al. (2008). G2A plays proinflammatory roles in human keratinocytes under oxidative stress as a receptor for 9-hydroxyoctadecadienoic acid. J. Investig. Dermatol. 128, 1123-1133. doi: 10.1038/sj.jid.5701172

Hauge, M., Vestmar, M. A., Husted, A. S., Ekberg, J. P., Wright, M. J., Di Salvo, J., et al. (2015). GPR40 (FFAR1) - Combined Gs and Gq signaling in vitro is associated with robust incretin secretagogue action ex vivo and in vivo. Mol. Metab. 4, 3-14. doi: 10.1016/j.molmet.2014.10.002

Hayakawa, M., Sugiyama, S., Takamura, T., Yokoo, K., Iwata, M., Suzuki, K., et al. (1986). Neutrophils biosynthesize leukotoxin, 9, 10-epoxy-12octadecenoate. Biochem. Biophys. Res. Commun. 137, 424-430. doi: 10.1016/0006-291X(86)91227-1

Hellstrom, F., Gouveia-Figueira, S., Nording, M. L., Bjorklund, M., and Fowler, C. J. (2016). Association between plasma concentrations of linoleic acid-derived oxylipins and the perceived pain scores in an exploratory study in women with chronic neck pain. BMC Musculoskelet. Disord. 17, 103. doi: 10.1186/ s12891-016-0951-9

Hennebelle, M., Zhang, Z., Metherel, A. H., Kitson, A. P., Otoki, Y., Richardson, C. E., et al. (2017). Linoleic acid participates in the response to ischemic brain injury through oxidized metabolites that regulate neurotransmission. Sci. Rep. 7 , 4342. doi: 10.1038/s41598-017-02914-7

Hiesinger, K., Wagner, K. M., Hammock, B. D., Proschak, E., and Hwang, S. H. (2019). Development of multitarget agents possessing soluble epoxide hydrolase inhibitory activity. Prostaglandins Other Lipid Mediat. 140, 31-39. doi: 10.1016/j.prostaglandins.2018.12.003
Hohmann, S. W., Angioni, C., Tunaru, S., Lee, S., Woolf, C. J., Offermanns, S., et al. (2017). The G2A receptor (GPR132) contributes to oxaliplatininduced mechanical pain hypersensitivity. Sci. Rep. 7, 446. doi: 10.1038/ s41598-017-00591-0

Hu, J., Dziumbla, S., Lin, J., Bibli, S. I., Zukunft, S., de Mos, J., et al. (2017). Inhibition of soluble epoxide hydrolase prevents diabetic retinopathy. Nature 552, 248-252. doi: 10.1038/nature25013

Hung, Y. W., Hung, S. W., Wu, Y. C., Wong, L. K., Lai, M. T., Shih, Y. H., et al. (2015). Soluble epoxide hydrolase activity regulates inflammatory responses and seizure generation in two mouse models of temporal lobe epilepsy. Brain Behav. Immun. 43, 118-129. doi: 10.1016/j.bbi.2014.07.016

Imig, J. D., and Hammock, B. D. (2009). Soluble epoxide hydrolase as a therapeutic target for cardiovascular diseases. Nat. Rev. Drug Discov. 8, 794-805. doi: $10.1038 / \mathrm{nrd} 2875$

Inceoglu, B., Jinks, S. L., Schmelzer, K. R., Waite, T., Kim, I. H., and Hammock, B. D. (2006). Inhibition of soluble epoxide hydrolase reduces LPS-induced thermal hyperalgesia and mechanical allodynia in a rat model of inflammatory pain. Life Sci. 79, 2311-2319. doi: 10.1016/j.lfs.2006.07.031

Inceoglu, B., Schmelzer, K. R., Morisseau, C., Jinks, S. L., and Hammock, B. D. (2007). Soluble epoxide hydrolase inhibition reveals novel biological functions of epoxyeicosatrienoic acids (EETs). Prostaglandins Other Lipid Mediat. 82, 42-49. doi: 10.1016/j.prostaglandins.2006.05.004

Inceoglu, B., Jinks, S. L., Ulu, A., Hegedus, C. M., Georgi, K., Schmelzer, K. R., et al. (2008). Soluble epoxide hydrolase and epoxyeicosatrienoic acids modulate two distinct analgesic pathways. Proc. Natl. Acad. Sci. U. S. A. 105, 18901-18906. doi: 10.1073/pnas.0809765105

Inceoglu, B., Wagner, K. M., Yang, J., Bettaieb, A., Schebb, N. H., Hwang, S. H., et al. (2012). Acute augmentation of epoxygenated fatty acid levels rapidly reduces pain-related behavior in a rat model of type I diabetes. Proc. Natl. Acad. Sci. U. S. A. 109, 11390-11395. doi: 10.1073/pnas. 1208708109

Inoue, M., Rashid, M. H., Fujita, R., Contos, J. J., Chun, J., and Ueda, H. (2004). Initiation of neuropathic pain requires lysophosphatidic acid receptor signaling. Nat. Med. 10, 712-718. doi: 10.1038/nm1060

Inoue, M., Ma, L., Aoki, J., Chun, J., and Ueda, H. (2008). Autotaxin, a synthetic enzyme of lysophosphatidic acid (LPA), mediates the induction of nerveinjured neuropathic pain. Mol. Pain 4, 6. doi: 10.1186/1744-8069-4-6

Itoh, T., Fairall, L., Amin, K., Inaba, Y., Szanto, A., Balint, B. L., et al. (2008). Structural basis for the activation of PPARgamma by oxidized fatty acids. Nat. Struct. Mol. Biol. 15, 924-931. doi: 10.1038/nsmb.1474

Jensen, J. R., Pitcher, M. H., Yuan, Z. X., Ramsden, C. E., and Domenichiello, A. F. (2018). Concentrations of oxidized linoleic acid derived lipid mediators in the amygdala and periaqueductal grey are reduced in a mouse model of chronic inflammatory pain. Prostaglandins Leukot. Essent. Fatty Acids 135, 128-136. doi: 10.1016/j.plefa.2018.07.015

Ji, R. R., Xu, Z. Z., and Gao, Y. J. (2014). Emerging targets in neuroinflammationdriven chronic pain. Nat. Rev. Drug Discov. 13, 533-548. doi: 10.1038/nrd4334

Ji, R.-R., Chamessian, A., and Zhang, Y.-Q. (2016). Pain regulation by nonneuronal cells and inflammation. Science 354, 572-577. doi: 10.1126/science. aaf8924

Jiang, J. X., Zhang, S. J., Liu, Y. N., Lin, X. X., Sun, Y. H., Shen, H. J., et al. (2014). EETs alleviate ox-LDL-induced inflammation by inhibiting LOX-1 receptor expression in rat pulmonary arterial endothelial cells. Eur. J. Pharmacol. 727, 43-51. doi: 10.1016/j.ejphar.2014.01.045

Jisaka, M., Kim, R. B., Boeglin, W. E., Nanney, L. B., and Brash, A. R. (1997). Molecular cloning and functional expression of a phorbol ester-inducible 8S-lipoxygenase from mouse skin. J. Biol. Chem. 272, 24410-24416. doi: 10.1074/jbc.272.39.24410

Jones, S. B., Pfeifer, L. A., Bleisch, T. J., Beauchamp, T. J., Durbin, J. D., Klimkowski, V. J., et al. (2016). Novel autotaxin inhibitors for the treatment of osteoarthritis pain: Lead optimization via structure-based drug design. ACS Med. Chem. Lett. 7, 857-861. doi: 10.1021/acsmedchemlett.6b00207

Justus, C. R., Dong, L., and Yang, L. V. (2013). Acidic tumor microenvironment and $\mathrm{pH}$-sensing G protein-coupled receptors. Front. Physiol. 4, 354. doi: $10.3389 /$ fphys.2013.00354

Kabarowski, J. H. (2009). G2A and LPC: regulatory functions in immunity. Prostaglandins Other Lipid Mediat. 89, 73-81. doi: 10.1016/j. prostaglandins.2009.04.007 
Karki, P., Kurihara, T., Nakamachi, T., Watanabe, J., Asada, T., Oyoshi, T., et al. (2015). Attenuation of inflammatory and neuropathic pain behaviors in mice through activation of free fatty acid receptor GPR40. Mol. Pain 11, 6. doi: 10.1186/s12990-015-0003-8

Kawabata, A. (2011). Prostaglandin E2 and pain-an update. Biol. Pharm. Bull. 34, 1170-1173. doi: 10.1248/bpb.34.1170

Kern, K., Schafer, S. M. G., Cohnen, J., Pierre, S., Osthues, T., Tarighi, N., et al. (2018). The G2A Receptor Controls Polarization of Macrophage by Determining Their Localization Within the Inflamed Tissue. Front. Immunol. 9, 2261. doi: 10.3389/fimmu.2018.02261

Kiguchi, N., Kobayashi, Y., and Kishioka, S. (2012). Chemokines and cytokines in neuroinflammation leading to neuropathic pain. Curr. Opin. Pharmacol. 12, 55-61. doi: 10.1016/j.coph.2011.10.007

Kobayashi, Y., Kiguchi, N., Fukazawa, Y., Saika, F., Maeda, T., and Kishioka, S. (2015). Macrophage-T cell interactions mediate neuropathic pain through the glucocorticoid-induced tumor necrosis factor ligand system. J. Biol. Chem. 290, 12603-12613. doi: 10.1074/jbc.M115.636506

Kozak, W., Aronoff, D. M., Boutaud, O., and Kozak, A. (2003). 11,12-epoxyeicosatrienoic acid attenuates synthesis of prostaglandin E2 in rat monocytes stimulated with lipopolysaccharide. Exp. Biol. Med. (Maywood, N. J.) 228, 786-794. doi: 10.1177/15353702-0322807-03

Krotz, F., Riexinger, T., Buerkle, M. A., Nithipatikom, K., Gloe, T., Sohn, H. Y., et al. (2004). Membrane-potential-dependent inhibition of platelet adhesion to endothelial cells by epoxyeicosatrienoic acids. Arterioscler. Thromb. Vasc. Biol. 24, 595-600. doi: 10.1161/01.ATV.0000116219.09040.8c

Kuner, R. (2010). Central mechanisms of pathological pain. Nat. Med. 16, 1258. doi: $10.1038 / \mathrm{nm} .2231$

Kuner, R., and Flor, H. (2016). Structural plasticity and reorganisation in chronic pain. Nat. Rev. Neurosci. 18, 20-30. doi: 10.1038/nrn.2016.162

Kwan, H. Y., Huang, Y., and Yao, X. (2007). TRP channels in endothelial function and dysfunction. Biochim. Biophys. Acta 1772, 907-914. doi: 10.1016/j. bbadis.2007.02.013

Lahvic, J. L., Ammerman, M., Li, P., Blair, M. C., Stillman, E. R., Fast, E. M., et al. (2018). Specific oxylipins enhance vertebrate hematopoiesis via the receptor GPR132. Proc. Natl. Acad. Sci. U. S. A. 115, 9252-9257. doi: 10.1073/pnas.1806077115

Latremoliere, A., Latini, A., Andrews, N., Cronin, S. J., Fujita, M., Gorska, K., et al. (2015). Reduction of Neuropathic and Inflammatory Pain through Inhibition of the Tetrahydrobiopterin Pathway. Neuron 86, 1393-1406. doi: 10.1016/j. neuron.2015.05.033

Law, S. H., Chan, M. L., Marathe, G. K., Parveen, F., Chen, C. H., and Ke, L. Y. (2019). An Updated Review of Lysophosphatidylcholine Metabolism in Human Diseases. Int. J. Mol. Sci. 20. doi: 10.3390/ijms20051149

Lazaar, A. L., Yang, L., Boardley, R. L., Goyal, N. S., Robertson, J., Baldwin, S. J., et al. (2016). Pharmacokinetics, pharmacodynamics and adverse event profile of GSK2256294, a novel soluble epoxide hydrolase inhibitor. Br. J. Clin. Pharmacol. 81, 971-979. doi: 10.1111/bcp.12855

Lee, K. S., Liu, J. Y., Wagner, K. M., Pakhomova, S., Dong, H., Morisseau, C., et al. (2014). Optimized inhibitors of soluble epoxide hydrolase improve in vitro target residence time and in vivo efficacy. J. Med. Chem. 57, 7016-7030. doi: $10.1021 /$ jm500694p

Leung, L., and Cahill, C. M. (2010). TNF-alpha and neuropathic pain-a review. J. Neuroinflammation. 7, 27. doi: 10.1186/1742-2094-7-27

Li, P. L., and Campbell, W. B. (1997). Epoxyeicosatrienoic acids activate K+ channels in coronary smooth muscle through a guanine nucleotide binding protein. Circ. Res. 80, 877-884. doi: 10.1161/01.RES.80.6.877

Li, P. L., Chen, C. L., Bortell, R., and Campbell, W. B. (1999). 11,12-Epoxyeicosatrienoic acid stimulates endogenous mono-ADPribosylation in bovine coronary arterial smooth muscle. Circ. Res. 85, 349-356. doi: 10.1161/01.RES.85.4.349

Lim, E. Y., and Kim, Y. T. (2016). Food-derived natural compounds for pain relief in neuropathic pain. Biomed. Res. Int. 2016, 7917528. doi: 10.1155/2016/7917528

Liu, Y., Rosenthal, R. E., Haywood, Y., Miljkovic-Lolic, M., Vanderhoek, J. Y., and Fiskum, G. (1998). Normoxic ventilation after cardiac arrest reduces oxidation of brain lipids and improves neurological outcome. Stroke 29, 1679-1686. doi: 10.1161/01.STR.29.8.1679

Liu, Y., Zhang, Y., Schmelzer, K., Lee, T. S., Fang, X., Zhu, Y., et al. (2005). The antiinflammatory effect of laminar flow: the role of PPARgamma, epoxyeicosatrienoic acids, and soluble epoxide hydrolase. Proc. Natl. Acad. Sci. U. S. A. 102, 16747-16752. doi: 10.1073/pnas.0508081102

Liu, X., Qian, Z. Y., Xie, F., Fan, W., Nelson, J. W., Xiao, X., et al. (2017). Functional screening for $\mathrm{G}$ protein-coupled receptor targets of 14,15-epoxyeicosatrienoic acid. Prostaglandins Other Lipid Mediat. 132, 31-40. doi: 10.1016/j. prostaglandins.2016.09.002

Loot, A. E., and Fleming, I. (2011). Cytochrome P450-derived epoxyeicosatrienoic acids and pulmonary hypertension: central role of transient receptor potential C6 channels. J. Cardiovasc. Pharmacol. 57, 140-147. doi: 10.1097/ FJC.0b013e3181ed088d

Lu, T., Ye, D., Wang, X., Seubert, J. M., Graves, J. P., Bradbury, J. A., et al. (2006). Cardiac and vascular KATP channels in rats are activated by endogenous epoxyeicosatrienoic acids through different mechanisms. J. Physiol. 575, 627644. doi: 10.1113/jphysiol.2006.113985

Lucas, K. K., Svensson, C. I., Hua, X. Y., Yaksh, T. L., and Dennis, E. A. (2005) Spinal phospholipase A2 in inflammatory hyperalgesia: role of group IVA cPLA2. Br. J. Pharmacol. 144, 940-952. doi: 10.1038/sj.bjp.0706116

Ma, L., Uchida, H., Nagai, J., Inoue, M., Aoki, J., and Ueda, H. (2010). Evidence for de novo synthesis of lysophosphatidic acid in the spinal cord through phospholipase A2 and autotaxin in nerve injury-induced neuropathic pain. J. Pharmacol. Exp. Ther. 333, 540-546. doi: 10.1124/jpet.109.164830

Mabey, T., Taleongpong, P., Udomsinprasert, W., Jirathanathornnukul, N., and Honsawek, S. (2015). Plasma and synovial fluid autotaxin correlate with severity in knee osteoarthritis. Clin. Chim. Acta 444, 72-77. doi: 10.1016/j. cca.2015.01.032

Maceyka, M., Harikumar, K. B., Milstien, S., and Spiegel, S. (2012). Sphingosine1-phosphate signaling and its role in disease. Trends Cell Biol. 22, 50-60. doi: 10.1016/j.tcb.2011.09.003

Manzanares, J., Julian, M., and Carrascosa, A. (2006). Role of the cannabinoid system in pain control and therapeutic implications for the management of acute and chronic pain episodes. Curr. Neuropharmacol. 4, 239-257. doi: 10.2174/157015906778019527

Marowsky, A., Burgener, J., Falck, J. R., Fritschy, J. M., and Arand, M. (2009). Distribution of soluble and microsomal epoxide hydrolase in the mouse brain and its contribution to cerebral epoxyeicosatrienoic acid metabolism. Neuroscience 163, 646-661. doi: 10.1016/j.neuroscience.2009.06.033

Mayer, E. A., Knight, R., Mazmanian, S. K., Cryan, J. F., and Tillisch, K. (2014). Gut microbes and the brain: paradigm shift in neuroscience. J. Neurosci. 34, 15490-15496. doi: 10.1523/JNEUROSCI.3299-14.2014

Michaelis, U. R., Falck, J. R., Schmidt, R., Busse, R., and Fleming, I. (2005). Cytochrome P4502C9-derived epoxyeicosatrienoic acids induce the expression of cyclooxygenase-2 in endothelial cells. Arterioscler. Thromb. Vasc. Biol. 25, 321-326. doi: 10.1161/01.ATV.0000151648.58516.eb

Moghaddam, M. F., Grant, D. F., Cheek, J. M., Greene, J. F., Williamson, K. C., and Hammock, B. D. (1997). Bioactivation of leukotoxins to their toxic diols by epoxide hydrolase. Nat. Med. 3, 562-566. doi: 10.1038/nm0597-562

Moran, M. M., McAlexander, M. A., Biro, T., and Szallasi, A. (2011). Transient receptor potential channels as therapeutic targets. Nat. Rev. Drug Discov. 10, 601-620. doi: 10.1038/nrd3456

Morin, C., Sirois, M., Echave, V., Gomes, M. M., and Rousseau, E. (2008). EET displays anti-inflammatory effects in TNF-alpha stimulated human bronchi: putative role of CPI-17. Am. J. Respir. Cell Mol. Biol. 38, 192-201. doi: 10.1165/ rcmb.2007-0232OC

Morisseau, C., Inceoglu, B., Schmelzer, K., Tsai, H. J., Jinks, S. L., Hegedus, C. M., et al. (2010). Naturally occurring monoepoxides of eicosapentaenoic acid and docosahexaenoic acid are bioactive antihyperalgesic lipids. J. Lipid Res. 51, 3481-3490. doi: 10.1194/jlr.M006007

Morisseau, C., Schebb, N. H., Dong, H., Ulu, A., Aronov, P. A., and Hammock, B. D. (2012). Role of soluble epoxide hydrolase phosphatase activity in the metabolism of lysophosphatidic acids. Biochem. Biophys. Res. Commun. 419, 796-800. doi: 10.1016/j.bbrc.2012.02.108

Mule, N. K., Orjuela Leon, A. C., Falck, J. R., Arand, M., and Marowsky, A. (2017). 11,12 -Epoxyeicosatrienoic acid $(11,12 \mathrm{EET})$ reduces excitability and excitatory transmission in the hippocampus. Neuropharmacology 123, 310-321. doi: 10.1016/j.neuropharm.2017.05.013

Murakami, M., and Kudo, I. (2002). Phospholipase A2. J. Biochem. 131, 285-292. doi: 10.1093/oxfordjournals.jbchem.a003101 
Murakami, N., Yokomizo, T., Okuno, T., and Shimizu, T. (2004). G2A is a protonsensing G-protein-coupled receptor antagonized by lysophosphatidylcholine. J. Biol. Chem. 279, 42484-42491. doi: 10.1074/jbc.M406561200

Murray, M. (2016). CYP2J2 - regulation, function and polymorphism. Drug Metab. Rev. 48, 351-368. doi: 10.1080/03602532.2016.1188938

Nagy, L., Tontonoz, P., Alvarez, J. G., Chen, H., and Evans, R. M. (1998). Oxidized LDL regulates macrophage gene expression through ligand activation of PPARgamma. Cell 93, 229-240. doi: 10.1016/S0092-8674(00)81574-3

Nakamoto, K., Nishinaka, T., Matsumoto, K., Kasuya, F., Mankura, M., Koyama, Y., et al. (2012). Involvement of the long-chain fatty acid receptor GPR40 as a novel pain regulatory system. Brain Res. 1432, 74-83. doi: 10.1016/j. brainres.2011.11.012

Nakamura, M. T., and Nara, T. Y. (2003). Essential fatty acid synthesis and its regulation in mammals. Prostaglandins Leukot. Essent. Fatty Acids 68, 145-150. doi: 10.1016/S0952-3278(02)00264-8

Narumiya, S. (2007). Physiology and pathophysiology of prostanoid receptors. Proc. Jpn. Acad. Ser. B Phys. Biol. Sci. 83, 296-319. doi: 10.2183/pjab.83.296

Newcomer, M. E., and Brash, A. R. (2015). The structural basis for specificity in lipoxygenase catalysis. Protein Sci. 24, 298-309. doi: 10.1002/pro.2626

Newman, J. W., Morisseau, C., Harris, T. R., and Hammock, B. D. (2003). The soluble epoxide hydrolase encoded by EPXH2 is a bifunctional enzyme with novel lipid phosphate phosphatase activity. P. Natl. Acad. Sci. U. S. A. 100, 1558-1563. doi: 10.1073/pnas.0437724100

Ng, V. Y., Huang, Y., Reddy, L. M., Falck, J. R., Lin, E. T., and Kroetz, D. L. (2007). Cytochrome P450 eicosanoids are activators of peroxisome proliferatoractivated receptor alpha. Drug Metab. Dispos. 35, 1126-1134. doi: 10.1124/ dmd.106.013839

Nieto-Posadas, A., Picazo-Juarez, G., Llorente, I., Jara-Oseguera, A., MoralesLazaro, S., Escalante-Alcalde, D., et al. (2011). Lysophosphatidic acid directly activates TRPV1 through a C-terminal binding site. Nat. Chem. Biol. 8 (1), 78-85. doi: 10.1038/nchembio.712

Node, K., Huo, Y., Ruan, X., Yang, B., Spiecker, M., Ley, K., et al. (1999). Anti-inflammatory properties of cytochrome $\mathrm{P} 450$ epoxygenase-derived eicosanoids. Science 285, 1276-1279. doi: 10.1126/science.285.5431.1276

Node, K., Ruan, X. L., Dai, J., Yang, S. X., Graham, L., Zeldin, D. C., et al. (2001). Activation of Galpha s mediates induction of tissue-type plasminogen activator gene transcription by epoxyeicosatrienoic acids. J. Biol. Chem. 276, 1598315989. doi: 10.1074/jbc.M100439200

Norwood S., L. J., Hammock, B. D., and Yang, G.-Y. (2010). Epoxyeicosatrienoic acids and soluble epoxide hydrolase: potential therapeutic targets for inflammation and its induced carcinogenesis. Am. J. Transl. Res. 4, 447-457.

O'Connor, A. B., and Dworkin, R. H. (2009). Treatment of neuropathic pain: an overview of recent guidelines. Am. J. Med. 122, S22-S32. doi: 10.1016/j. amjmed.2009.04.007

Obata, K., and Noguchi, K. (2004). MAPK activation in nociceptive neurons and pain hypersensitivity. Life Sci. 74, 2643-2653. doi: 10.1016/j.lfs.2004.01.007

Obinata, H., and Izumi, T. (2009). G2A as a receptor for oxidized free fatty acids. Prostaglandins Other Lipid Mediat. 89, 66-72. doi: 10.1016/j. prostaglandins.2008.11.002

Obinata, H., Hattori, T., Nakane, S., Tatei, K., and Izumi, T. (2005). Identification of 9-hydroxyoctadecadienoic acid and other oxidized free fatty acids as ligands of the G protein-coupled receptor G2A. J. Biol. Chem. 280, 40676-40683. doi: 10.1074/jbc.M507787200

Oliw, E. H. (1994). Oxygenation of polyunsaturated fatty acids by cytochrome P450 monooxygenases. Prog. Lipid Res. 33, 329-354. doi: 10.1016/0163-7827(94)90029-9

Ozawa, T., Sugiyama, S., Hayakawa, M., Satake, T., Taki, F., Iwata, M., et al. (1988). Existence of leukotoxin 9,10-epoxy-12-octadecenoate in lung lavages from rats breathing pure oxygen and from patients with the adult respiratory distress syndrome. Am. Rev. Respir. Dis. 137, 535-540. doi: 10.1164/ajrccm/137.3.535

Park, S. B., Goldstein, D., Krishnan, A. V., Lin, C. S., Friedlander, M. L., Cassidy, J., et al. (2013). Chemotherapy-induced peripheral neurotoxicity: a critical analysis. CA Cancer J. Clin. 63, 419-437. doi: 10.3322/caac.21204

Park, S. K., Herrnreiter, A., Pfister, S. L., Gauthier, K. M., Falck, B. A., Falck, J. R., et al. (2018). GPR40 is a low-affinity epoxyeicosatrienoic acid receptor in vascular cells. J. Biol. Chem. 293, 10675-10691. doi: 10.1074/jbc.RA117.001297

Patwardhan, A. M., Scotland, P. E., Akopian, A. N., and Hargreaves, K. M. (2009). Activation of TRPV1 in the spinal cord by oxidized linoleic acid metabolites contributes to inflammatory hyperalgesia. Proc. Natl. Acad. Sci. U. S. A. 106, 18820-18824. doi: 10.1073/pnas.0905415106

Patwardhan, A. M., Akopian, A. N., Ruparel, N. B., Diogenes, A., Weintraub, S. T., Uhlson, C., et al. (2010). Heat generates oxidized linoleic acid metabolites that activate TRPV1 and produce pain in rodents. J. Clin. Investig. 120, 1617-1626. doi: $10.1172 /$ JCI41678

Peirs, C., and Seal, R. P. (2016). Neural circuits for pain: Recent advances and current views. Science 354, 578-584. doi: 10.1126/science.aaf8933

Pelletier, D., and Hafler, D. A. (2012). Fingolimod for multiple sclerosis. N. Engl. J. Med. 366, 339-347. doi: 10.1056/NEJMct1101691

Pinho-Ribeiro, F. A., Verri, W. A., Jr., and Chiu, I. M. (2017). Nociceptor sensory neuron-immune interactions in pain and inflammation. Trends Immunol. 38, 5-19. doi: 10.1016/j.it.2016.10.001

Pober, J. S., and Sessa, W. C. (2014). Inflammation and the blood microvascular system. Cold Spring Harb. Perspect. Biol. 7, a016345. doi: 10.1101/cshperspect. a016345

Popp, R., Brandes, R. P., Ott, G., Busse, R., and Fleming, I. (2002). Dynamic modulation of interendothelial gap junctional communication by 11,12-epoxyeicosatrienoic acid. Circ. Res. 90, 800-806. doi: 10.1161/01. RES.0000015328.20581.D6

Pozzi, A., Macias-Perez, I., Abair, T., Wei, S., Su, Y., Zent, R., et al. (2005). Characterization of 5,6- and 8,9-epoxyeicosatrienoic acids (5,6- and 8,9EET) as potent in vivo angiogenic lipids. J. Biol. Chem. 280, 27138-27146. doi: 10.1074/jbc.M501730200

Radu, C. G., Nijagal, A., McLaughlin, J., Wang, L., and Witte, O. N. (2005). Differential proton sensitivity of related $G$ protein-coupled receptors $T$ cell death-associated gene 8 and G2A expressed in immune cells. Proc. Natl. Acad. Sci. U. S. A. 102, 1632-1637. doi: 10.1073/pnas.0409415102

Ramanadham, S., Ali, T., Ashley, J. W., Bone, R. N., Hancock, W. D., and Lei, X. (2015). Calcium-independent phospholipases A2 and their roles in biological processes and diseases. J. Lipid Res. 56, 1643-1668. doi: 10.1194/jlr.R058701

Ramsden, C. E., Domenichiello, A. F., Yuan, Z. X., Sapio, M. R., Keyes, G. S., Mishra, S. K., et al. (2017). A systems approach for discovering linoleic acid derivatives that potentially mediate pain and itch. Sci. Signal. 10. doi: 10.1126/ scisignal.aal5241

Reinaud, O., Delaforge, M., Boucher, J. L., Rocchiccioli, F., and Mansuy, D. (1989). Oxidative metabolism of linoleic acid by human leukocytes. Biochem. Biophys. Res. Commun. 161, 883-891. doi: 10.1016/0006-291X(89)92682-X

Ricote, M., Welch, J. S., and Glass, C. K. (2000). Regulation of macrophage gene expression by the peroxisome proliferator-activated receptor-gamma. Horm. Res. 54, 275-280. doi: 10.1159/000053271

Rivat, C., Sar, C., Mechaly, I., Leyris, J. P., Diouloufet, L., Sonrier, C., et al. (2018). Inhibition of neuronal FLT3 receptor tyrosine kinase alleviates peripheral neuropathic pain in mice. Nat. Commun. 9, 1042. doi: 10.1038/ s41467-018-03496-2

Rousseaux, C., Thuru, X., Gelot, A., Barnich, N., Neut, C., Dubuquoy, L., et al. (2007). Lactobacillus acidophilus modulates intestinal pain and induces opioid and cannabinoid receptors. Nat. Med. 13, 35-37. doi: 10.1038/nm1521

Ruparel, S., Green, D., Chen, P., and Hargreaves, K. M. (2012a). The cytochrome P450 inhibitor, ketoconazole, inhibits oxidized linoleic acid metabolite-mediated peripheral inflammatory pain. Mol. Pain 8, 73. doi: 10.1186/1744-8069-8-73

Ruparel, S., Henry, M. A., Akopian, A., Patil, M., Zeldin, D. C., Roman, L., et al. (2012b). Plasticity of cytochrome P450 isozyme expression in rat trigeminal ganglia neurons during inflammation. Pain. 153 (10), 20312039. doi: 10.1016/j.pain.2012.04.027

Ruparel, S., Hargreaves, K. M., Eskander, M., Rowan, S., de Almeida, J. F. A., Roman, L., et al. (2013). Oxidized linoleic acid metabolite-cytochrome P450 system (OLAM-CYP) is active in biopsy samples from patients with inflammatory dental pain. Pain 154, 2363-2371. doi: 10.1016/j.pain.2013.07.011

Russo, G. L. (2009). Dietary n-6 and n-3 polyunsaturated fatty acids: from biochemistry to clinical implications in cardiovascular prevention. Biochem. Pharmacol. 77, 937-946. doi: 10.1016/j.bcp.2008.10.020

Russo, R., Cristiano, C., Avagliano, C., De Caro, C., La Rana, G., Raso, G. M., et al. (2018). Gut-brain axis: role of lipids in the regulation of inflammation, pain and CNS diseases. Curr. Med. Chem. 25, 3930-3952. doi: 10.2174/092986732 4666170216113756

Samokhvalov, V., Alsaleh, N., El-Sikhry, H. E., Jamieson, K. L., Chen, C. B., Lopaschuk, D. G., et al. (2013). Epoxyeicosatrienoic acids protect cardiac cells 
during starvation by modulating an autophagic response. Cell Death Dis. 4, e885. doi: $10.1038 /$ cddis. 2013.418

Samokhvalov, V., Vriend, J., Jamieson, K. L., Akhnokh, M. K., Manne, R., Falck, J. R., et al. (2014). PPARgamma signaling is required for mediating EETs protective effects in neonatal cardiomyocytes exposed to LPS. Front. Pharmacol. 5, 242. doi: 10.3389/fphar.2014.00242

Samokhvalov, V., Jamieson, K. L., Darwesh, A. M., Keshavarz-Bahaghighat, H., Lee, T. Y. T., Edin, M., et al. (2018). Deficiency of Soluble Epoxide Hydrolase Protects Cardiac Function Impaired by LPS-Induced Acute Inflammation. Front. Pharmacol. 9, 1572. doi: 10.3389/fphar.2018.01572

Schmelzer, K. R., Inceoglu, B., Kubala, L., Kim, I. H., Jinks, S. L., Eiserich, J. P., et al. (2006). Enhancement of antinociception by coadministration of nonsteroidal anti-inflammatory drugs and soluble epoxide hydrolase inhibitors. Proc. Natl. Acad. Sci. U. S. A. 103, 13646-13651. doi: 10.1073/pnas.0605908103

Scholz, J., and Woolf, C. J. (2002). Can we conquer pain? Nat. Neurosci. 5 Suppl, 1062-1067. doi: $10.1038 / \mathrm{nn} 942$

Sharkey, K. A., and Wiley, J. W. (2016). The role of the endocannabinoid system in the brain-gut axis. Gastroenterology 151, 252-266. doi: 10.1053/j. gastro.2016.04.015

Shen, H. C., and Hammock, B. D. (2012). Discovery of inhibitors of soluble epoxide hydrolase: a target with multiple potential therapeutic indications. J. Med. Chem. 55, 1789-1808. doi: 10.1021/jm201468j

Sisignano, M., Park, C. K., Angioni, C., Zhang, D. D., von Hehn, C., Cobos, E. J., et al. (2012). 5,6-EET is released upon neuronal activity and induces mechanical pain hypersensitivity via TRPA1 on central afferent terminals. J. Neurosci. Off. J. Soc. Neurosci. 32, 6364-6372. doi: 10.1523/JNEUROSCI.5793-11.2012

Sisignano, M., Angioni, C., Ferreiros, N., Schuh, C. D., Suo, J., Schreiber, Y., et al. (2013). Synthesis of lipid mediators during UVB-induced inflammatory hyperalgesia in rats and mice. PloS One 8, e81228. doi: 10.1371/journal. pone. 0081228

Sisignano, M., Bennett, D. L., Geisslinger, G., and Scholich, K. (2014). TRPchannels as key integrators of lipid pathways in nociceptive neurons. Prog. Lipid Res. 53, 93-107. doi: 10.1016/j.plipres.2013.11.002

Sisignano, M., Angioni, C., Park, C. K., Meyer Dos Santos, S., Jordan, H., Kuzikov, M., et al. (2016). Targeting CYP2J to reduce paclitaxel-induced peripheral neuropathic pain. Proc. Natl. Acad. Sci. U. S. A. 113, 12544-12549. doi: 10.1073/pnas.1613246113

Slim, R., Hammock, B. D., Toborek, M., Robertson, L. W., Newman, J. W., Morisseau, C. H., et al. (2001). The role of methyl-linoleic acid epoxide and diol metabolites in the amplified toxicity of linoleic acid and polychlorinated biphenyls to vascular endothelial cells. Toxicol. Appl. Pharmacol. 171, 184-193. doi: 10.1006/taap.2001.9131

Snider, N. T., Nast, J. A., Tesmer, L. A., and Hollenberg, P. F. (2009). A cytochrome P450-derived epoxygenated metabolite of anandamide is a potent cannabinoid receptor 2-selective agonist. Mol. Pharmacol. 75, 965-972. doi: 10.1124/ mol.108.053439

Sommer, K., Jakob, H., Badjlan, F., Henrich, D., Frank, J., Marzi, I., et al. (2019). 11,12 and 14,15 epoxyeicosatrienoic acid rescue deteriorated wound healing in ischemia. PLoS One 14, e0209158. doi: 10.1371/journal.pone.0209158

Spector, A. A., and Kim, H. Y. (2015). Cytochrome P450 epoxygenase pathway of polyunsaturated fatty acid metabolism. Biochim. Biophys. Acta 1851, 356-365. doi: 10.1016/j.bbalip.2014.07.020

Spector, A., and Norris, A. W. (2007). Action of epoxyeicosatrienoic acids on cellular function. Am. J. Physiol., Cell Physiol. 292, C996-1012. doi: 10.1152/ ajpcell.00402.2006

Spector, A. A., Fang, X., Snyder, G. D., and Weintraub, N. L. (2004). Epoxyeicosatrienoic acids (EETs): metabolism and biochemical function. Prog. Lipid Res. 43, 55-90. doi: 10.1016/S0163-7827(03)00049-3

Srikanth, M., Chew, W. S., Hind, T., Lim, S. M., Hay, N. W. J., Lee, J. H. M., et al. (2018). Lysophosphatidic acid and its receptor LPA1 mediate carrageenan induced inflammatory pain in mice. Eur. J. Pharmacol. 841, 49-56. doi: 10.1016/j.ejphar.2018.10.005

Stockstill, K., Doyle, T. M., Yan, X., Chen, Z., Janes, K., Little, J. W., et al. (2018). Dysregulation of sphingolipid metabolism contributes to bortezomib-induced neuropathic pain. J. Exp. Med. 215, 1301-1313. doi: 10.1084/jem.20170584

Stoll, L. L., Morland, M. R., and Spector, A. A. (1994). 13-HODE increases intracellular calcium in vascular smooth muscle cells. Am. J. Physiol. 266, C990-C996. doi: 10.1152/ajpcell.1994.266.4.C990
Sun, G. Y., Chuang, D. Y., Zong, Y., Jiang, J., Lee, J. C., Gu, Z., et al. (2014). Role of cytosolic phospholipase A2 in oxidative and inflammatory signaling pathways in different cell types in the central nervous system. Mol. Neurobiol. 50, 6-14. doi: 10.1007/s12035-014-8662-4

Talbot, S. F., Woolf, S. L., and C. J. (2016). Neuroimmune physiology and pathology. Annu. Rev. Immunol. 16, 1-16.27. doi: 10.1146/ annurev-immunol-041015-055340

Tang, X. L., Wang, Y., Li, D. L., Luo, J., and Liu, M. Y. (2012). Orphan G proteincoupled receptors (GPCRs): biological functions and potential drug targets. Acta Pharmacol. Sin. 33, 363-371. doi: 10.1038/aps.2011.210

Terashvili, M., Tseng, L. F., Wu, H. E., Narayanan, J., Hart, L. M., Falck, J. R., et al. (2008). Antinociception produced by 14,15-epoxyeicosatrienoic acid is mediated by the activation of beta-endorphin and met-enkephalin in the rat ventrolateral periaqueductal gray. J. Pharmacol. Exp. Ther. 326, 614-622. doi: 10.1124/jpet.108.136739

Tesfaye, S., Wilhelm, S., Lledo, A., Schacht, A., Tolle, T., Bouhassira, D., et al. (2013). Duloxetine and pregabalin: high-dose monotherapy or their combination? The "COMBO-DN study"-a multinational, randomized, double-blind, parallelgroup study in patients with diabetic peripheral neuropathic pain. Pain 154, 2616-2625. doi: 10.1016/j.pain.2013.05.043

Thirunavukkarasu, K., Swearingen, C. A., Oskins, J. L., Lin, C., Bui, H. H., Jones, S. B., et al. (2017). Identification and pharmacological characterization of a novel inhibitor of autotaxin in rodent models of joint pain. Osteoarthritis and cartilage/OARS. Osteoarthr. Res. Soc. 25, 935-942. doi: 10.1016/j. joca.2016.09.006

Thompson, D. A., and Hammock, B. D. (2007). Dihydroxyoctadecamonoenoate esters inhibit the neutrophil respiratory burst. J. Biosci. 32, 279-291. doi: 10.1007/s12038-007-0028-x

Thomson, S. J., Askari, A., and Bishop-Bailey, D. (2012). Anti-inflammatory effects of epoxyeicosatrienoic acids. Int. J. Vasc. Med. 2012, 605101. doi: $10.1155 / 2012 / 605101$

Tsuda, M., Hasegawa, S., and Inoue, K. (2007). P2X receptors-mediated cytosolic phospholipase A2 activation in primary afferent sensory neurons contributes to neuropathic pain. J. Neurochem. 103, 1408-1416. doi: $10.1111 / j .1471-4159.2007 .04861 . x$

Uchida, H., Nagai, J., and Ueda, H. (2014). Lysophosphatidic acid and its receptors LPA1 and LPA3 mediate paclitaxel-induced neuropathic pain in mice. Mol. Pain 10, 71. doi: 10.1186/1744-8069-10-71

Ueda, H. (2011). Lysophosphatidic acid as the initiator of neuropathic pain. Biol. Pharm. Bull. 34, 1154-1158. doi: 10.1248/bpb.34.1154

Ueda, H., Matsunaga, H., Olaposi, O. I., and Nagai, J. (2013). Lysophosphatidic acid: chemical signature of neuropathic pain. Biochim. Biophys. Acta 1831, 61-73. doi: 10.1016/j.bbalip.2012.08.014

van Hecke, O., Austin, S. K., Khan, R. A., Smith, B. H., and Torrance, N. (2014). Neuropathic pain in the general population: a systematic review of epidemiological studies. Pain 155, 654-662. doi: 10.1016/j.pain.2013.11.013

Vanden Abeele, F., Zholos, A., Bidaux, G., Shuba, Y., Thebault, S., Beck, B., et al. (2006). Ca2+-independent phospholipase A2-dependent gating of TRPM8 by lysophospholipids. J. Biol. Chem. 281, 40174-40182. doi: 10.1074/jbc. M605779200

Vangaveti, V., Shashidhar, V., Collier, F., Hodge, J., Rush, C., Malabu, U., et al. (2018). 9- and 13-HODE regulate fatty acid binding protein-4 in human macrophages, but does not involve HODE/GPR132 axis in PPARgamma regulation of FABP4. Ther. Adv. Endocrinol. Metab. 9, 137-150. doi: $10.1177 / 2042018818759894$

Wagner, K., Inceoglu, B., Gill, S. S., and Hammock, B. D. (2011). Epoxygenated fatty acids and soluble epoxide hydrolase inhibition: novel mediators of pain reduction. J. Agric. Food Chem. 59, 2816-2824. doi: 10.1021/jf102559q

Wagner, R., Kaiser, G., Gerst, F., Christiansen, E., Due-Hansen, M. E., Grundmann, M., et al. (2013). Reevaluation of fatty acid receptor 1 as a drug target for the stimulation of insulin secretion in humans. Diabetes 62, 2106-2111. doi: 10.2337/db12-1249

Watanabe, H., Vriens, J., Prenen, J., Droogmans, G., Voets, T., and Nilius, B. (2003). Anandamide and arachidonic acid use epoxyeicosatrienoic acids to activate TRPV4 channels. Nature 424, 434-438. doi: 10.1038/nature01807

Weng, Z., Fluckiger, A. C., Nisitani, S., Wahl, M. I., Le, L. Q., Hunter, C. A., et al. (1998). and stress inducible G protein-coupled receptor blocks cells in G2/M. Proc. Natl. Acad. Sci. U. S. A. 95, 12334-12339. doi: 10.1073/pnas.95.21.12334 
Widstrom, R. L., Norris, A. W., and Spector, A. A. (2001). Binding of cytochrome P450 monooxygenase and lipoxygenase pathway products by heart fatty acid-binding protein. Biochemistry 40, 1070-1076. doi: 10.1021/ bi001602y

Widstrom, R. L., Norris, A. W., Van Der Veer, J., and Spector, A. A. (2003). Fatty acid-binding proteins inhibit hydration of epoxyeicosatrienoic acids by soluble epoxide hydrolase. Biochemistry 42, 11762-11767. doi: 10.1021/ bi034971d

Wong, P. Y., Lai, P. S., Shen, S. Y., Belosludtsev, Y. Y., and Falck, J. R. (1997). Postreceptor signal transduction and regulation of $14(\mathrm{R}), 15(\mathrm{~S})$-epoxyeicosatrienoic acid (14,15-EET) binding in U-937 cells. J. Lipid Mediat. Cell Signal. 16, 155169. doi: 10.1016/S0929-7855(97)00005-9

Wong, P. Y., Lai, P. S., and Falck, J. R. (2000). Mechanism and signal transduction of $14(\mathrm{R}), 15$ (S)-epoxyeicosatrienoic acid (14,15-EET) binding in guinea pig monocytes. Prostaglandins Other Lipid Mediat. 62, 321-333. doi: 10.1016/ S0090-6980(00)00079-4

Wu, H. F., Chen, Y. J., Wu, S. Z., Lee, C. W., Chen, I. T., Lee, Y. C., et al. (2017). Soluble epoxide hydrolase inhibitor and 14,15-epoxyeicosatrienoic acidfacilitated long-term potentiation through cAMP and CaMKII in the hippocampus. Neural Plast. 2017, 3467805. doi: 10.1155/2017/3467805

Xu, M., Ju, W., Hao, H., Wang, G., and Li, P. (2013a). Cytochrome P450 2J2: distribution, function, regulation, genetic polymorphisms and clinical significance. Drug Metab. Rev. 45, 311-352. doi: 10.3109/03602532.2013.806537

Xu, Z. Z., Liu, X. J., Berta, T., Park, C. K., Lu, N., Serhan, C. N., et al. (2013b). Neuroprotectin/protectin D1 protects against neuropathic pain in mice after nerve trauma. Ann. Neurol. 74, 490-495. doi: 10.1002/ana.23928

Xu, Z. Z., Kim, Y. H., Bang, S., Zhang, Y., Berta, T., Wang, F., et al. (2015). Inhibition of mechanical allodynia in neuropathic pain by TLR5-mediated A-fiber blockade. Nat. Med. 21, 1326-1331. doi: 10.1038/nm.3978

Yang, W., Tuniki, V. R., Anjaiah, S., Falck, J. R., Hillard, C. J., and Campbell, W. B. (2008). Characterization of epoxyeicosatrienoic acid binding site in U937 membranes using a novel radiolabeled agonist, 20-125i-14,15-epoxyeicosa8(Z)-enoic acid. J. Pharmacol. Exp. Ther. 324, 1019-1027. doi: 10.1124/ jpet.107.129577

Yin, H., Chu, A., Li, W., Wang, B., Shelton, F., Otero, F., et al. (2009). Lipid G protein-coupled receptor ligand identification using beta-arrestin PathHunter assay. J. Biol. Chem. 284, 12328-12338. doi: 10.1074/jbc.M806516200

Yokomizo, T. (2015). Two distinct leukotriene B4 receptors, BLT1 and BLT2. J. Biochem. 157, 65-71. doi: 10.1093/jb/mvu078
Yoshida, Y., and Niki, E. (2006). Bio-markers of lipid peroxidation in vivo: hydroxyoctadecadienoic acid and hydroxycholesterol. Biofactors 27, 195-202. doi: 10.1002/biof.5520270117

Yu, Z., Xu, F., Huse, L. M., Morisseau, C., Draper, A. J., Newman, J. W., et al. (2000). Soluble epoxide hydrolase regulates hydrolysis of vasoactive epoxyeicosatrienoic acids. Circ. Res. 87, 992-998. doi: 10.1161/01.RES.87.11.992

Yung, Y. C., Stoddard, N. C., and Chun, J. (2014). LPA receptor signaling: pharmacology, physiology, and pathophysiology. J. Lipid Res. 55, 1192-1214. doi: 10.1194/jlr.R046458

Zhang, G., Kodani, S., and Hammock, B. D. (2014). Stabilized epoxygenated fatty acids regulate inflammation, pain, angiogenesis and cancer. Prog. Lipid Res. 53, 108-123. doi: 10.1016/j.plipres.2013.11.003

Zhang, Q., Wang, X., Yan, G., Lei, J., Zhou, Y., Wu, L., et al. (2018). Anti- Versus Pro-Inflammatory Metabololipidome Upon Cupping Treatment. Cell Physiol. Biochem. Intl. J. Exp. Cell Physiol. Biochem. Pharmacol. 45, 1377-1389. doi: 10.1159/000487563

Zheng, J., Plopper, C. G., Lakritz, J., Storms, D. H., and Hammock, B. D. (2001). Leukotoxin-diol: a putative toxic mediator involved in acute respiratory distress syndrome. Am. J. Respir. Cell Mol. Biol. 25, 434-438. doi: 10.1165/ ajrcmb.25.4.4104

Zimmer, B., Angioni, C., Osthues, T., Toewe, A., Thomas, D., Pierre, S. C., et al. (2018). The oxidized linoleic acid metabolite 12,13-DiHOME mediates thermal hyperalgesia during inflammatory pain. BBA-Mol. Cell Biol. Lipids 1863, 669-678. doi: 10.1016/j.bbalip.2018.03.012

Zinn, S., Sisignano, M., Kern, K., Pierre, S., Tunaru, S., Jordan, H., et al. (2017). The leukotriene B4 receptors BLT1 and BLT2 form an antagonistic sensitizing system in peripheral sensory neurons. J. Biol. Chem. 292, 6123-6134 doi: 10.1074/jbc.M116.769125.

Conflict of Interest: The authors declare that the research was conducted in the absence of any commercial or financial relationships that could be construed as a potential conflict of interest.

Copyright (C) 2019 Osthues and Sisignano. This is an open-access article distributed under the terms of the Creative Commons Attribution License (CC BY). The use, distribution or reproduction in other forums is permitted, provided the original author(s) and the copyright owner(s) are credited and that the original publication in this journal is cited, in accordance with accepted academic practice. No use, distribution or reproduction is permitted which does not comply with these terms. 